\title{
CONSEQÜÊNCIAS DA DEFAUNAÇÃO NA DISPERSÃO E PREDAÇÃO DE SEMENTES E NO RECRUTAMENTO DE PLÂNTULAS DA PALMEIRA BREJAÚVA (Astrocaryum aculeatissimum) NA MATA ATLÂNTICA
}

\author{
CAMila Iotte DonatTI
}

Dissertação apresentada à Escola Superior de Agricultura "Luiz de Queiroz", Universidade de São Paulo, para a obtenção do título de Mestre em Ecologia de Agroecossistemas.

P I R A C I C A B A

Estado de São Paulo - Brasil

Outubro -2004 


\section{CONSEQÜÊNCIAS DA DEFAUNAÇÃO NA DISPERSÃO E PREDAÇÃO DE SEMENTES E NO RECRUTAMENTO DE PLÂNTULAS DA PALMEIRA BREJAÚVA (Astrocaryum aculeatissimum) NA MATA ATLÂNTICA}

\section{CAMILA IOTTE DONATTI}

Ecóloga

Orientador: Prof. Dr. MAURO GALETTI RODRIGUES

Dissertação apresentada à Escola Superior de Agricultura "Luiz de Queiroz", Universidade de São Paulo, para obtenção do título de Mestre em Ecologia de Agroecossistemas.

P I R A C I C A B A

Estado de São Paulo - Brasil

Outubro -2004 


\section{Dados Internacionais de Catalogação na Publicação (CIP) DIVISÃO DE BIBLIOTECA E DOCUMENTAÇÃO - ESALQ/USP}

\section{Donatti, Camila lotte}

Conseqüências da defaunação na dispersão e predação de sementes e no recrutamento de plântulas da palmeira brejaúva (Astrocaryum aculeatissimum) na Mata Atlântica / Camila lotte Donatti. - - Piracicaba, 2004.

89 p. : il.

Dissertação (Mestrado) - - Escola Superior de Agricultura Luiz de Queiroz, 2004.

Bibliografia.

1. Animal frugívoro 2. Biodiversidade 4. Conservação biológica 5. Desmatamento 6. Dispersão de semente 7. Mata Atlântica 8. Palmeira I. Título

CDD 634.94

\section{"Permitida a cópia total ou parcial deste documento, desde que citada a fonte - O autor"}


"O tempo passa muito rápido, as pessoas entram e saem da sua vida. Você nunca deve perder a oportunidade de dizer a estas pessoas o quanto elas são importantes para você."

À minha família eu dedico.

E a vocês, meus amigos, eu ofereço. 
A enorme diversidade de árvores em florestas tropicais é um dos grandes mistérios da biologia. A gama de possiveis explicações, algumas sobre interações bióticas, outras não, têm sido sugeridas. Cada explicação parece, entretanto, ter uma oposta igualmente plausivel.

(Egbert G. Leigh Jr., 1990). 


\section{AGRADECIMENTOS}

* Ao meu orientador Prof. Dr. Mauro Galetti por todo o apoio, pela amizade e pelas oportunidades que tem me dado;

* À Prof. Dra. Leila Cunha de Moura e ao Prof. Dr. Hilton Thadeu Z. do Couto pelas sugestões durante a elaboração da dissertação;

* A minha família, principalmente meus pais, Maria José e José Airton, que sempre me apoiaram, me ajudaram e entenderam a minha ausência para o trabalho de campo, os dias que passei furando sementes, os vários dias que fiquei horas e horas em frente ao computador;

* A Christine Steiner São Bernardo, Renato Matos Marques e Ricardo S. Bovendorp por gentilmente me fornecerem os dados de censo de mamiferos;

* Aos meus amigos que me ajudaram no trabalho de campo: Robson Louiz Capretz, Paulo Rogério Tanaka, Lilian Bonjourne de Almeida, Rodrigo Fadini e Cláudio Bernardo;

* A todos os pesquisadores do LABIC e, em especial, meus amigos: Rodrigo de Castro, Christine Steiner São Bernardo, Rodrigo Fadini, Renato Matos Marques, Alexandra S. Pires, Eliana Cazetta, Julieta Genini, Ariane Diaz Alvarez, Carolina Denzin, Marina Correa Cortês, Flávia Campassi, Rodrigo Nobre e Ricardo S. Bovendorp;

* Ao Rodrigo de Castro pelo imenso apoio durante este ano e, principalmente, pela amizade que se fortaleceu ainda mais;

* Ao Paulo Guimarães Júnior pela valiosa ajuda com a estatística e por sempre estar disposto a me ajudar;

* Ao Adelson Gomes do Nascimento pela amizade e apoio com os relatórios financeiros;

* Ao meu primo João pela ajuda com a impressão do trabalho; 
* Ao Departamento de Ecologia da UNESP;

* Ao Instituto Florestal pela autorização para trabalhar nas Unidades de Conservação;

* Aos diretores e funcionários das Unidades de Conservação pelo apoio logístico;

* Ao IBC (Instituto de Biologia da Conservação) pela parceria;

* Sou imensamente grata à "Fundação O Boticário de Proteção a Natureza" e à FAPESP (Fundação de Amparo à Pesquisa do Estado de São Paulo, processo $\left.n^{\circ} 01 / 10300-4\right)$ pelo fundamental apoio financeiro concedido ao projeto;

* A Idea Wild pela doação dos equipamentos $e$

* A CAPES (Coordenação de Aperfeiçoamento de Pessoal de Nível Superior) pela bolsa de estudos concedida. 


\section{SUMÁRIO}

RESUMO

Página

SUMMARY

1 Introdução Geral........................................................... 1

2 Revisão de Literatura.................................................... 4

2.1 A defaunação e suas conseqüêencias................................... 4

2.2 A Mata Atlântica.................................................. 4

2.3 Palmeiras e sua importância......................................... 6

3 Dispersão e predação de sementes de Astrocaryum aculeatissimum (Arecaceae) na Mata Atlântica...................................................... 10

Resumo............................................................ 10

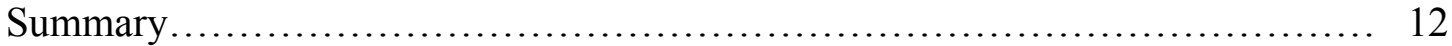

3.1 Introdução.......................................................... 14

3.2 Material e Métodos....................................................... 15

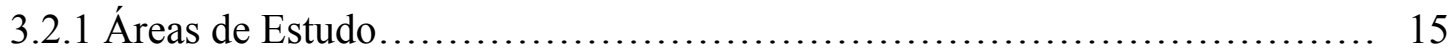

3.2.2 A espécie Astrocaryum aculeatissimum.................................. 19

3.2 .3 Remoção de sementes.............................................. 20

3.2.4 Predação por vertebrados e invertebrados e recrutamento de plântulas........ 26

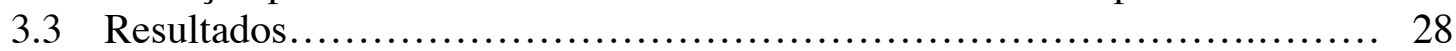

3.3.1 Remoção de sementes.............................................. 28

3.3.2 Predação por vertebrados e invertebrados e recrutamento de plântulas........ 34

3.4 Discussão.......................................................... 35

3.4.1 Remoção de sementes............................................... 35

3.4.2 Predação por vertebrados e invertebrados e recrutamento de plântulas........ 38

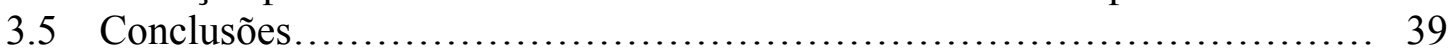

$4 \mathrm{O}$ efeito da defaunação na dispersão e predação de sementes e no recrutamento de plântulas de Astrocaryum aculeatissimum (Arecaceae) na Mata Atlântica.... 40

Resumo............................................................... 40

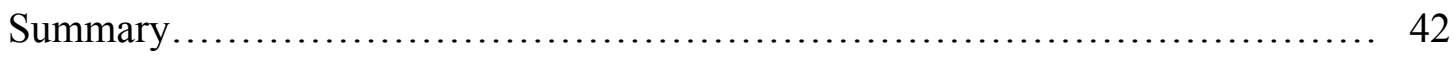

4.1 Introdução.......................................................... 44

4.2 Material e Métodos................................................... 47

4.2.1 Áreas de estudo........................................................ 47

4.2.2 Remoção de sementes.............................................. 53 
4.2.3 Predação por vertebrados e invertebrados e recrutamento de plântulas........ 57

4.2.4 Densidade de plântulas, jovens e adultos................................ 59

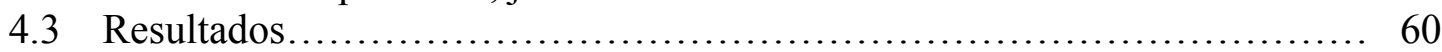

4.3.1 Remoção de sementes.............................................. 60

4.3.2 Predação por vertebrados e invertebrados e recrutamento de plântulas....... 64

4.3.3 Densidade de plântulas, jovens e adultos................................ 67

4.4 Discussão....................................................... 68

4.4.1 Remoção de sementes................................................ 68

4.4.2 Predação por vertebrados e invertebrados e recrutamento de plântulas....... 72

4.4.3 Densidade de plântulas, jovens e adultos............................... 73

4.5 Conclusões.......................................................... 75

5 Conclusões Gerais..................................................... 76

Referências bibliográficas........................................... 77 


\title{
CONSEQÜÊNCIAS DA DEFAUNAÇÃO NA DISPERSÃO E PREDAÇÃO DE SEMENTES E NO RECRUTAMENTO DE PLÂNTULAS DA PALMEIRA BREJAÚVA (Astrocaryum aculeatissimum) NA MATA ATLÂNTICA
}

\author{
Autora: CAMILA IOTTE DONATTI \\ Orientador: Prof. Dr. MAURO GALETTI RODRIGUES
}

\section{RESUMO}

As palmeiras figuram entre as espécies vegetais mais importantes aos animais, já que seus frutos são bastante nutritivos e estão disponíveis geralmente em épocas de escassez de alimentos. Uma gama de animais alimentam-se de seus frutos, incluindo aves, morcegos, mamíferos não voadores, répteis, peixes e insetos. As palmeiras com frutos grandes apresentam, entretanto, limitação na dispersão de suas sementes, pois apenas poucas espécies animais podem atuar como dispersoras. As florestas tropicais vêm sofrendo da chamada "síndrome de florestas vazias", onde interações mutualísticas e agonísticas entre animais e plantas já foram perdidas, pela ausência de dispersores e predadores de sementes e herbívoros de grande porte. O primeiro capítulo teve como objetivo verificar os frugívoros que dispersam e predam as sementes da palmeira brejaúva, Astrocaryum aculeatissimum, bem como avaliar as proporções de predação das sementes por invertebrados e o recrutamento de plântulas próximos às plantas-mãe. No segundo capítulo foi avaliado o efeito da defaunação, relacionado a abundância de cutias, na remoção e na distância de dispersão das sementes. A predação por invertebrados e o recrutamento de plântulas e jovens ao redor da planta mãe também foram comparados em cinco áreas na Mata Atlântica com diferentes abundâncias de cutias. As hipóteses testadas foram que as áreas com baixas abundâncias de cutias apresentariam uma menor remoção das sementes, uma maior predação por invertebrados e um menor recrutamento de plântulas. Além das cutias (Dasyprocta spp.), ratos de espinho (Trynomis iheringi) e esquilos (Sciurus aestuans) também foram os responsáveis pela remoção de sementes e atuaram mais como dispersores do que predadores nos cinco dias de exposição das sementes. A massa das sementes não mostrou relação com a remoção pelas espécies animais. Sementes mais pesadas foram levadas a maiores distâncias da planta-mãe e as sementes predadas foram levadas a maiores distâncias do que as sementes dispersas. As áreas mais defaunadas mostraram 
uma menor porcentagem de remoção de sementes, bem como de predação e dispersão. A proporção de endocarpos predados por vertebrados foi maior na área com maior abundância de cutias (Ilha Anchieta) e as proporções de endocarpos intactos e predados por invertebrados foram maiores na área com menor abundância (Xixová Japuí). $\mathrm{O}$ recrutamento de plântulas embaixo das plantas-mãe amostradas não mostrou diferença significativa entre as áreas. O número de plântulas de Astrocaryum aculeatissimum nos 0,8 ha amostrados em cada área foi maior na Ilha do Cardoso, onde há também uma alta densidade de cutias e o menor recrutamento foi encontrado em Xixová Japuí, a área mais defaunada. Como a espécie estudada não é dispersa por uma grande diversidade de frugívoros, mudanças sutis na composição faunística do local podem ter efeitos cruciais na população da brejaúva a longo prazo. O estudo mostrou que o decréscimo populacional de cutias diminui a remoção, a predação e a dispersão de sementes, aumenta a proporção de sementes predadas por invertebrados embaixo das plantas-mãe, diminuindo o recrutamento das plântulas de Astrocaryum aculeatissimum. 


\title{
CONSEQUENCES OF DEFAUNATION ON SEED DISPERSAL, SEED PREDATION AND SEEDLINGS RECRUITMENT OF THE BREJAÚVA PALM (Astrocaryum aculeatissimum) IN THE ATLANTIC FOREST
}

\author{
Author: CAMILA IOTTE DONATTI \\ Adviser: Prof. Dr. MAURO GALETTI RODRIGUES
}

\section{SUMMARY}

The palms are among the most important plant species to the animals, because their fruits are nutritive and are available in periods of fruit scarcity. Lots of animals feed on palm fruits, including birds, bats, non-volant mammals, reptiles, fishes and insects. The palm species with big fruits show, however, limitation in seed dispersal because only a few animal's species can act as dispersers. The tropical forest has suffered the "Empty Forest Syndrome", where mutualistic and agonistic interactions between animals and plants have just gone due to the absence of seed dispersers and predators and large size herbivores. The first chapter has as an objective study the frugivores responsible to disperse and predate the seeds of the palm brejaúva Astrocaryum aculeatissimum and evaluate the proportion of seed predation by invertebrates and the seedling recruitment close to the mother-plant. In the second chapter, the defaunation effect was evaluated, related to the agoutis' abundance, on the removal and on the seed dispersal distance. The seed predation by invertebrates and the seedling and juvenile recruitment near the mother-plant were compared in five study sites with different agoutis abundance. The principal hypothesis was that in areas with low agoutis' abundance, the seed removal and the seedling recruitment were lower and the seed predation by invertebrates were higher. Besides agoutis (Dasyprocta spp.), spiny rats (Trynomis iheringi) and squirrels (Sciurus aestuans) were also responsible for the seed removal and acted more as seed dispersers than seed predators, during the five days of the experiment. The seed mass didn`t show relation with the seed removal by each of the animal species. Heavier seeds were carried to long distances, and the predated seeds were carried longer than the dispersed seeds. The most defaunated study site showed less seed removal, seed dispersal and seed predation. The proportion of seed predation by vertebrates was higher in study site with higher agoutis` abundance (Ilha Anchieta) and the proportion of intacts endocarps and predated by invertebrates 
were higher in the study site with less agoutis' abundance (Xixová Japuí). The seedling recruitment near the mother plant didn't show difference among the areas. The number of Astrocaryum aculeatissimum seedlings in the 0,8 hectares sampled in each area was higher at Ilha do Cardoso, where we have a high agoutis' abundance and the smaller recruitment was found in Xixová Japuí, the more defaunated area. The study showed that the decrease in agoutis ' population, decrease the Astrocaryum aculeatissimum seed removal, dispersal and predation and increase the seed predation by invertebrates, decreasing the seedling recruitment. 


\section{INTRODUÇÃO GERAL}

A defaunação consiste na diminuição da riqueza, diversidade e/ou biomassa de animais da floresta que ocorre principalmente devido à caça e fragmentação do habitat (Redford, 1992). Reduz de forma rápida e drástica as espécies de mamíferos e aves de médio e grande porte, tendo conseqüências imediatas na demografia, diversidade e densidade de espécies animais (Bodmer et al., 1997; Chiarello, 1999; Cullen Júnior et al., 2001; Galetti et al., 1997; Redford, 1992; Redford \& Robinson, 1987; Terborgh et al., 1993; Wright et al., 1994; Wright et al., 2000; Fa \& Peres, 2001).

A fragmentação do habitat, além de causar a perda de várias espécies vegetais (Tabarelli et al., 2004), contribui também com a defaunação. As populações animais nas áreas mais fragmentadas mostram-se mais isoladas, o acesso de caçadores é mais fácil e há uma redução no número de habitats disponívies (Peres, 2001). Apesar da caça e perda do habitat serem as causas da diminuição da diversidade nas florestas tropicais, há fortes evidências de que esta seja causada principalmente pela defaunação, sendo a fragmentação, em muitos casos considerada uma causa secundária (Fa et al., 2000; Fa \& Peres, 2001; Redford, 1992).

Relações negativas entre o tamanho da área e o grau de caça foram encontradas na Amazônia (Peres, 2001) e a extinção estimada das espécies ocorre mais rápido em áreas menores que sofrem caça moderada ou intensa. Áreas relativamente pequenas (de 150 a 450 ha) podem abrigar espécies cinegéticas se estiverem totalmente protegidas da caça (Chiarello, 2000), mas sua viabilidade populacional genética é questionada (Galetti et al., in prep.).

Na maioria das florestas tropicais, os animais preferencialmente caçados são os ungulados, roedores e primatas de grande porte, que além de apresentarem uma 
biomassa grande, vivem em grandes grupos e forrageaiam em locais previsíveis (Carillo et al., 2000; Wright, 2003).

As espécies negligenciadas pelos caçadores são as de pequeno porte como gambás, carnívoros, edendatos e primatas raros e os nunca caçados são os animais de pequeno porte, como ratos, morcegos e primatas de pequeno porte (Wright et al., 2000; Wright, 2003). As espécies animais preferencialmente caçadas respondem de formas diferentes aos altos níveis de caça, sendo as espécies mais sensíveis aquelas que apresentam uma baixa taxa de crescimento populacional e alta longevidade, como as antas, os veados e os primatas de grande porte (Wright, 2003). Algumas espécies de ungulados e roedores, apesar de também serem considerados os mais preferidos pelos caçadores, são menos sensíveis aos altos níveis de caça, uma vez que apresentam baixa longevidade e altas taxas de crescimento populacional.

Mesmo as espécies menos sensíveis à caça e as raramente caçadas podem, entretanto, terem suas densidades altamente afetadas se as espécies preferenciais e mais sensíveis já encontrarem-se escassas ou inexistentes (Crooks \& Soulé, 1999; Fa et al., 2000; Peres, 2001; Wright et al., 2000).

Como os herbívoros de médio e grande porte são seletivos no consumo de sementes e plântulas, a sua ausência pode levar a uma dominância das espécies vegetais, pela diminuição na dispersão de sementes (Bleher \& Bohning-Gaese, 2001; Cordeiro \& Howe, 2003) e herbivoria de plântulas. A conseqüência da defaunação é um aumento na densidade e sobrevivência de plântulas, podendo reduzir a diversidade vegetal a longo prazo (De Steven \& Putz, 1984; Dirzo \& Miranda, 1991; Roldán \& Simonetti, 2001; Terborgh \& Wright, 1994; Terborgh et al., 2002; Wright \& Duber, 2001; Wright, 2003).

O efeito nas populações de plantas é agravado pelo fato da intensidade da caça ser semelhante em espécies intimamente relacionadas ou espécies que compartilham o mesmo recurso (Wright, 2003). As taxas de remoção e predação de sementes e distâncias de dispersão de sementes são menores em áreas com menor número de agentes dispersores (Asquith et al. 1999; Bleher \& Bohning-Gaese, 2001; Cordeiro \& Howe, 2003; Roldán \& Simonetti, 2001) e em áreas intensamente caçadas (Wright et al., 2000; Wright \& Duber, 2001; Wright, 2003). As taxas de predação de sementes por 
insetos e microorganismos são maiores em áreas intensamente caçadas pelo aumento no número de sementes embaixo da planta-mãe que não são removidas devido às baixas densidades de vertebrados (Wright et al., 2000).

A ausência de animais dispersores de sementes pode afetar tanto a quantidade da dispersão, pela redução no número de sementes dispersas, quanto a qualidade da dispersão, a qual pode ocorrer se o dispersor substituto manipula ou deposita as sementes em locais inapropriados para o seu sucesso no estabelecimento e germinação (Cordeiro \& Howe, 2001).

Estudos envolvendo a dispersão de sementes, o recrutamento de plântulas (Webb \& Peart, 2001; Wenny, 2000) e a distribuição de jovens e adultos são raros (Bleher \& Bohning - Gaese, 2001; Cordeiro \& Howe, 2001; Silva \& Tabarelli, 2001) e são ainda mais escassos os trabalhos envolvendo dispersão de sementes e recrutamento de plântulas em áreas que perderam muitos ou todos os seus vertebrados dispersores (Asquith et al., 1999; Guariguata et al., 2000; Guariguata et al., 2002; Wright et al., 2000; Webb \& Peart, 2001; Wright \& Duber, 2001).

No primeiro capítulo trato dos aspectos da dispersão e predação de sementes de Astrocaryum aculeatissimum, especificando os animais responsáveis pela remoção das sementes e comparando-os em relação ao destino e distância de remoção das sementes. As taxas de predação por invertebrados e de endocarpos intactos e o recrutamento de plântulas ao redor da planta-mãe também foram amostrados. No segundo capítulo exploro como a defaunação afeta a remoção, predação e dispersão de sementes de Astrocaryum aculeatissimum que é dispersa principalmente por cutias (Dasyprocta spp.), um roedor de médio porte que é alvo da caça. Espera-se que as áreas com menor abundância de cutias apresentem menores taxas de remoção de sementes e maiores taxas de predação por invertebrados embaixo da planta-mãe, comprometendo o recrutamento da espécie. A médio e longo prazo as populações de $A$. aculeatissimum podem sofrer reduções demográficas em áreas defaunadas. 


\section{REVISÃO DE LITERATURA}

\subsection{A defaunação e suas conseqüências}

A maioria dos animais caçados nas regiões neotropicais possuem uma forte relação com a vegetação, como os herbívoros, os predadores e os dispersores de sementes. Redford (1992) estimou que 80\% da biomassa de vertebrados em florestas neotropicais é composta de herbívoros e frugívoros, como antas, queixadas, catetos e macacos. Os mamíferos terrestres frugívoros compõem um dos mais ricos grupos de vertebrados em termos de espécie e biomassa nas florestas tropicais (Feer et al., 2001).

A ausência desses mamíferos cria as chamadas "florestas vazias", onde há um decréscimo das interações entre animais e plantas (Redford, 1992). Os efeitos indiretos nas espécies vegetais são a diminuição da remoção, predação e dispersão de sementes, da herbivoria e pisoteio de plântulas (Bleher \& Bohning-Gaese, 2001; Chapman \& Chapman, 1995; Connell, 1971; Dirzo \& Miranda, 1991; Forget, 1990; Forget, 1992; Forget et al., 2001; Janzen, 1970; Peres \& Van Roosmalen, 2002; Redford, 1992; Roldán \& Simonetti, 2001; Smythe, 1989; Terborgh et al., 1993; Webb \& Peart, 2001; Wright et al., 2000; Wright \& Duber, 2001). Como conseqüência, há um decréscimo no recrutamento das plântulas das espécies que são dispersas por estes animais e um decréscimo da diversidade vegetal pela diminuição da herbivoria e predação das sementes.

\subsection{A Mata Atântica}

A Mata Atlântica brasileira vem sofrendo uma rápida devastação antes mesmo da chegada dos europeus (Dean, 1997; Galetti, 2001) aumentando consideravelmente no início do século XX, com o crescimento urbano, industrialização e agricultura extensiva 
(Myers, 1997). Este Bioma originalmente ocupava uma área estimada em mais de 1 milhão de $\mathrm{km}^{2}$ (Consórcio Mata Atlântica - Unicamp, 1992; S.O.S. Mata Atlântica \& INPE, 1998) e ocorria quase que continuamente do Estado do Rio Grande do Norte ao Rio Grande do Sul, atingindo 16 Estados brasileiros. Acredita-se que hoje restam menos de $8 \%$ de sua extensão original, distribuídos em milhares de fragmentos florestais e algumas poucas florestas contínuas (Ministério do Meio Ambiente, 1999; S.O.S. Mata Atlântica \& INPE, 1998).

As áreas de Mata Atlântica do sudeste brasileiro podem ser consideradas umas das mais perturbadas de toda a sua extensão, pois além de abrigar a maioria das cidades, as áreas mais populosas e regiões metropolitanas do Brasil, sedia também pólos industriais, químicos, petroleiros e portuários do Brasil (Consórcio Mata Atlântica Unicamp, 1992).

A caça na Mata Atlântica é executada principalmente pelas populações que vivem no entorno das áreas de floresta, sendo os catetos, queixadas, veados e tatus os preferencialmente caçados (Cullen Júnior et al., 2001). Em muios remanescentes de Mata Atlântica, os vertebrados frugívoros de grande porte como primatas, tucanos, cracídeos e cotingídeos têm sido totalmente extirpados ou apresentam-se em número extremamente reduzido (Galetti, et al., 1997, Silva \& Tabarelli, 2000).

Pelo fato de a Mata Atlântica apresentar-se já muito fragmentada (Ministério do Meio Ambiente, 1999; Tabanez \& Viana, 2000), o impacto da caça sobre estas populações torna-se ainda mais agravante (Cullen Júnior et al., 1999; Fa \& Peres, 2001).

Apesar de ser considerado um dos mais ricos em biodiversidade do mundo, com altas taxas de endemismo (Costa et al., 2000; Myers et al., 2000), pouco se sabe sobre este complexo bioma. Estudos que tratem dos efeitos da defaunação e fragmentação são de extrema importância antes de se tratar e definir as estratégias de conservação e manejo das áreas remanescentes (Asquith, 2001), focando os esforços nas áreas mais representativas e que podem, de fato, ser responsáveis pela manutenção da biodiversidade.

Alguns autores sugerem que mesmo extinções de populações locais podem reduzir a diversidade da comunidade, mudando o curso da evolução, levando a 
permanente reestruturação de todo o ecossistema, gerando efeitos "cascata" e apreciável influência nas comunidades vizinhas (Brown \& Brown, 1992).

\subsection{Palmeiras e sua importância}

As palmeiras representam os maiores símbolos das florestas tropicais justamente por que quase $70 \%$ de todas as espécies existentes ocorrerem exclusivamente nos trópicos (Jones, 1995) e por pertencerem a uma das maiores famílias de plantas, tanto em riqueza quanto em abundância, ocupando quase que todos os habitats (Henderson et al., 1995).

Acredita-se que existam 2600 espécies e 200 gêneros de palmeiras em todo o mundo, sendo amplamente distribuídas em áreas bem drenadas, mas raras em áreas muito secas ou frias (Jones, 1995). Nos trópicos existem 550 espécies e 67 gêneros e no Brasil estão distribuídas 119 espécies, pertencentes a 39 gêneros (Henderson et al., 1995).

As palmeiras figuram entre as espécies vegetais mais importantes para os animais já que seus frutos apresentam, em geral, pouca sincronia de frutificação quando comparado com outras espécies do mesmo bioma (Galetti, 1996; Peres, 1994; Terborgh, 1986). Devido a esta importância para os animais em épocas de escassez de alimentos, as palmeiras são frequentemente chamadas de "espécies chave" (Peres, 2000; Terborgh, 1986), podendo causar um colapso na comunidade de frugívoros se estas estiverem ausentes. Seus frutos são consumidos por aves, morcegos, mamíferos não voadores, répteis, peixes e insetos (Galetti \& Aleixo, 1998; Galetti et al., 1999; Terborgh, 1986; Zona \& Henderson, 1989) e apresentam, em geral, uma rica fonte de energia para os animais, pela grande quantidade de óleos e carboidratos (Zona \& Henderson, 1989).

As espécies de palmeiras são também importantes para os seres humanos pois são exploradas como fonte de alimento e potencial econômico (Kahn, 1993). As populações indígenas já há mais de milhares de anos (Vormisto, 2002), aproveitam cocos, tâmaras, óleos, palmito, açúcares, ceras, folhas e estipes (Alves \& Demattê, 1987), como uso medicinal, alimentício e cosmético, assim como o fazem as populações 
ribeirinhas na região amazônica (Miranda, et al. 2001) e as populações caiçaras na Mata Atlântica (Araújo, 2000).

A Mata Atlântica abriga 10 gêneros e 31 espécies de palmeiras, todas elas pertencentes a subfamília Arecoideae, com um gênero (Polyandrococos) e muitas espécies consideradas endêmicas (Tabela 1) (Henderson et al., 1995). Apesar da distribuição das espécies já ser bastante conhecida, aspectos relativos a frugivoria e dispersão de sementes desta família tão importante é ainda pouco estudada (Zona \& Henderson, 1989).

Apesar da sua extrema importância em todos os ecossistemas tropicais, poucos estudos enfocam a ecologia de palmeiras. A dispersão de sementes é a fase mais crítica no ciclo de vida de uma planta e representa a ligação da última fase reprodutiva com a primeira fase demográfica da população (Harper, 1977). Muitas espécies de palmeiras estão ameaçadas na Mata Atlântica pelo corte seletivo (ex. Palmito juçara, Euterpe edulis) (Henderson et al., 1995) ou pela extinção de dispersores (Silva \& Tabarelli 2004; Wright et al., 2000; Wright \& Duber, 2001). Portanto, estudos que busquem avaliar como se encontram as populações de palmeiras nesse bioma são altamente estratégicos. 
Tabela 1 Espécies de palmeiras que ocorrem na Mata Atlântica, o habitat de ocorrência, o diâmetro médio dos frutos e os principais agentes dispersores. As informações foram retiradas de Lorenzi et al. (1996), Henderson et al.(1995), Zona \& Henderson (1989) e outras referências complementares encontram-se na tabela

\begin{tabular}{|c|c|c|c|c|c|}
\hline \multicolumn{2}{|c|}{ Espécie } & \multirow{2}{*}{$\frac{\text { Habitat }}{\text { Dunas e vegetação de restinga, } 0-10 \text { metros de elevação }}$} & \multirow{2}{*}{\multicolumn{2}{|c|}{$\begin{array}{c}\begin{array}{c}\text { Diâmetro } \\
\text { do fruto }\end{array} \\
1,15\end{array}$}} & \multirow[t]{2}{*}{ Referências } \\
\hline Allogoptera & arenaria* & & & & \\
\hline Astrocaryum & aculeatissimum* & Mata úmida de planície, em solos não inundados e em baixas elevações & Mamíferos & 3,25 & \\
\hline Attalea & Dubia* & Mata úmida de planície & Mamíferos & 3 & Voltolini, 2004 \\
\hline Attalea & funifera & Mata úmida de planície ou restinga, em baixas altitudes & Mamíferos & 6 & Voeks, 2002 \\
\hline Attalea & humilis* & Floresta de baixas altitudes ou vegetação de restinga próximo ao mar & Mamíferos & 5,25 & \\
\hline Attalea & oleifera* & Floresta de transição entre a Mata Atlântica e o Cerrado, em 800 metros de elevação & Mamíferos & 5 & Pimentel \& Tabarelli, 2004 \\
\hline Bactris & acanthocarpa & Floresta de planície em solos não inundados de baixas elevações & Mamíferos & 1,4 & Silva \& Tabarelli, 2001 \\
\hline Bactris & bahiensis & Mata úmida de planície em áreas não inindadas, abaixo de 350 metros de elevação & Mamíferos & 1,1 & \\
\hline Bactris & caryotifolia & Mata primária ou secundária úmida de planície, em áreas não inundadas de baixas elevações & Mamíferos & 1,4 & \\
\hline Bactris & glassmanii & Restinga ou vegetação arbustiva em dunas e florestas adjacentes & Mamíferos & 1,3 & \\
\hline Bactris & ferruginea & Floresta úmida de planície em áreas não inundadas de baixas elevações & Mamíferos & 1,65 & \\
\hline Bactris & horridispatha & Restinga, floresta secundária próxima ao mar em solos arenosos & Mamíferos & 2,4 & \\
\hline Bactris & pickelli & Mata úmida de planície em áreas não inundáveis de baixas elevações & Mamíferos & 1,35 & \\
\hline Bactris & Setosa* & Florestas ou áreas abertas, quase sempre em áreas bastante baixas e úmidas & Mamíferos & 1,75 & \\
\hline Bactris & soeiroana & Restinga ou vegetação arbustiva em dunas & Mamíferos & 2,1 & \\
\hline Bactris & vulgaris* & Mata úmida de planície em áreas não inundadas, abaixo dos 700 metros de elevação & Mamíferos & 2,1 & \\
\hline Desmoncus & polyacanthus & $\begin{array}{l}\text { Mata de galeria, áreas abertas, subbosque de floresta de planície e áreas costeiras, } \\
\text { nas encostas leste dos andes }\end{array}$ & Aves & 1,3 & \\
\hline Desmoncus & orthacanthos & $\begin{array}{l}\text { Principalmente em áreas perturbadas, florestas secundárias, margens dos rios } \\
\text { e bastante comum nas áreas costeiras, geralemente em baixas elevações }\end{array}$ & Aves & 1,25 & \\
\hline Euterpe & edulis* & $\begin{array}{l}\text { Florestas costeiras em encostas íngrimes e porções de floresta no interior, } \\
\qquad \text { do nível do mar até } 1000 \text { metros de altitude }\end{array}$ & $\begin{array}{l}\text { amíferos não voadores, } \\
\text { morcegos e aves }\end{array}$ & 1,2 & Galetti \& Aleixo (1998) \\
\hline Geonoma & gamiova* & $\begin{array}{l}\text { Floresta em áreas costeias, abaixo de } 800 \text { metos de elevação, } \\
\text { atingindo raramente } 1300 \text { metros de altitude }\end{array}$ & Aves & 0,8 & Galetti et al., 2000 \\
\hline Geonoma & gastoniana & Matas de altitude & Aves & 0,7 & \\
\hline
\end{tabular}


Tabela 1 Espécies de palmeiras que ocorrem na Mata Atlântica, o habitat de ocorrência, o diâmetro médio dos frutos e os principais agentes dispersores. As informações foram retiradas de Lorenzi et al. (1996), Henderson et al.(1995), Zona \& Henderson (1989) e outras referências complementares encontram-se na tabela

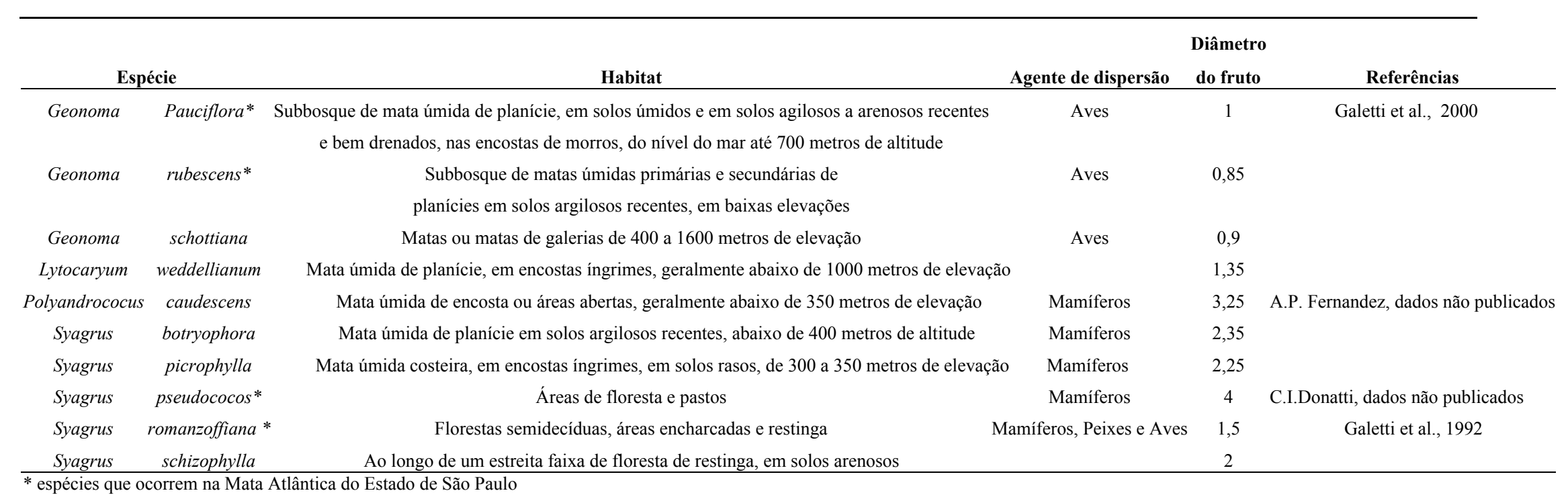

* espécies que ocorrem na Mata Atlântica do Estado de São Paulo 
3 Dispersão e predação de sementes de Astrocaryum aculeatissimum (Arecaceae) na Mata Atlântica

\section{Resumo}

A predação e a dispersão das sementes influenciam a dinâmica da floresta e são alguns dos eventos responsáveis pela manutenção da diversidade a longo prazo. Em florestas tropicais, a maior parte das espécies arbóreas com frutos carnosos são adaptados ao consumo e a dispersão por aves e/ou mamíferos. A diversidade e densidade dos dispersores é crucial para o sucesso da dispersão das sementes. As espécies vegetais com sementes grandes, como a utilizada neste estudo, apresentam limitação de dispersão já que apenas algumas espécies animais podem remover e dispersar as suas sementes. Este capítulo descreve os padrões de predação e dispersão das sementes de Astrocaryum aculeatissimum, bem como identifica os frugívoros responsáveis pela remoção das sementes. A predação por vertebrados e invertebrados e o recrutamento de plântulas embaixo das plantas-mãe também foram amostrados. $O$ experimento foi montado em três áreas na Mata Atlântica do Estado de São Paulo (P.E. Ilha Anchieta, P.E. Ilha do Cardoso e E.E. Juréia Itatins). Das 450 sementes utilizadas no experimento, 58,89\% $(n=265)$ foram removidas após 5 dias de exposição. A espécie de frugívoro foi inferida e a distância de dispersão medida para cada semente removida. A maior parte das sementes foram encontradas intactas, seguidas de enterradas, dispersas no solo e predadas. A cutia (Dasyprocta spp.) foi o frugívoro que mais interagiu com as sementes, removendo $55,66 \%$ das sementes, seguida pelo rato de espinho (Trynomis iheringi) que removeu $21,18 \%$ e pelo esquilo (Sciurus aestuans), responsável por remover 3,94\% das sementes. Todos os frugívoros agiram mais como dispersores do que predadores de sementes. Não houve diferença significativa na massa das sementes removidas pelas espécies de frugívoros. Apesar de não haver diferença significativa na distância de dispersão entre as espécies de frugívoros, as cutias levaram as sementes a maiores distâncias das plantas-mãe. A maior parte dos endocarpos encontrados embaixo das plantas-mãe estavam predados por vertebrados $(59,24 \%)$ e apenas $8,05 \%$ estavam predados por invertebrados. Não houve diferença entre o número de plântulas e jovens encontrados de 0 a 2 metros e o encontrado de 2 a 4 metros das plantas-mãe. As cutias podem ser consideradas os dispersores mais efetivos das sementes da espécie, já que removeram mais sementes, estocaram a maioria delas e as levaram a maiores distâncias do que os ratos de espinho e os esquilos. A remoção das sementes por vertebrados, além de 
aumentar as chances de dispersão, diminui também a predação por invertebrados. Sendo assim, as áreas que sofreram redução ou extinções locais das populações de cutias podem sofrer problemas na dispersão e recrutamento de Astrocaryum aculeatissimum. 


\section{Seed dispersal and predation of the Astrocaryum aculeatissimum (Arecaceae) in the Atlantic Forest}

\section{Summary}

The seed dispersal and predation influence the forest dinamic and are some of the events responsible to maintain the diversity in long term. In topical forests, the largest porcentage of arboreal species with flesh fruit are adapted to the consume and dispersal by birds an/or mammals. The diversity and density of dispersers is crucial to the seed dispersal success. The vegetal species with big seeds, like the one studied here, show dispersal limitation, because just a few animal species can remove their seeds from the mother plant. This chapter describes the seed dispersal and seed predation patters of the palm Astrocaryum aculeatissimum and identifies the frugivores responsible to the seed removal as well. The seed predation by vertebrates and invertebrates and the seedling recruitment were also sampled. The experiment were carried out in three areas in the Atlantic Forest in São Paulo state (P.E. Ilha Anchieta, P.E. Ilha do Cardoso e E.E. Juréia Itatins). Of the 450 seeds used in the experiment, $58,89 \%(\mathrm{n}=265)$ were removed after 5 days. The frugivore specie was inferential and the seed dispersal distance measured to each seed removed. The largest part of the seeds was found intact, followed by scattered, dipersed on the soil and predated. The agouti (Dasyprocta spp.) removed 55,66\% of the seeds, followed by spiny rats (Trynomis iheringi) that removed $21,18 \%$ and by the squirrel (Sciurus aestuans), that removed 3,94\% of the seeds. All these frugivores acted more as seed dispersers than seed predators. There was no difference among the seed mass removed by each of the three frugivore species. Despite no statistical difference among the seed dispersal distance by the three species, the agoutis carried the seeds far from the mother plant than the squirrels and spiny rats. The biggest part of the endocarps below the mother plant was predated by vertebrates $(59,24 \%)$ and just a few $(8,05 \%)$ predated by invertebrates. There was no difference between the number of seedlings and juveniles found from 0 to 2 meters from the mother plant and the number found from 2 to 4 meters. The agoutis can be considered the most effective dispersers of this specie, because were responsible for removing more seeds from the mother plant, scattered most of them and carried them farther from the mother plant than the squirrels and spiny rats. The seed removal by vertebrates, besides increases the dispersal chances, also decreases the predation by invertebrates. That is why, the areas that suffered reduction or local 
extinction of agoutis can suffer problems in the seed dispersal and seedling recruitment of the Astrocaryum aculeatissimum. 


\subsection{Introdução}

Em florestas tropicais estima-se que entre 50 a $75 \%$ das espécies arbóreas produzam frutos carnosos adaptados ao consumo e a dispersão de sementes por aves e/ou mamíferos (Howe \& Smallwood, 1982; Howe, 1984), superando a dispersão pelo vento, água e outros processos abióticos. A dispersão de sementes por mamíferos é particularmente importante em regiões tropicais (Van der Pijl, 1982), sendo os mamíferos terrestres os maiores responsáveis pela remoção de frutos e sementes no chão, constituindo-se em importantes predadores e dispersores de sementes (Hammond et al., 1999; Sanchez-Cordeiro \& Martinez-Gallardo, 1998; Wright et al 2000; Wright \& Duber, 2001).

A dispersão das sementes é um dos mais importantes fatores que afetam o recrutamento de plântulas, a distribuição espacial e a viabilidade das populações a longo prazo (Asquith et al., 1999; Forget, 1990; Harper, 1977; Herrera, 2002; Janzen, 1970). A predação e a dispersão das sementes influenciam a estrutura da vegetação e a dinâmica da floresta a longo prazo (Bleher \& Bohing-Gaese, 2001; Redford \& Robinson, 1987) e são uns dos eventos responsáveis pela manutenção da diversidade vegetal (Howe, 1984; Janzen, 1970). A dispersão das sementes permite a retirada das sementes da alta concentração de predação próximo a planta mãe, favorecendo a sobrevivência e a germinação das plântulas (Connell, 1971; Forget, 1992b; Hulme, 1997; Jansen et al., 2002; Janzen, 1970, Sanchez-Cordeiro \& Martínez-Gallardo, 1998; Schupp, 1988 a,b; Silva \& Tabarelli, 2001; Terborgh et al., 1993; Vander Wall, 2002).

Nas espécies de plantas zoocóricas, o número e a diversidade de espécies animais pode ser crucial para o sucesso da dispersão das sementes (Bleher \& Bohning-Gaese, 2001). Se uma determinada espécie vegetal depender apenas de poucas espécies de frugívoros, a ausência de uma delas pode comprometer a dispersão das sementes (Loiselle \& Blake, 2002; Peres \& Van Rosmallen, 2002; Jordano \& Schupp, 2000).

Muitas espécies com frutos grandes apresentam limitação de dispersão e apenas poucas espécies animais, principalmente roedores estocadores, são responsáveis pela remoção e dispersão de suas sementes (Forget, 1991, 1996; Fragoso et al., 2003; 
Pimentel \& Tabarelli, 2004; Silvius, 2002; Voltolini, 2004; Wright et al., 2000; Wright \& Duber, 2001).

O comportamento de estocagem por mamíferos é um importante processo de dispersão secundária de sementes grandes (Vander Wall, 1992) e as cutias são os principais responsáveis pela remoção dessas sementes (Asquith et al., 1999; Forget, 1990, 1992, 1994, 1996; Hallwachs, 1986; Peres \& Baider, 1997).

Estudos que tratem da dispersão e predação de sementes são de extrema importância para o entendimento da estrutura das comunidades vegetais, já que o destino das sementes removidas é um importante aspecto do recrutamento e demografia de plântulas (Harper, 1977). O número de espécies de dispersores e os efeitos de cada um deles na dispersão das sementes são importantes para o entendimento da primeira etapa do recrutamento de plântulas. O conhecimento dos padrões de dispersão e predação de sementes é um dos subsídios para o estudo da diversidade e abundância de espécies vegetais.

Este capítulo tem como objetivo descrever os padrões de remoção, predação e dispersão das sementes de Astrocaryum aculeatissimum e responder às seguintes perguntas: 1) quais os frugívoros responsáveis pela remoção das sementes de Astrocaryum aculeatissimum?, 2) há diferença nas taxas de remoção das sementes entre as espécies de frugívoros?, 3) há diferença na distância de remoção das sementes e na massa das sementes removidas pelos frugívoros?, 4) há relação entre a massa e o destino das sementes? 5) como variam as proporções de endocarpos predados por vertebrados, invertebrados e intactos ao redor da planta-mãe? e 6) há relação entre as taxas de predação e a densidade de plântulas e jovens ao redor da planta-mãe?

\subsection{Material e Métodos}

\subsection{1 Áreas de Estudo}

O estudo foi desenvolvido em três áreas de Mata Atlântica do Estado de São Paulo (P.E. Ilha Anchieta, P.E. Ilha do Cardoso e E.E. Juréia Itatins) variando de 828 a 
79.230 ha (Figura 1) Os dados foram agrupados para determinar os aspectos da dispersão e predação de sementes da brejaúva (Astrocaryum aculeatissimum).

\subsubsection{Ilha Anchieta (PEIA)}

O Parque Estadual da Ilha Anchieta $\left(23^{\circ} 32^{\prime} \mathrm{S}\right.$ e $\left.45^{\circ} 03^{\prime} \mathrm{W}\right)$ possui 828 hectares e localiza-se no litoral norte do Estado de São Paulo, na costa do município de Ubatuba. O clima é segundo a classificação de Koppen, do tipo Af, tropical úmido, com chuvas o ano todo, sem uma estação seca definida e com temperaturas superiores a $20^{\circ} \mathrm{C}$.

A Ilha Anchieta teve a sua cobertura vegetal original bastante alterada em função, principalmente, da ativação do presídio, onde parte da vegetação foi destruída para a retirada de madeira (Guillaumon et al., 1989). Em 1983, 8 cutias (Dasyprocta spp.) e 7 capivaras (Hydrochaeris hydrochaeris) foram introduzidas na ilha, o que contribuiu para a alteração vegetal devido à superpopulação dessas espécies que se encontram hoje na área (Paes, 1997, R. S. Bovendorp, dados não publicados).

As aves de médio e grande porte pertencentes às famílias Cracidae, Ramphastidae e Tinamidae, importantes frugívoros, não encontram-se na área de estudo (R.S. Bovendorp, dados não publicados; C.I.Donatti, obs. pessoal). A abundância de cutias é bastante alta, com 6,95 inds $/ 10 \mathrm{~km}$ percorridos.

\subsubsection{Ilha do Cardoso (PEIC)}

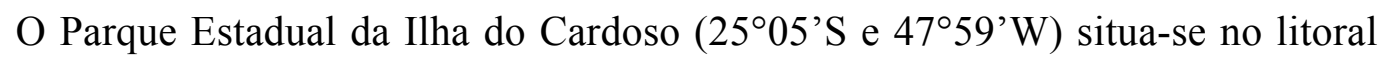
sul do Estado de São Paulo, na costa do município de Cananéia, fazendo fronteira com o Estado do Paraná. O parque foi criado em 1962 e possui uma área de 15.100 hectares. (Secretaria do Estado do Meio Ambiente, 2001).

A topografia da ilha é predominantemente montanhosa, com a parte central dominada por elevações com mais de 814 metros (Secretaria do Estado do Meio Ambiente, 2001). O clima da região não apresenta estação seca definida e, segundo a classificação de Koppen, é do tipo Cfa, subtropical úmido. As chuvas estão bem distribuídas ao longo do ano com temperaturas médias mensais superiores a $22^{\circ} \mathrm{C}$ nos meses mais quentes e inferiores a $18^{\circ} \mathrm{C}$ nos meses mais frios. 
$\mathrm{Na}$ ilha encontram-se 6 povoamentos típicos caiçaras e índios da etnia Guarani Mbya, que estabeleceram-se na unidade em 1992 (Olmos et al., no prelo; Secretaria do Estado do Meio Ambiente, 2001).

A cobertura vegetal é composta por cinco tipos principais de formações vegetais: vegetação pioneira de duna, vegetação de restinga, floresta pluvial tropical da planície litorânea, floresta pluvial tropical da Serra do Mar e vegetação de mangue (Noffs \& Baptista-Noffs, 1982). Um levantamento florístico por parcelas, totalizando uma amostragem de 1 hectare, indicou a presença de 157 espécies de indivíduos arbóreos pertencentes a 47 famílias, cujas mais representativas foram Myrtaceae (29 espécies), Rubiaceae (10 espécies), Sapotaceae (7 espécies) e Arecaceae (5 espécies) (Fiuza de Melo, 1993).

Os levantamentos de fauna realizados indicam a existência de cerca de 70 espécies de mamíferos e 436 espécies de aves, número este que o torna um dos sítios de maior diversidade de espécies de aves dentro do domínio atlântico brasileiro (Secretaria do Estado do Meio Ambiente, 2001). A fauna se distribui diferentemente ao longo do gradiente altitudinal, do nível do mar até os picos de altitude, mas muitos grupos animais ainda permanecem desconhecidos (Secretaria do Estado do Meio Ambiente, 2001).

Estudos recentes sobre a fauna de mamíferos encontraram uma densidade de 28,78 indivíduos $/ \mathrm{km}^{2}$, com uma abundância de 0,7 cutias $/ 10 \mathrm{~km}$ percorridos (Dasyprocta leporina), 0,33 esquilos/10 km (Sciurus aestuans), 0,14 queixadas/10 km (Tayassu pecari) e 0,03 catetos/10 km (Pecari tajacu) (São Bernardo, 2004).

\subsubsection{Juréia Itatins (EEJI)}

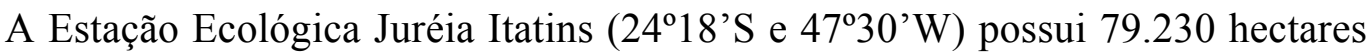
de área e tornou-se Unidade de Conservação em 1986, abrangendo parte dos municípios de Itariri, Miracatu, Peruíbe e Iguape, sendo neste localizada a sua maior extensão.

Segundo a classificação de Koppen, o clima da região é do tipo Cfa, subtropical úmido, com chuvas bem distribuídas ao longo do ano, temperaturas médias mensais superiores a $22^{\circ} \mathrm{C}$ nos meses mais quentes e inferiores a $18^{\circ} \mathrm{C}$ nos meses mais frios. 
A ocupação remonta do século XVIII, iniciada por grupos negros, índios e descendentes de europeus (Secretaria do Estado do Meio Ambiente, 2000). Hoje, índios Guarani Mbya e aproximadamente 320 famílias de caiçaras povoam a unidade (Sanches, 2004).

O levantamento florístico pelo método de pontos quadrantes, indicou a presença de 178 espécies arbóreas, pertencentes a 51 famílias, cujas mais representativas foram Myrtaceae (37 espécies), Rubiaceae ( 9 espécies), Sapotaceae (6 espécies) e Lauraceae (5 espécies) (Mantovani, 1993).

Apresenta grande riqueza faunística, incluindo a onça pintada (Panthera onca), a onça parda (Puma concolor), a jaguatirica (Leopardus pardalis), o mono carvoeiro (Brachytelles arachnoides) e a anta (Tapirus terrestris). A área apresenta levantamento de fauna, com o registro de 314 espécies de aves (Develey, 2004) e 32 espécies de mamíferos de médio e grande porte (Pardini \& Develey, 2004).

Estudos recentes sobre a fauna indicam a presença de 39,84 mamíferos $/ \mathrm{km}^{2}$, com uma abundância de 0,27 queixadas/10 km percorridos (Tayassu pecari), 0,18 catetos/ 10 km (Pecari tajacu) e 1,19 esquilos/10 km percorridos (Sciurus aestuans) (C.S. São Bernardo, dados não publicados), números bastante baixos. 


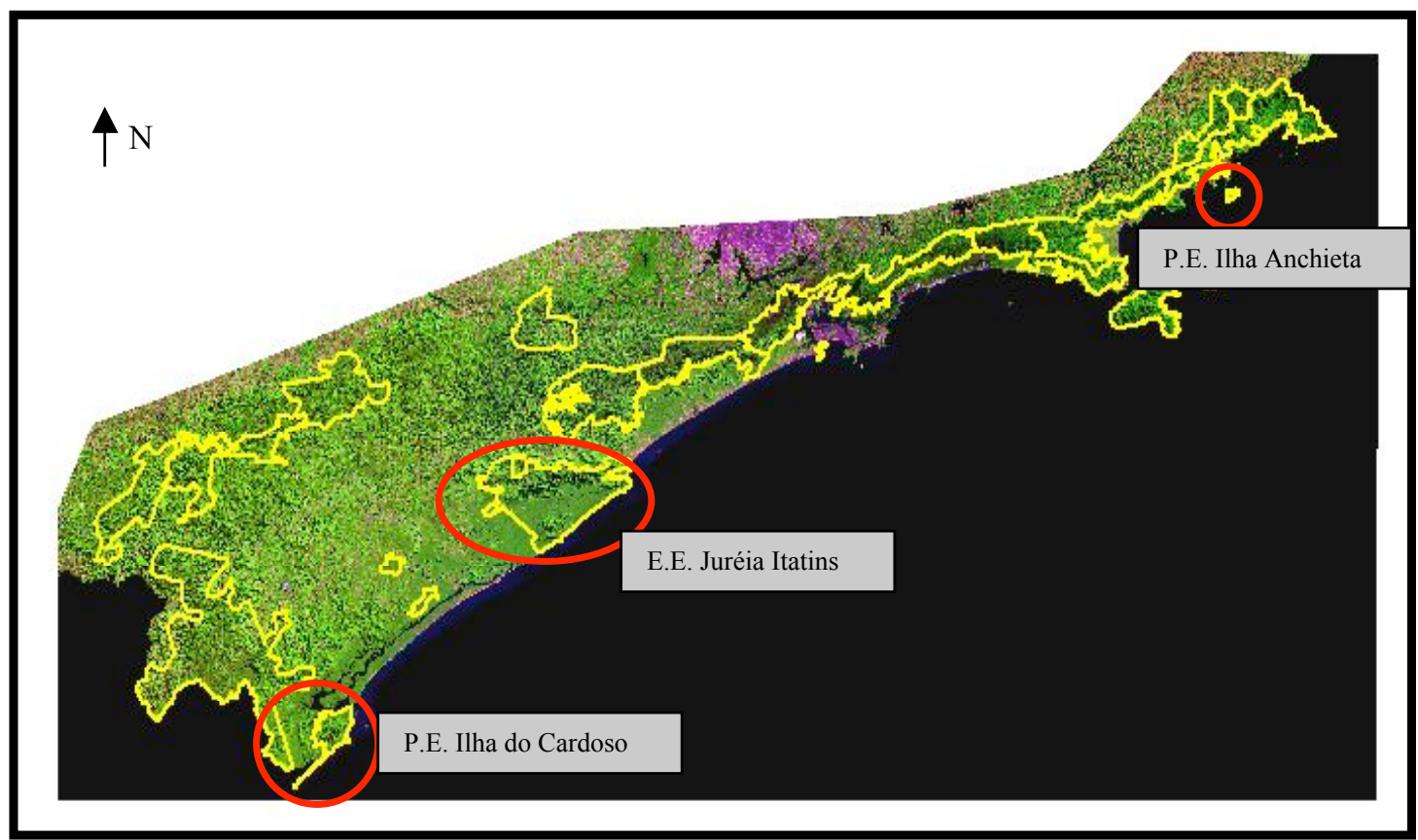

Figura 1 - Áreas de estudo no litoral do Estado de São Paulo, Brasil

\subsubsection{A espécie Astrocaryum aculeatissimum}

O gênero Astrocaryum pertence a família Arecaceae e compreende 18 espécies, a maioria delas caracterizada pela grande quantidade de espinhos presente em seus estipes (Henderson et al., 1995). As espécies estão distribuídas desde o México até o leste do Brasil, com a maior diversidade do gênero ocorrendo na região amazônica (Henderson et al., 1995).

O gênero Astrocaryum é conhecido por atrair uma gama de predadores de sementes como besouros, roedores e pecarídeos (Beck \& Terborgh, 2002; Brewer, 2001; Roldán \& Simonetti, 2001; Smythe, 1989; Terborgh et al., 1993; Wright et al., 2000) e apesar da ecologia de diferentes espécies do gênero Astrocaryum já ter sido estudada (Brewer, 2001; Cintra, 1997; Cintra \& Horna, 1997; Losos, 1995; Sanchez-Cordeiro \& Martinez-Gallardo, 1998; Terborgh et al., 1993 para A. mexicanum; Beck \& Terborgh, 
2002 para A. murumuru; Alvarez-Sánchez \& Guevara, 1999; Smythe, 1989; Wright et al., 2000 para $A$. standleyanum), pouco se sabe sobre A. aculeatissimum.

Astrocaryum aculeatissimum (Scott) Burret (Figura 2) é endêmica da Mata Atlântica, ocorrendo do Estado da Bahia ao Estado de Santa Catarina (Henderson et al., 1995; Lorenzi et al., 1996;). Seu florescimento ocorre em janeiro (Lorenzi et al., 1996, E.R. Castro, dados não publicados) e a maturidade de seus frutos de maio a outubro (E.R. Castro, dados não publicados; Galetti, et al., 1999).

Os indivíduos são monóicos (Lorenzi et al., 1996) e podem apresentar mais de um estipe por indivíduo $(2,14 \pm 1,36, n=66)$ e mais de uma infrutescência por estipe $(0,47 \pm 0,7 ; \mathrm{n}=130)$. As infrutescências apresentam uma média de 22 frutos $(22,21 \pm 22,94$; $\mathrm{n}=76$ ) (figura 3), ovóides com um fino mesocarpo, apresentando um único denso e duro endocarpo cada (Figura 4), fazendo com que o fruto seja consumido por poucas espécies de vertebrados (Bodmer, 1991). O epicarpo é marrom, com pequenos espinhos, o mesocarpo é amarelado e bastante fibroso. Os frutos apresentam um comprimento de 4,79 $\pm 0,42 \mathrm{~cm}$, um diâmetro de $3,22 \pm 0,24 \mathrm{~cm}$ e uma massa de $28,79 \pm 4,12 \mathrm{~g}$ ( $\mathrm{n}=30)$. Os

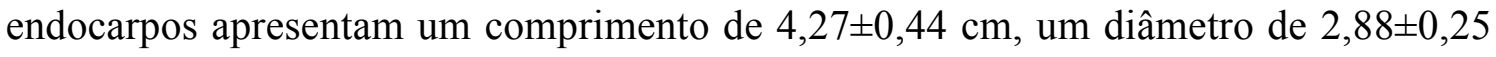
cm e uma massa de $17,36 \pm 3,35 \mathrm{~g}(\mathrm{n}=30)$.

\subsubsection{Remoção de sementes}

Um estudo de campo piloto foi feito em 2002 para verificar quais espécies interagiam com as sementes e também para escolher o método dentro os mais efetivos no monitoramento das sementes removidas (veja Voltolini, 2004). O tipo de marcação na semente (Figura 5) bem como o comportamento na dispersão puderam ser inferidos para cada uma das espécies animais. Para evitar problemas de nomenclatura, o termo

semente refere-se aqui ao pirênio do fruto, que inclui o endocarpo e a semente propriamente dita. 


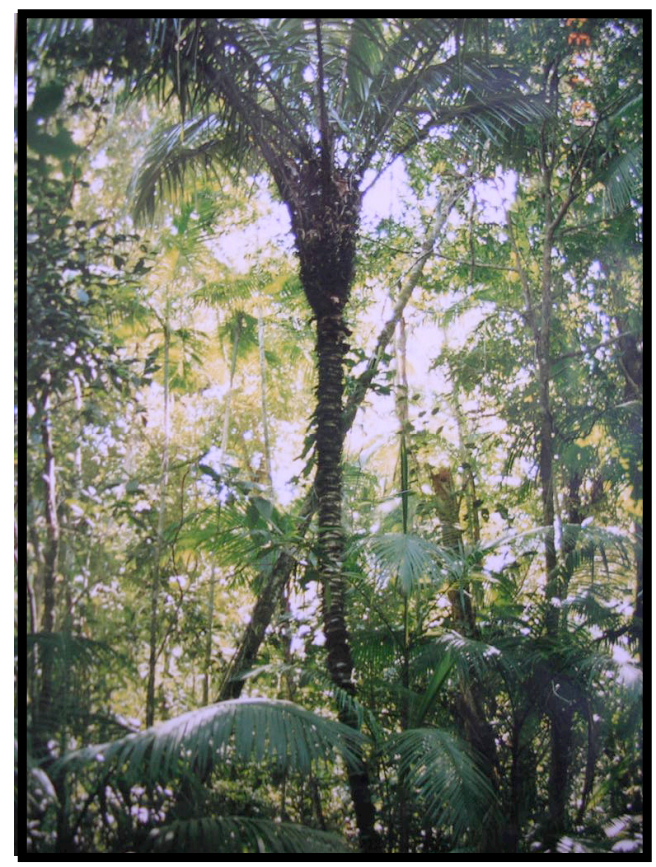

Figura 2 - Indivíduo adulto da espécie Astrocaryum aculeatissimum na Ilha do Cardoso, na Mata Atlântica do Estado de São Paulo, Brasil

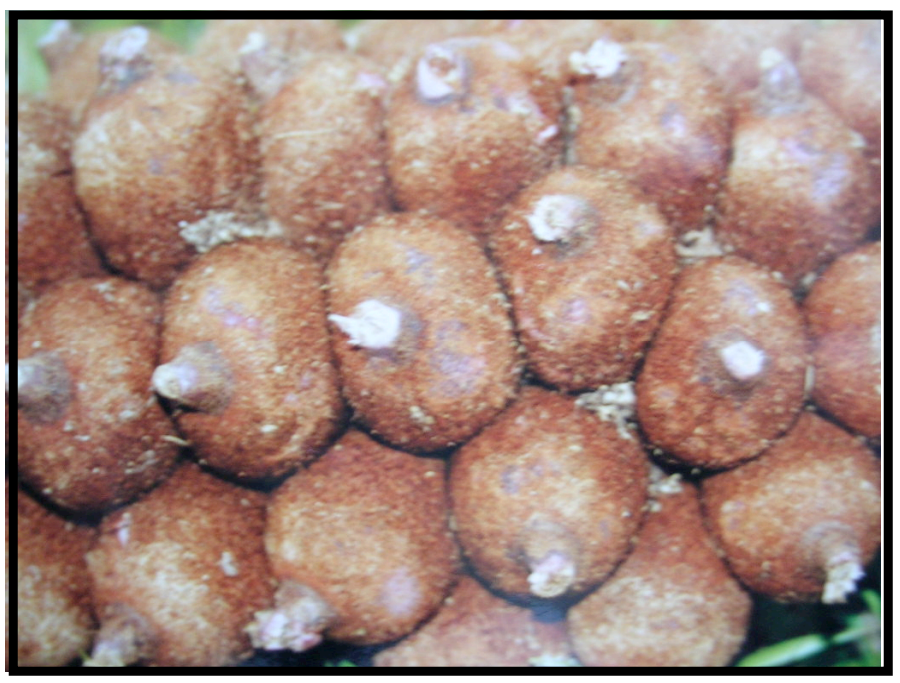

Figura 3 - Infrutecência de Astrocaryum aculeatissimum 


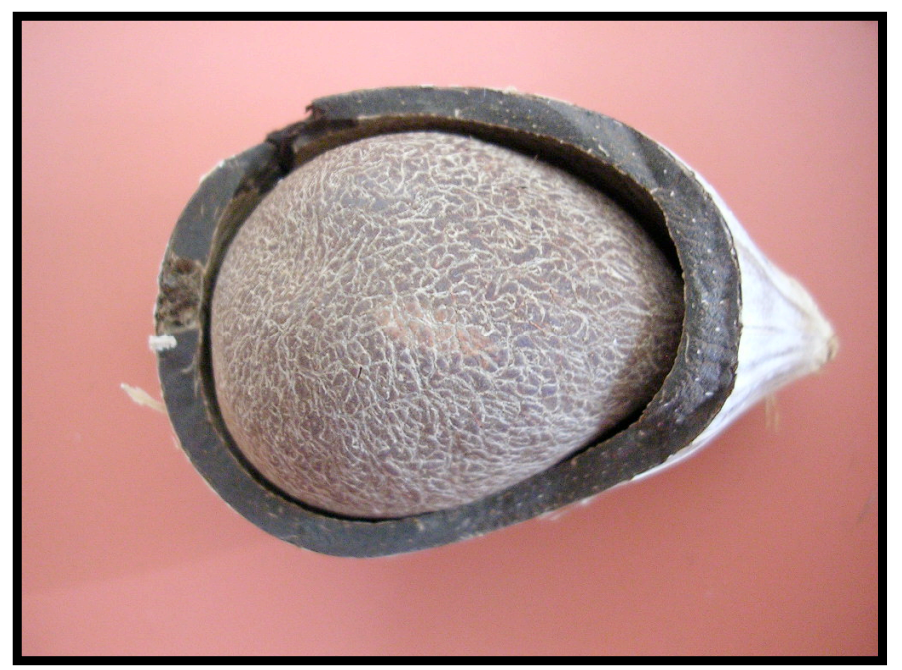

Figura 4 - Pirênio de Astrocaryum aculeatissimum,com corte do endocarpo mostrando a semente

Antes do experimento ser montado, cada uma das sementes foi marcada com um número para permitir a identificação individual. Para medir a distância de dispersão, uma linha de pesponto Gutermann ${ }^{\circledR}$ (por ser mais resistente) foi amarrada a cada semente. A linha foi amarrada a um anel de arame que foi transpassado pela semente, evitando assim o corte da linha pelos frugívoros. A linha foi presa em um carretel de costura que foi colocado dentro da embalagem de filme fotográfico (Figura 6). Diversos estudos utilizaram-se de sementes marcadas para o acompanhamento do destino das mesmas (Forget, 1990, 1991, 1993, 1996; Forget \& Milleron, 1991; Forget et al., 2000; Hallwachs, 1986; Peres \& Baider, 1997).

Cinco sementes de Astrocaryum aculeatissimum amarradas aos carretéis foram distribuídos ao redor da palmeira e a aproximadamente $20 \mathrm{~cm}$ do estipe (Figura 7). Foram utilizados 90 indivíduos adultos distribuídos em três áreas de estudo. As sementes foram colocados embaixo dos indivíduos adultos de Astrocaryum aculeatissimum, pois foi assumido que os animais forrageiam de forma mais intensa e freqüente nos locais onde têm mais chances de encontrar o recurso (Forget et al., 2000).

Os experimentos foram instalados entre dezembro de 2002 e fevereiro de 2003, imediatamente após o período de queda dos frutos, coincidindo com a época de disponibilidade das sementes aos animais. Os frutos de Astrocaryum aculeatissimum foram coletados diretamente dos indivíduos adultos, suas polpas foram removidas 
manualmente e as sementes foram secas ao sol. Dessa forma, somente as relações entre as sementes e os frugívoros foram aqui analisadas, excluindo-se portanto, os animais interessados somente na polpa do fruto.

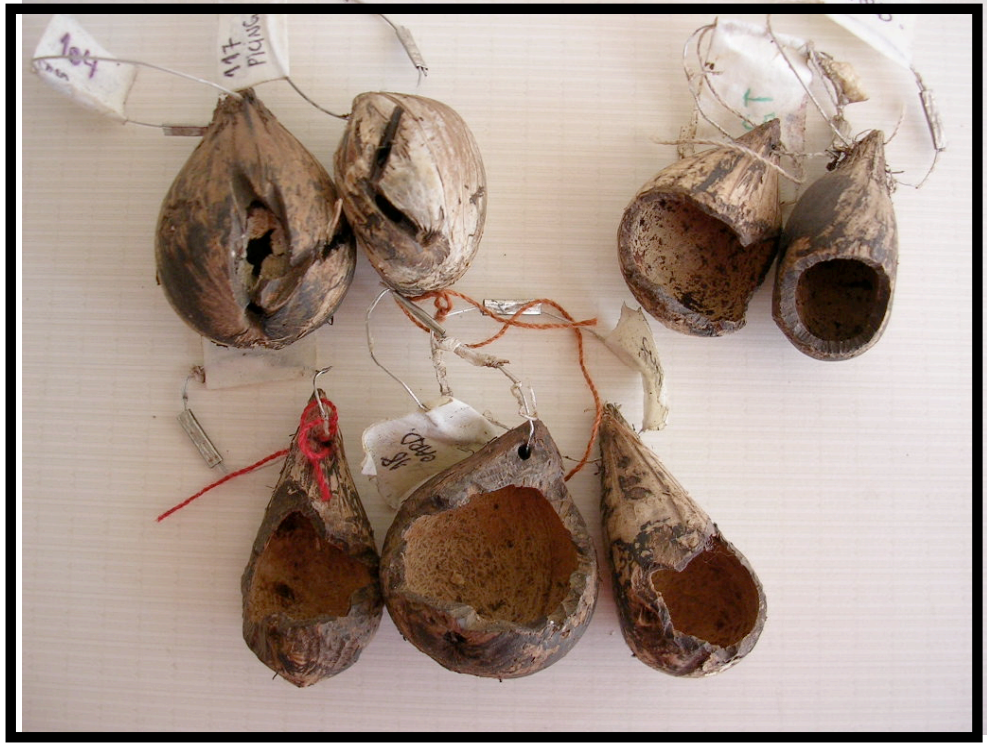

Figura 5 - Predação das sementes de Astrocaryum aculeatissimum pelos frugivoros durante o experimento de remoção de sementes. No allto a esquerda, predação por esquilo (Sciurus aestuans), no alto a direita, predação por ratos de espinho (Trynomis iheringi) e embaixo, predação por cutia (Dasyprocta spp.)

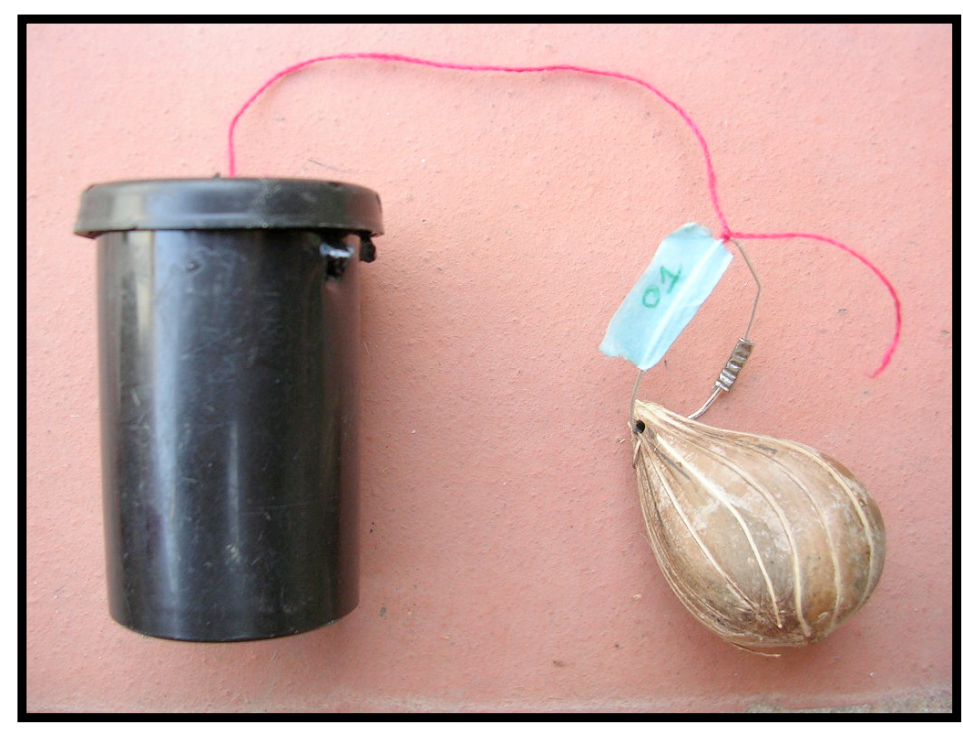

Figura 6 - Método empregado para avaliar o destino das sementes de Astrocaryum aculeatissimum, as quais foram furadas e envoltas em um arame onde amarra-se a linha 


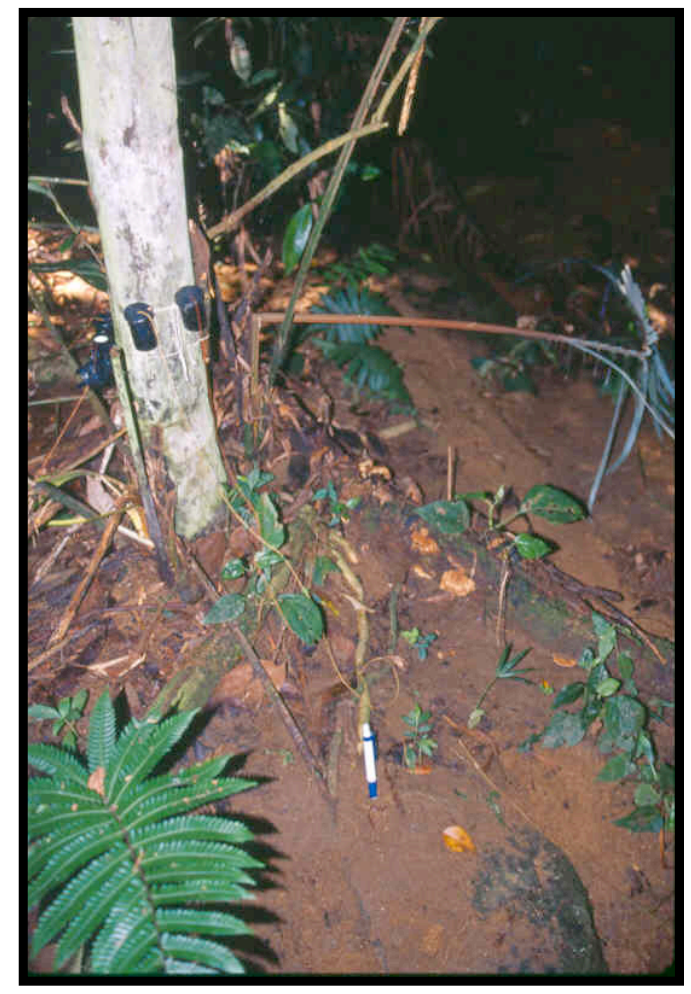

Figura 7 - Representação de um das estações experimentais com as embalagens de filme fotográfico amarradas ao estipe da palmeira brejaúva, Astrocaryum aculeatissimum, para o experimento de remoção de sementes

Os indivíduos de Astrocaryum aculeatissimum usados nos experimentos foram selecionados por apresentarem os seguintes critérios: 1) estarem separados por pelo menos 50 metros uns dos outros; 2) situarem-se a 10 metros de qualquer outro indivíduo adulto da espécie; 3) localizarem-se em locais planos para evitar que os frutos rolassem ao chegarem ao solo e 4) localizarem-se nas mesmas trilhas onde foram realizados os censos de mamíferos e aves nos anos anteriores (exceto em Xixová Japuí onde o censo não foi realizado).

As sementes marcadas puderam ser seguidas, a distância de remoção foi medida e a espécie de frugívoro pôde ser inferida pelo tipo de marcação deixada nas sementes. Durante o projeto piloto, definiu-se que cinco dias seriam suficientes para verificar a remoção das sementes, devido a rápida remoção nas áreas com alta abundância de cutias. No geral em florestas tropicais, a falta de uma rápida remoção das sementes 
grandes dentro de uma semana sugerem que os roedores estocadores são menos abundantes (Asquith et al., 1999; Forget et al., 2001).

O comprimento da linha utilizada foi de 30 metros, tamanho suficiente quando levada em conta a dispersão de sementes executada por alguns roedores que em geral não ultrapassa esta medida (Forget, 1990; Peres et al., 1997; Forget et al., 2000, Pimentel \& Tabarelli, 2004). Apesar de cutias eventualmente levarem as sementes à distâncias que podem chegar a mais de 50 metros (Forget, 1991, 1999; Hallwachs, 1986) e a linha fixa poder atrapalhar o movimento dos frugívoros, a marcação com a linha permite um encontro mais rápido e eficiente das sementes removidas (ver Voltolini, 2004).

A dispersão foi considerada quando as sementes foram movidas a mais de 0,5 metro do estipe da palmeira e foram encontradas intactas ou enterradas (Guariguata et al., 2000) e a predação considerada quando as sementes foram total ou parcialmente destruídas (Forget, 1996; Guariguata et al., 2000). Aquelas sementes que foram encontradas sem a linha e aquelas que enroscaram no carretel também foram consideradas, mas usadas apenas para estimar a remoção e não o destino das sementes. A distância de remoção foi medida em linha reta, do local da instalação do experimento até o local onde a semente foi encontrada.

A separação entre predação e dispersão de sementes é necessária uma vez que a remoção das mesmas não é um bom indicador de predação e nem de disperão (Forget, 1990, 1996; Forget \& Milleron, 1991). Estes eventos, principalmente em relação aos roedores estocadores, dependem de fatores internos do animal, como sexo e idade e também de fatores relacionados ao ambiente como tipo de alimento disponível e estação do ano (Vander Wall, 1990).

Todos as sementes de Astrocaryum aculeatissimum foram marcadas individualmente e pesadas em balança de precisão, para que fosse possível verificar se havia escolha das sementes pelos animais e para verificar se havia relação entre a massa das sementes e a distância de remoção.

O número de sementes predadas, dispersas e intactas foram comparados por um teste de Kruskal-Wallis. O número de sementes removidas pelas espécies de frugívoros 
em cada uma das estações experimentais também foi comparada pelo teste de KruskalWallis, já que os dados não apresentam distribuição normal nem homegeneidade de variâncias, mesmo após transformações.

A massa das sementes removidas foi comparada entre cada um dos frugívoros (cutias - Dasyprocta spp., ratos de espinho - Trynomis iheringi e esquilos - Sciurus aestuans) retirando-se neste caso as sementes enroscadas, perdidas, intactas e aquelas que não tiveram os seus dispersores identificados. Os dados foram transformados em log $(\mathrm{x}+1)$ e atingiram a normalidade e homocedasticidade (respectivamente pelos testes de Shapiro-Wilk W=0,9712; $\mathrm{p}=0,0555$ e Levene $=2,0878 ; \mathrm{p}=0,1273$ ), sendo possível a comparação através de uma Análise de Variância (ANOVA).

A massa das sementes dispersas no solo, enterradas, intactas e predadas, retirando-se as sementes enroscadas e perdidas, também foi comparada pelo teste de Kruskal-Wallis. A distância de dispersão foi também comparada entre cada um dos frugívoros pelo teste de Kruskal-Wallis, considerando-se somente as sementes dispersas.

A distância de remoção foi comparada entre as sementes predadas e dispersas pelo teste $t$, já que os dados, após transformados em $\log (x+1)$ apresentaram distribuição normal e homogeneidade de variâncias (respectivamente Shapiro Wilk $=0,9745$; $p=0,0808 ;$ Levene $=1,3569 ; p=0,2454)$. A relação entre a massa da semente e a distância de remoção, retirando-se as sementes enroscadas, intactas e perdidas, foi feita através da Correlação de Spearman (rs), assim como foi analisada a relação entre a massa das sementes e a distância de remoção feita pelas espécies de frugívoros e para cada um dos destinos.

\subsubsection{Predação por vertebrados e invertebrados e recrutamento de plântulas}

Para quantificar a predação das sementes por vertebrados e invertebrados e o recrutamento de plântulas e jovens embaixo das plantas-mãe foram utilizados os mesmos indivíduos adultos de Astrocaryum aculeatissimum dos experimentos de remoção de sementes.

Todos os endocarpos recentes encontrados num raio de 2 metros da planta mãe (Nascimento et al., 1997) foram amostrados em cada uma das áreas de estudo. Os 
indivíduos de Astrocaryum aculeatissimum localizavam-se em áreas planas e a pelo menos 10 metros de outro indivíduo adulto, para diminuir a possibilidade de coletar endocarpos de outros indivíduos próximos.

Os endocarpos encontrados foram separados em predados por vertebrados, invertebrados ou intactos (Cintra, 1997; Wright et al, 2000; Wright \& Duber, 2001) os quais foram identificados por furos de emergência e marcas de entrada de invertebrados, marcas de dentes e sem marcações, respectivamente (Figura 8). Os endocarpos que podiam ser quebrados com a mão foram descartados da amostragem (Wright $\&$ Duber, 2001), por ser difícil definir o tipo de predação em endocarpos quebrados e por estar-se restringindo a amostragem em eventos recentes.

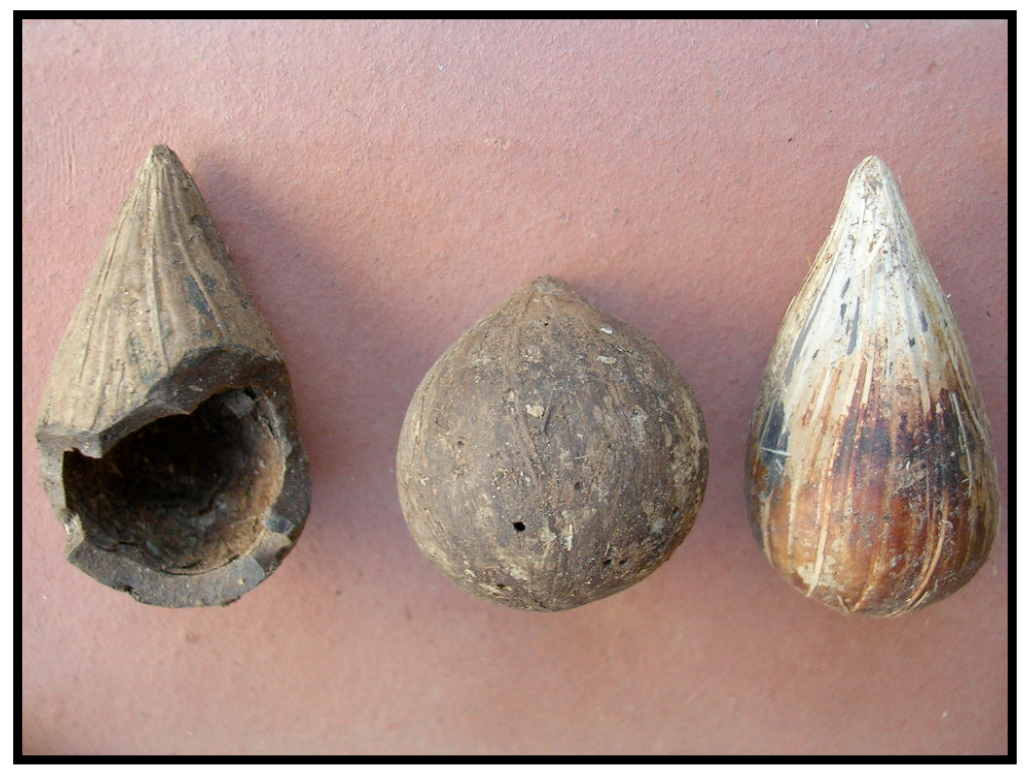

Figura 8 - Endocarpos de Astrocaryum aculeatissimum predados por vertebrados, invertebrados e intactos (da esquerda para a direita)

As proporções de endocapos predados por vertebrados (número de endocarpos predados por vertebrados/número total de endocarpos encontrados embaixo das plantasmãe), invertebrados e intactos em cada indivíduo adulto amostrado foram comparadas pelo teste de Kruskal-Wallis.

As plântulas (indivíduos com até $50 \mathrm{~cm}$ de altura) e jovens (indivíduos com mais de $50 \mathrm{~cm}$ de altura mas que não apresentavam sinais de reprodução) da espécie presentes 
até $2 \mathrm{~m}$ e de 2 a $4 \mathrm{~m}$ de raio da planta mãe (Nascimento et al., 1997) foram amostrados. Essas distâncias utilizadas para medir o recrutamento da palmeira foram escolhidas porque assumiu-se que a espécie, por possuir frutos pesados $(\mathrm{x}=28,8 \mathrm{~g})$ e pelos indivíduos escolhidos estarem localizados em áreas planas, as plântulas e os jovens encontrados a mais de 2 metros de raio da planta mãe, seriam provavelmente provenientes de sementes dispersas. Como as taxas de predação de sementes tendem a ser maiores próximo a planta-mãe, devido a alta densidade de sementes, espera-se que um maior número de jovens e plântulas sejam encontradas mais longe da planta-mãe (de 2 a 4 metros do estipe da palmeira).

A proporção de plântulas encontradas até 2 metros da planta-mãe (número de plântulas encontradas de 0 a 2 metros da planta-mãe/número total de plântulas encontradas de 0 a 4 metros da planta-mãe) em cada indivíduo amostrado foi comparada com a proporção encontrada de 2 a 4 metros pelo teste de Mann-Whitney. As proporções de jovens encontrados até 2 metros da planta-mãe e de 2 a 4 metros da planta-mãe foram comparadas da mesma forma, assim como foi feita a comparação da proporção de plântulas e jovens entre as duas classes de distância da planta-mãe.

A probabilidade de $5 \%$ ou menos para rejeição da hipótese nula foi considerada para todos os testes, que seguiram Zar (1999) e Sokal \& Rohlf (1996) e foram feitos no programa estatístico JMP (SAS 2002).

\subsection{Resultados}

\subsubsection{Remoção de sementes}

Das 450 sementes utilizadas no experimento de remoção, $58,89 \%$ foram removidas ( $\mathrm{n}=265)$ após 5 dias de exposição. A maior parte das sementes foi encontrada intacta $(41,11 \%, \mathrm{n}=185), 19,78 \%(\mathrm{n}=89)$ foram encontradas enterradas, $12,44 \%(\mathrm{n}=56)$ dispersas no solo, $12,89 \%(\mathrm{n}=58)$ foram predadas e $13,78 \%(\mathrm{n}=62)$ foram perdidas ou enroscadas (Figura 9). Houve diferença significativa o número de sementes predadas, dispersas e intactas $(\square 2=21,1179 ; \mathrm{p}<0,0001, \mathrm{~g} .1 .=2)$. 
A maior porcentagem de remoção, retirando-se as sementes enroscadas e as perdidas $(n=203)$, foi executada pela cutia (Dasyprocta spp.) $(55,66 \%, n=113)$, seguida pelo rato de espinho (Trynomis iheringi) $(21,18 \%, \mathrm{n}=43$ ) e pelo esquilo (Sciurus aestuans $)(3,94 \%, \mathrm{n}=8)$. Houve diferença significativa no número de sementes removidas em cada estação experimental pelas espécies de frugívoros $(\square 2=38,0282$, $\mathrm{p}<0,0001$, g.1.=2) (Figura 10).

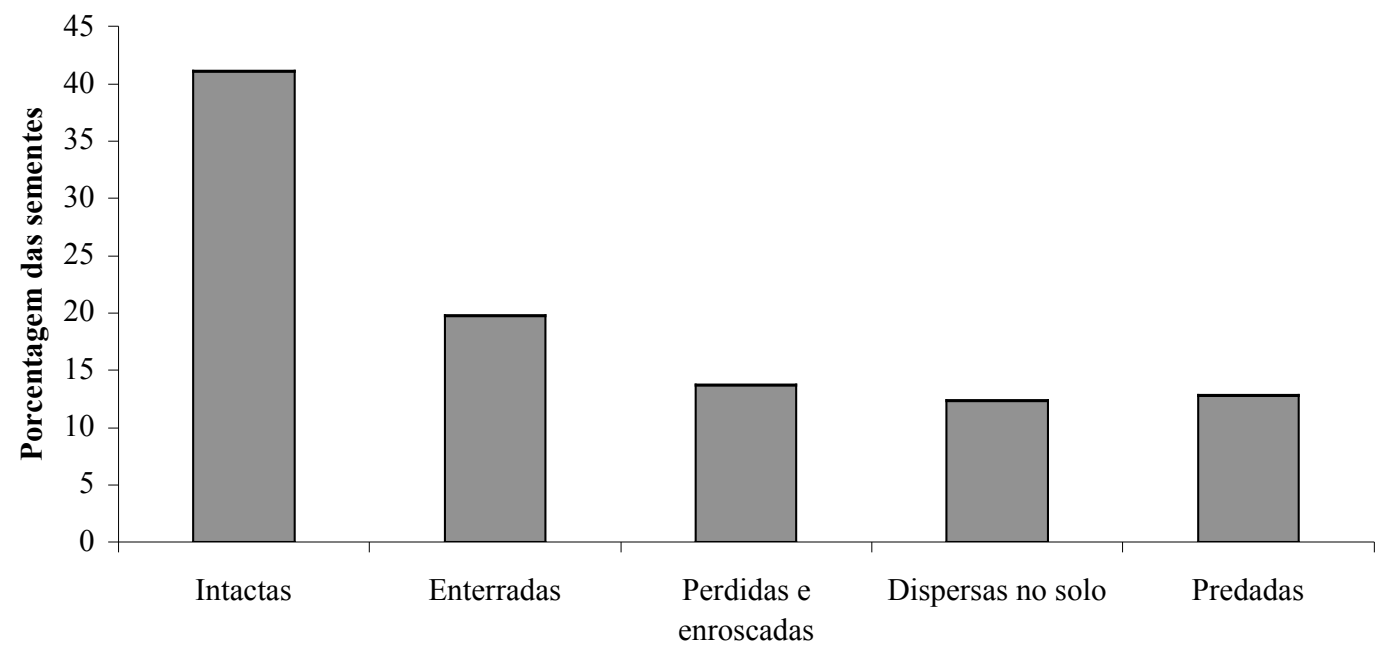

Destino das sementes

Figura 9 - Porcentagem dos destinos das sementes de Astrocaryum aculeatissimum na Mata Atlântica do Estado de São Paulo, Brasil

Algumas sementes foram removidas mas permaneceram no solo sem nenhum tipo de marcação e não tiverem seus dispersores identificados $(19,22 \%, n=39)$. A cutia atuou mais como dispersora do que predadora de sementes (respectivamente 58,4\% vs. $41,6 \% ; n=113)$, assim como o esquilo $(62,5 \%$ vs. $37,5 \%, n=8)$ e o rato de espinho $(83,72 \%$ vs. $16,28 \%, n=43)$ nos cinco dias de exposição das sementes.

Um endocarpo predado por pecarídeo foi encontrado fora dos experimentos na Juréia, mas nenhuma semente foi removida por catetos ou queixadas, já que, quando registradas, essas espécies possuem abundâncias extremamente baixas (R. M. Marques; R.S. Bovendorp, dados não publicados; São Bernardo, 2004). 


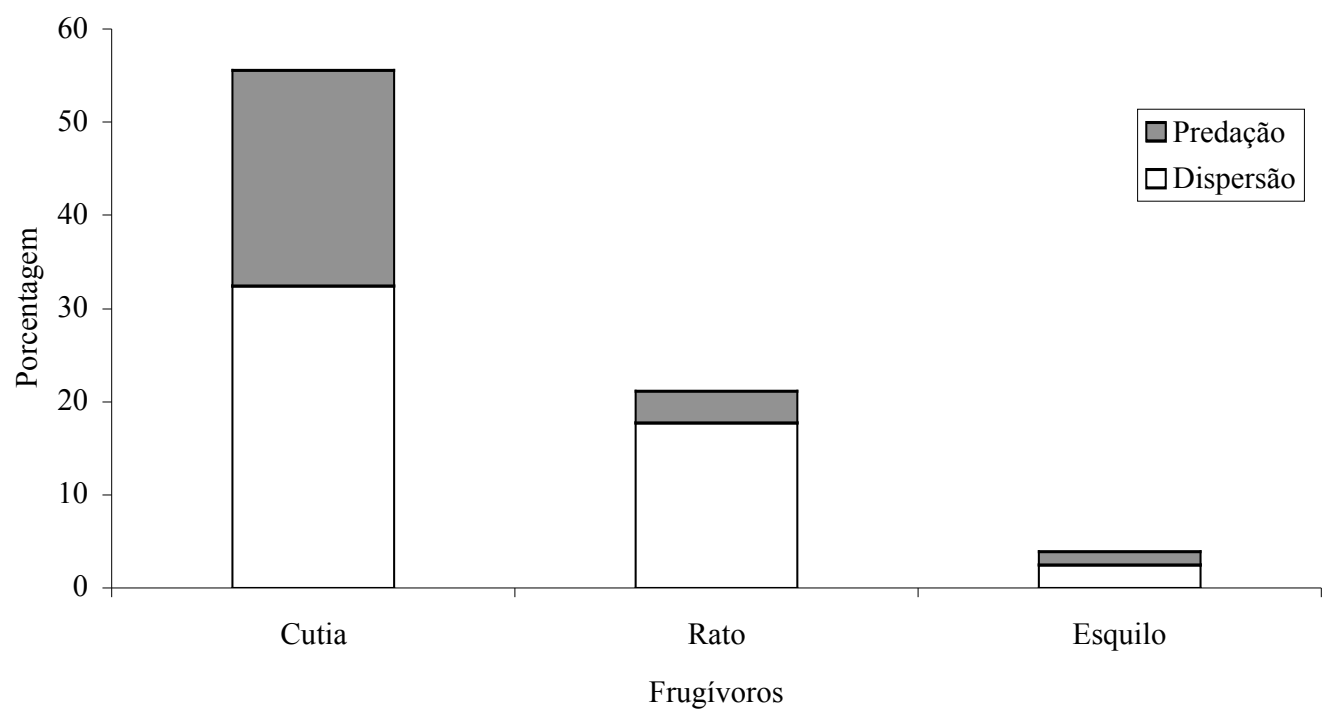

Figura 10 - Porcentagem das sementes de Astrocaryum aculeatissimum removidas, predadas e dispersas pelos frugívoros na Mata Atlântica do Estado de São Paulo, Brasil

A cutia enterrou 56,64\% das sementes $(n=113)$ removidas, o esquilo dispersou no solo $62,5 \%$ das sementes removidas $(n=8)$ e o rato enterrou $58,14 \%$ das sementes $(n=43)$. A cutia enterrou as sementes inteiras, deixando somente o anel de arame para fora, com o poro germinativo voltado para baixo (Figura 11). Os ratos de espinho dispersam as sementes embaixo da serrapilheira ou dentro de tocas. O esquilo freqüentemente levou as sementes na copa das árvores ou cipós, mas não estocou nenhuma. Todas as sementes enterradas foram estocadas individualmente e próximas à superfície do solo, comportamento de estocagem conhecido como Scatter-hoarding (Vander Wall, 1990). 


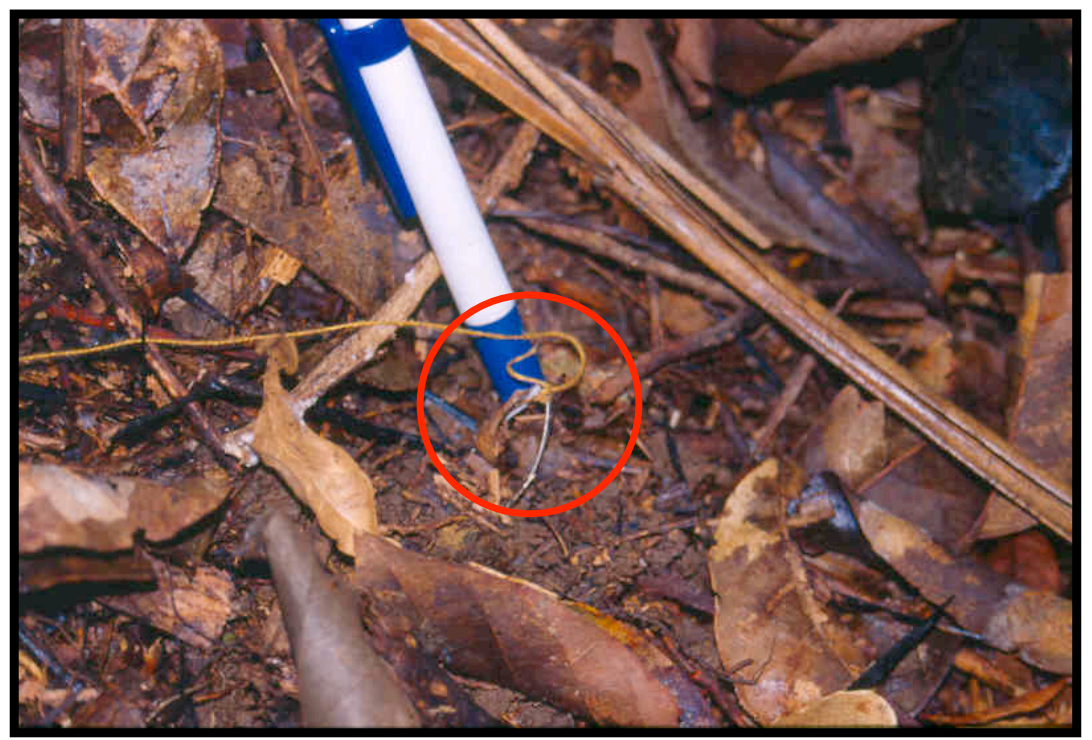

Figura 11 - Semente de Astrocaryum aculeatissimum entrerrada pela cutia (Dasyprocta spp.) durante o experimento de remoção de sementes na Ilha Anchieta, Ubatuba, São Paulo, Brasil. Repare, no círculo, que a semente foi completamente enterrada, restando somente o anel de arame para fora do solo

Não houve relação significativa entre a massa das sementes e a remoção feita pelos frugívoros, ou seja, não houve seleção pelo peso $(\mathrm{F}=1,1509 ; \mathrm{p}=0,3189$; g.l.=2; $\mathrm{n}=166$ ). Não houve diferença significativa entre a massa das sementes e o destino da mesma $(\square 2=3,1499 ; \mathrm{p}=0,3691 ; \mathrm{g} .1 .=3 ; \mathrm{n}=688)$. Não houve diferença na distância de dispersão feita pelos frugívoros $(\square 2=4,3167 ; \mathrm{p}=0,1155$; g.l. $=2 ; \mathrm{n}=109)$. (Tabela 2$)$.

Tabela 2 Média, desvio padrão e tamanho da amostra (N) da massa das sementes removidas e da distância de dispersão das sementes de Astrocaryum aculeatissimum executada pelos frugívoros. Valor da Análise de Variância e da probabilidade (p).

\begin{tabular}{cccccc}
\hline & Cutia & Rato de espinho & Esquilo & ANOVA & P \\
\hline Massa do pirênio & $11,49 \pm 2,41(113)$ & $12,36 \pm 1,85(43)$ & $11,23 \pm 2,70(8)$ & 1,1509 & 0,3189 \\
Distância de dispersão & $5,18 \pm 4,71(66)$ & $3,04 \pm 2,34(36)$ & $2,94 \pm 1,09(7)$ & 4,3167 & 0,1155 \\
\hline
\end{tabular}

Houve diferença significativa na distância de remoção entre as sementes predadas e dispersas (teste $\mathrm{t}=2,569, \mathrm{p}=0,0109$, g.1. $=1, \mathrm{n}=203$ ), com as sementes predadas sendo levadas a maiores distâncias da planta mãe do que as sementes dispersas. Para as 
cutias e ratos de espinho, não houve diferença significativa na distância de remoção das sementes em cada um dos destinos $(\square 2=1,5273, \mathrm{p}=0,4660$, g.l. $=2, \mathrm{n}=113$ e $\square 2=1,2347$, $\mathrm{p}=0,5394, \mathrm{gl}=2, \mathrm{n}=43$, respectivamente). Já as distâncias de remoção feitas pelo esquilo mostraram diferença significativa entre os destinos $(\square 2=5, \mathrm{p}=0,0253$, g.l. $=1, \mathrm{n}=8)$, com sementes predadas sendo levadas a maiores distâncias que as sementes dispersas.

Houve correlação positiva e significativa entre a massa das sementes e a distância de remoção (Correlação de Spearman rs $=0,2327 ; \mathrm{p}=0,0008$ ) (Figura 12), sendo esta significativa para as sementes removidas pelas cutias ( $r s=0,2000, p=0,0337, n=113$ ) e esquilos ( $\mathrm{rs}=0,8333, \mathrm{p}=0,0102, \mathrm{n}=8$ ), mas não para os ratos de espinho ( $\mathrm{rs}=0,0761$, $\mathrm{p}=0,6639, \mathrm{n}=35$ ) (Figura 13). A correlação entre a massa da semente e a distância de remoção foi significativa e positiva para as sementes dipersas no solo $(\mathrm{rs}=0,3773$, $\mathrm{p}=0,0038, \mathrm{n}=56)$, mas não para as predadas ( $\mathrm{rs}=0,2108, \mathrm{p}=0,1122, \mathrm{n}=57)$ nem para as sementes enterradas ( $\mathrm{rs}=0,1785, \mathrm{p}=0,1064, \mathrm{n}=83)$.

Dentre as sementes dispersas $(\mathrm{n}=146), 67,12 \%$ foram removidas até uma distância de 4 metros da estação experimental, 27,40\% foram dispersas de 4 a 10 metros, $4,80 \%$ de 10,1 a 20 metros e apenas uma semente $(0,68 \%)$ foi dispersa a mais de 20 metros da estação experimental (Figura 14).

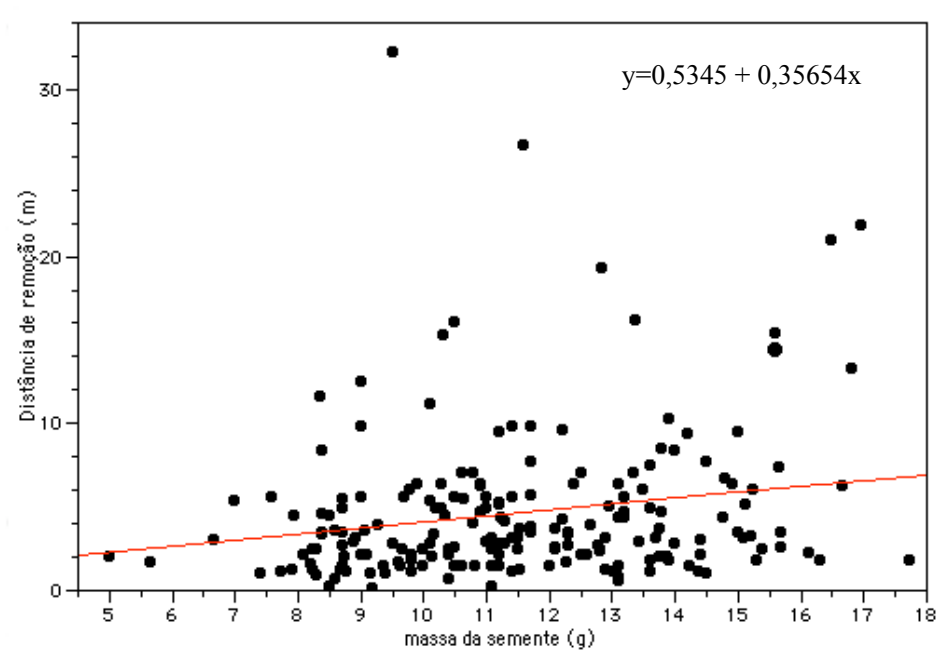

Figura 12 - Relação entre a massa da semente de Astrocaryum aculeatissimum e a distância de dispersão por roedores na Mata Atlântica do Estado de São Paulo, Brasil 


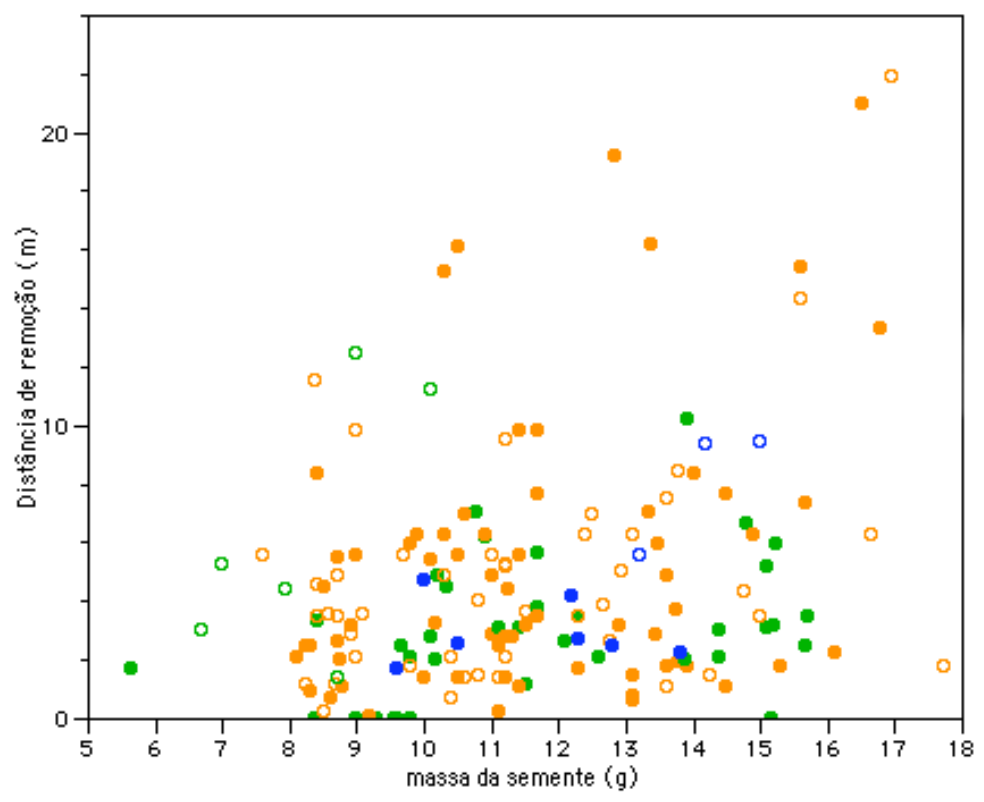

Figura 13 - Relação entre massa da semente de Astrocaryum aculeatissimum e a distância de remoção para cada uma das espécies de frugívoros e para cada destino das sementes removidas (laranja $=$ cutia, azul=esquilo e verde $=$ ratos de espinho, as bolas cheias representam a dispersão e as vazias a predação)

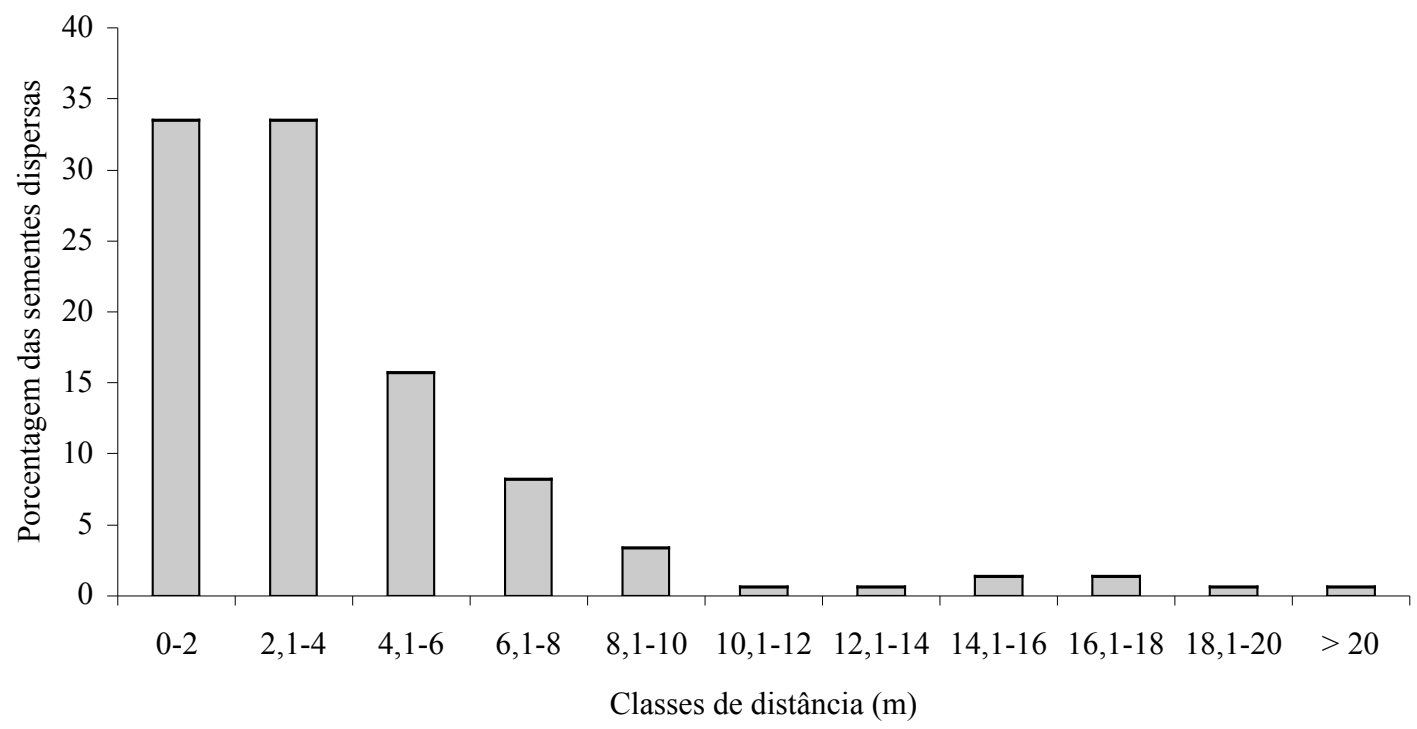

Figura 14 - Porcentagem de sementes de Astrocaryum aculeatissimum dispersas em cada uma das classes de distância da planta-mãe, na Mata Atlântica do Estado de São Paulo, Brasil 


\subsubsection{Predação por vertebrados e invertebrados e recrutamento de plântulas}

Um total de 211 endocarpos foram encontrados embaixo dos 90 indivíduos de Astrocaryum aculeatissimum amostrados, sendo 59,24\% $(\mathrm{n}=125)$ predados por vertebrados, 32,7\% $(\mathrm{n}=69)$ intactos e $8,05 \%(\mathrm{n}=17)$ predados por invertebrados. Houve diferença significativa na proporção de endocarpos predados por vertebrados, invertebrados e intactos $(\square 2=21,1179, \mathrm{p}<0,0001$, g.1.=2) (Figura 15).

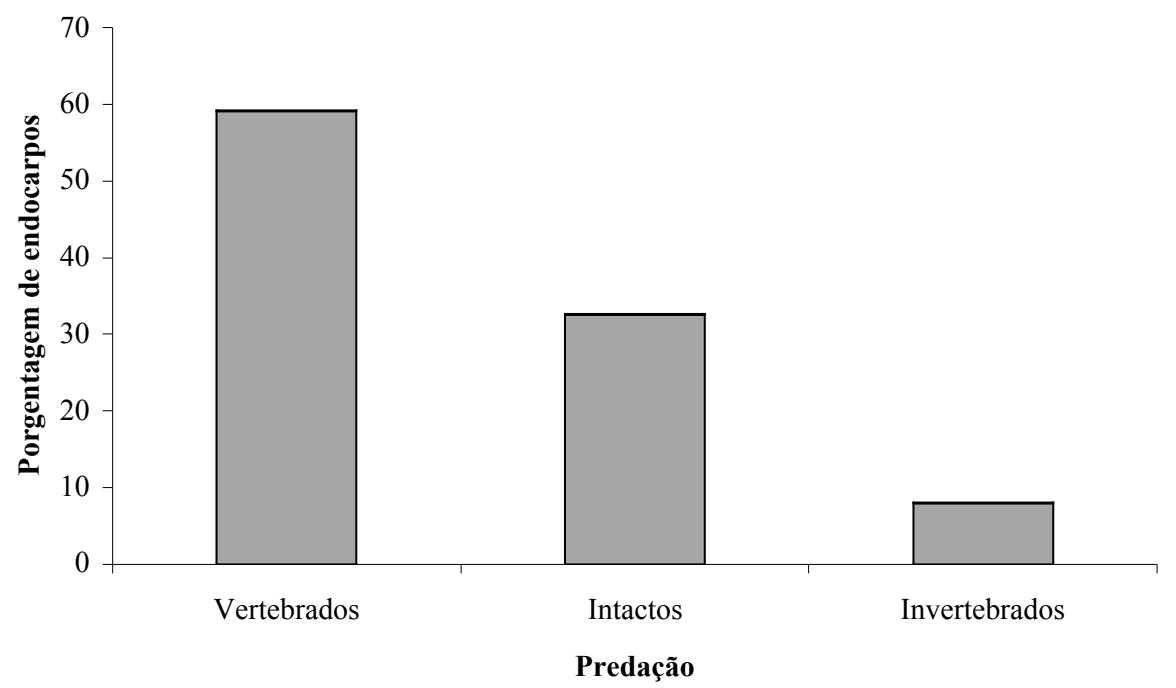

Figura 15 - Porcentagem de endocarpos de Astrocaryum aculeatissimum predados por vertebrados, invertebrados e intactos embaixo das plantas-mãe na Mata Atlântica do Estado de São Paulo, Brasil

Foram encontrados 60 indivíduos, entre plântulas e jovens, até 4 metros dos 90 indivíduos amostrados. A maior parte dos indivíduos eram jovens e estavam localizados até 2 metros da planta-mãe $(41,66 \%, n=25)$, seguidos de plântulas até 2 metros da planta-mãe e de jovens de 2 a 4 metros $(21,66 \%, n=13$ para ambos) e por último plântulas de 2 a 4 metros das plantas-mãe $(15 \%, n=9)$. Não houve diferença significativa entre a proporção de plântulas de 0 a 2 metros e de 2 a 4 metros $(\square 2=0,4378, p=0,5082$, g.l.=1) e entre a proporção de jovens de 0 a 2 metros e de 2 a 4 metros da planta-mãe $(\square 2=2,8366, p=0,0921$, g.l.=1) (Figura 16). Não houve diferença significativa na 
proporção de plântulas e jovens entre as duas classes de distância da planta mãe $(\square 2=3,1002 ; \mathrm{p}=0,0783 ; \mathrm{g} .1 .=1)$.

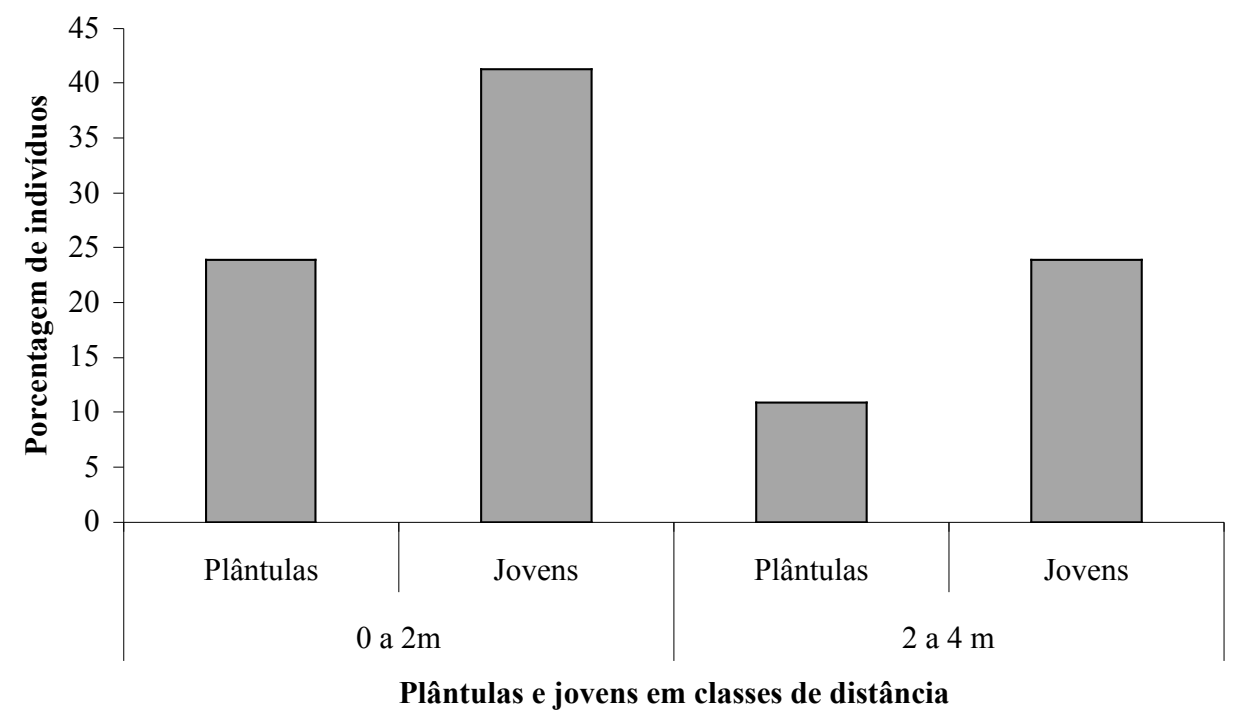

Figura 16 - Porcentagem de plântulas e jovens de Astrocaryum aculeatissimum em cada uma das classes de distância das plantas-mãe, na Mata Atlântica do Estado de São Paulo, Brasil

\subsection{Discussão}

\subsubsection{Remoção de sementes}

A cutia foi o frugívoro que mais interagiu com as sementes, concordando com outros estudos sobre dispersão e predação de sementes com frutos grandes (Forget, 1990, 1991, 1994, 1996; Fragoso et al., 2003; Hallwachs, 1986; Wright et al., 2000; Wright \& Duber, 2001), atuando mais como dispersora do que predadora das sementes removidas.

As maiores taxas de dispersão do que predação das sementes de Astrocaryum aculeatissimum concorda com outros estudos de curta duração (Forget et al., 2002), já que os roedores estocadores, depois de dispersarem secundariamente as sementes, 
podem reencontrá-las e estocá-las novamente mais 5 vezes, aumentando em cada estocagem a chance da semente ser predada (Vander Wall, 2002).

Apesar deste estudo ter encontrado que os pequenos roedores dispersaram mais sementes do que predaram, o mesmo não foi observado com Bertholletia excelsa (Lecythidaceae)(Peres \& Baider, 1997).

Tanto os ratos de espinho como as cutias estocaram a maioria das sementes removidas, ao contrário dos esquilos que dispersaram no solo a maioria delas, embora a estocagem seja um comportamento usual (Paschoal \& Galetti, 1995; Voltolini, 2004). Apesar da deposição da semente no solo por estocadores de sementes não ser um pré requisito para a germinação (Souza et al., 2000), as sementes enterradas apresentam, em geral, uma maior sobrevivência e germinação se comparadas com aquelas que ficam expostas no solo já que estariam mais susceptíveis ao ataque de predadores (Asquith, et al., 1999; Forget, 1990, 1992b; Forget \& Milleron, 1991; Forget et al., 1994, Silva \& Tabarelli, 2001; Smythe, 1989). Todas as sementes de Astrocaryum aculeatissimum enterrados pela cutia estavam com o poro germinativo para baixo, facilitando a fixação da plântula.

Os ratos de espinho depositaram as sementes embaixo da serrapilheira, evitando a desidratação e o encontro por outros predadores de sementes, aumentando assim as chances de sobrevivência das sementes e germinação das plântulas (Forget et al., 2000). Entretanto, muitas sementes foram dispersas dentro de tocas e embaixo das plantas-mãe, locais em que a germinação das sementes parece ser menos provável para acontecer.

As distâncias de dispersão das sementes foram relativamente curtas, com uma distância média de aproximadamente cinco metros da planta-mãe, concordando com outros estudos com espécies de sementes grandes dispersas por roedores (Forget, 1990; 1992a; Hallwachs, 1986; Peres \& Baider, 1997; Pimentel \& Tabarelli, 2004; Silva \& Tabarelli, 2001; Vander Wall, 1994; Voltolini, 2004). Como a maioria das sementes foram dispersas relativamente próximas às plantas-mãe, o comportamento de enterrar as sementes pode ter um papel fundamental na sobrevivência das sementes e germinação das plântulas. 
Houve uma relação positiva e significativa entre o peso da semente e a distância de remoção, mesmo resultado encontrado por Jansen et al. (2002). As sementes mais pesadas, por oferecem um maior retorno energético aos animais (Brewer, 2001), podem ter sido levadas mais longe da planta mãe para evitar o seu encontro por outros predadores de sementes, já que, embaixo das plantas-mãe, há um acúmulo de sementes e a predação tende a ser maior (Hipótese do Escape) (Connell, 1971; Janzen, 1970; Schupp, 1988 a,b).

Não houve diferença significativa na distância de remoção de sementes de Astrocaryum aculeatissimum entre as cutias (Dasyprocta sp.), ratos de espinhos (Trynomis sp.) e esquilos (Sciurus aestuans), diferente do observado por Pimentel \& Tabarelli (2004), onde os esquilos levaram as sementes de Attalea oleifera (Arecaceae) a maiores distâncias do que as pacas (Agouti paca), gambás (Didelphis albiventris) e cutias (Dasyprocta prymnolopha). Porém, neste estudo, a dispersão das sementes a mais de 12,5 metros da planta-mãe foi feita unicamente pelas cutias.

Não houve diferença significativa entre a massa e o destino da semente (predação, dispersão ou não remoção) assim como o observado para Attalea geraensis (Arecaceae) (Bonjourne \& Galetti, in prep.) e diferente do observado por Jansen et al. (2002), onde as sementes maiores de Carapa procera (Meliaceae) apresentaram mais chances de serem estocadas do que serem predadas. Apesar dos frugívoros não selecionarem as sementes pelo peso, as cutias e os esquilos removeram as sementes mais pesadas para mais longe da planta-mãe. Sementes com alto valor energético podem ser estocadas em condições que dificultem o seu encontro por outros predadores, como a maiores distâncias, em menores densidades e mais profundamente do que as sementes com menor valor (Jansen et al., 2002). Além disso, as sementes dispersas mais longe da planta-mãe têm mais chances de atingir ambientes onde a probabilidade de sobrevivência de plântulas é maior (Hoshizaki et al., 1997; Wenny, 2000), justamente por escapar dos predadores que se concentram ao redor da planta-mãe.

As sementes maiores tendem a apresentar uma maior reserva para o embrião e uma vez levadas a maiores distâncias da planta-mãe, podem ter sua germinação favorecida não só pela distância, como também por apresentar uma maior reserva. 
Verificou-se que sementes predadas foram levadas a maiores distâncias da planta-mãe do que as sementes dispersas, mesmo resultado obtido por Voltolini (2004) com sementes de palmito juçara (Euterpe edulis). Estas sementes predadas encontradas a maiores distâncias do que as dispersas, podem ter sido primeiramente dispersas, sendo levadas a maiores distâncias das plantas-mãe e depois reencontradas sofrendo uma predação pós dispersão.

\subsubsection{Predação por vertebrados e invertebrados e recrutamento de plântulas}

A. aculeatissimum apresentou uma baixa taxa de predação por invertebrados, diferente do observado em outras espécies com frutos grandes (Nascimento et al., 1997, Pimentel \& Tabarelli, 2004). Nenhum endocarpo apresentou predação por besouros brocadores, diferente do observado para a mesma espécie em áreas fragmentadas do Rio de Janeiro (A.P.Fernandez, dados não publicados) e para outras espécies do gênero (Terborgh et al, 1993 para Astrocaryum macrocalyx; Cintra, 1997 para Astrocaryum mигитити е Brewer, 2001 para Astrocaryum mexicanum).

A alta taxa de predação por vertebrados (quase $60 \%$ dos endocarpos encontrados), pode explicar a baixa predação por invertebrados, já que menos endocarpos ficariam expostos aos predadores ao redor da planta-mãe. Wright \& Duber (2001) observaram que os níveis de infestação por besouros brocadores são altos em áreas bastante pequenas ( $2 \mathrm{ha}$ ) e talvez as áreas grandes, como as deste estudo, podem não apresentar altas densidades de besouros brocadores, que seriam predadores de Astrocaryum aculeatissimum. Assim, a remoção das sementes por vertebrados pode beneficiar a planta através de duas formas: aumentando as chances das sementes serem dispersas e reduzindo as populações de invertebrados predadores pela menor disponibilidade de sementes embaixo das plantas-mãe (Herrera, 1989; Traveset, 1992).

$\mathrm{O}$ número de plântulas e jovens encontrados próximos à planta-mãe foi relativamente baixo, não havendo diferença no proporção de plântulas e jovens nas duas classes de distância da planta-mãe. Pela alta predação de sementes que ocorrem embaixo da planta-mãe, era de se esperar que uma maior proporção de plântulas e jovens fossem 
encontrados mais distantes do estipe da palmeira, no caso de 2 a 4 metros da planta-mãe, como o observado por Nascimento et al. (1997) com a espécie Astrocaryum aculeatum.

\subsection{Conclusões}

Astrocaryum aculeatissimum apresenta poucos dispersores de sementes e todos são roedores estocadores. As características do fruto, com pouca polpa e semente grande e dura, restringem o número de animais que podem dispersar ou predar esta espécie de palmeira. Entre os seus dispersores, a cutia (Dasyprocta spp.) removeu um maior número de sementes, estocou a maioria delas e as levou a maiores distâncias das plantasmãe do que os outros frugívoros (ratos de espinho - Trynomis iheringi e esquilos Sciurus aestuans), aumentando assim as chances das sementes germinarem e se estabelecerem como plântulas. As altas taxas de remoção e predação das sementes por vertebrados pode explicar as baixas taxas de predação por invertebrados encontradas embaixo das plantas-mãe. Dessa forma, as áreas que sofreram redução ou extinções locais das populações de cutias, seja pela caça ou perda do habitat, podem apresentar menor remoção e dispersão de $A$. aculeatissimum, afetando o recrutamento e a densidade de plântulas. 


\section{O efeito da defaunação na dispersão e predação de sementes e no recrutamento}

de plântulas de Astrocaryum aculeatissimum (Arecaceae) na Mata Atlântica

\section{Resumo}

As espécies arbóreas com sementes grandes são as que possuem menor riqueza de dispersores, sendo os roedores estocadores os principais dispersores e predadores destas sementes. A concentração de sementes embaixo das plantas-mãe, que não são removidas pelos vertebrados, atrai também invertebrados predadores de sementes como coleópteros e formigas. Além disso, as florestas tropicais vêm sofrendo da chamada "síndrome das florestas vazias", onde interações mutualísticas e agonísticas entre animais e plantas já foram perdidas pela ausência de predadores e dispersores de sementes e herbívoros de médio e grande portes. A cutia é o dispersor mais efetivo das sementes de $A$. aculeatissimum, então espera-se que as áreas defaunadas (com ausência ou baixa abundância de cutias) tenham a dispersão e o recrutamento de plântulas de $A$. aculeatissimum negativamente afetados. $\mathrm{O}$ estudo foi realizado em cinco áreas de Mata Atlântica do Estado de São Paulo (P.E. Xixová Japuí, P.E. Serra do Mar-Picinguaba, E.E. Juréia Itatins e P.E. Ilha do Cardoso), cada uma apresentando uma abundância de cutias que variou de 0 (muito rara) a 3 (muito abundante). A área com a maior abundância de cutias (Ilha Anchieta) apresentou um maior número de sementes removidas e também a maior porcentagem de sementes estocadas. Nas áreas com baixa abundância de cutias (Picinguaba e Juréia), a remoção das sementes foi feita, principalmente, por ratos de espinho (Trynomis iheringi) e esquilos (Sciurus aestuans). $\mathrm{Na}$ área mais defaunada (Xixová Japuí) nenhuma semente foi removida durante os cinco dias de experimento. A predação por invertebrados e o número de sementes intactas embaixo das plantas-mãe foram maiores na área mais defaunada (Xixová Japuí). A distância de dispersão de sementes foi maior na área com maior abundância de cutias (Ilha Anchieta), decrescendo até as áreas mais defaunadas (Picinguaba e Juréia), as quais apresentaram também uma maior proporção de plântulas e jovens de A. aculeatissimum embaixo das plantas-mãe. O recrutamento de plântulas de $A$. aculeatissimum amostrado em 0,8 ha em cada uma das áreas foi menor em Xixová Japuí, a área mais defaunada. A Ilha Anchieta, apesar de possuir uma alta abundância de cutias, não apresentou o maior número de plântulas/ha, já que, além de apresentar altas taxas de predação de sementes, possui também altas taxas de herbivoria por capivaras (Hydrochaeris hydrochaeris) que apresentam-se em alta densidade na área. O estudo mostrou que o decréscimo 
populacional de cutias diminui a remoção, a predação e dispersão de sementes, aumenta a predação por invertebrados e diminui o recrutamento de plântulas de $A$. aculeatissimum. Das 31 espécies de palmeiras da Mata Atlântica, pelo menos 10 são dispersas exclusivamente por roedores estocadores. Dessa forma, a defaunação pode comprometer a dispersão das sementes e o recrutamento de plântulas de, pelo menos, 1/3 das espécies de palmeiras da Mata Atlântica a longo prazo. 


\title{
4 The effect of defaunation on seed dispersal and predation and on the seedling
}

\author{
recruitment of Astrocaryum aculeatissimum in the Atlantic Forest
}

\section{Summary}

The species of plants with big seeds have low dispersers richness and the scatterhoarding rodents are the main important seed dispersers and predators of these species. The seed concentration below the mother plant that is not removed by the vertebrates, attract invertebrates seed predators like ants and coleopters. Besides, the tropical forests are suffering the "empty forest syndromes", where mutualistic and agonistic interactions between animals and plants have just gone due to the absence of the medium and large sizes seed dispersers and predators and herbivores. The agouti (Dasyprocta spp.) is the most effective seed disperser of the palm A. aculeatissimum, so we should expect that the defaunated areas (with absence or low agoutis` abundance) have the dipersal and seedling recruitment negatively affected. The study was carried out in five areas of the Atlantic forest in São Paulo state (P.E. Xixová Japuí, P.E. Serra do Mar-Picinguaba, E.E. Juréia Itatins e P.E. Ilha do Cardoso), each one showing an agouti's abundance that varied from 0 (very rare) to 3 (very abundant). The area with the higgest agoutis' abundance (Ilha Anchieta) showed the biggest number of seeds removed from the mother plant and also the largest porcentage of seeds scattered. In the areas with low agoutis` abundance (Picinguaba and Juréia), the seed removal was made mainly by squirrels (Sciurus aestuans) and spiny rats (Trynomis iheringi). In the defaunated area (Xixová Japuí) no one seed was removed during the five days of experiment. The predation by invertebrates and the number of intact seeds below the mother plant were higher in the most defaunated area (Xixová Japuí). The seed dispersal distance, although hadn't showed statistical difference between the areas, was larger in the area with higgest agoutis` abundance (Ilha Anchieta), decreasing until the more defaunated areas (Picinguaba e Juréia), that also showed high proportions of $A$. aculeatissimum seedlings and juveniles below the mother plants. The seedling recruitment sampled in the 0.8 ha in each area was low in Xixová Japuí, the most defaunated area. Despite of the higgest agoutis`abundance, Ilha Anchieta didn't show the biggest number of seedlings/ha because it had high seed predation and also had high herbivory by capibaras (Hydrochaeris hydrochaeris), that exist in high density in the area. The study showed that the agoutis ' low population decreases the seed removal, dispersal and predation, and it increases the predation by invertebrates and decreases the seedling recruitment of $A$. aculeatissimum. Ten out of the 31 Atlantic forest palm species are exclusively dispersed 
by scatter-hoarding rodents. That is why, the defaunation can compromise the seed dispersal and the seedling recruitment of at least $1 / 3$ of the Atlantic forest palm species in long term. 


\subsection{Introdução}

As plantas com sementes grandes são as que possuem menor riqueza de dispersores em florestas tropicais (Forget, 1991, 1996; Fragoso et al., 2003; Pimentel \& Tabarelli, 2004; Voltolini, 2004; Wright et al., 2000; Wright \& Duber, 2001), sendo os roedores estocadores os mais importantes dispersores e predadores dessas sementes (Asquith et al., 1999; Hallwachs, 1986, Forget, 1990, 1992, 1994, 1996, Peres \& Baider, 1997,). Além desses roedores estocadores, as sementes grandes são freqüentemente consumidas por invertebrados, como coleópteros e formigas (Forget, 1990, 1992, 1996; Fragoso et al., 2003; Guariguata et al., 2000; Hammond et al., 1999; Janzen, 1971; Pimentel \& Tabarelli, 2004; Silva \& Tabarelli, 2001; Silvius, 2002; Silvius \& Fragoso, 2002; Smythe, 1989; Vander Wall, 1994; Wright, 1983; Wright et al., 2000).

Nas espécies vegetais, cujos frutos permanecem próximos à planta mãe, os predadores vertebrados e invertebrados são atraídos para este local de grande densidade de sementes. Dessa forma, mecanismos de dispersão que façam com que a semente se mova para longe da planta-mãe aumentam a probabilidade de sobrevivência da semente dispersa, a chamada Hipótese do Escape (Connell, 1971; Forget, 1992b; Hallwachs, 1986; Hulme, 1998; Jansen et al., 2002; Janzen, 1970; Sanchez-Cordeiro \& MartínezGallardo, 1998; Schupp, 1988 a,b; Silva \& Tabarelli, 2001;Terborgh et al., 1993; Vander Wall, 2002).

Os predadores vertebrados e invertebrados diferem nas suas atividades em termos espaciais e temporais e na preferência por certas espécies de plantas (Hulme, 1997). A separação do impacto de cada um deles como predadores é importante já que a predação por vertebrados pode efetivamente manter em baixos níveis as populações de invertebrados predadores de sementes (Herrera, 1989; Traveset, 1992).

Os roedores do gênero Dasyprocta (cutias) são frugívoros diurnos de médio porte (Smythe, 1978; Emmons, 1990) e são conhecidos por apresentarem uma preferência por sementes do que por polpas, mais do que qualquer outro roedor presente em florestas tropicais (Feer et al., 2001; Henry, 1999; Smythe, 1986). As cutias são roedores 
estocadores e isso as torna um dos mais importantes dispersores de sementes (Forget, 1990, 1994; Forget \& Milleron, 1991; Smythe, 1978).

A estocagem dificulta o encontro das sementes por outros predadores, evita a dissecação e facilita a sua germinação, sendo extremamente importante para as espécies que possuem poucos dispersores (Asquith et al., 1999; Forget, 1996; Forget et al., 1999; Silva \& Tabarelli, 2001; Smythe, 1989; Vander Wall, 1994). Características dos indivíduos como sexo e idade e fatores do ambiente como estação do ano e disponibilidade de alimento podem determinar a estocagem das sementes (Vander Wall, 1990).

A caça e a perda do habitat têm afetado, principalmente, as espécies de mamíferos e aves de médio e grande porte (Bodmer et al., 1997; Chiarello, 1999; Cullen Júnior et al, 2001; Fa \& Peres, 2001; Galetti et al., 1997; Redford \& Robinson, 1987; Redford, 1992; Terborgh et al, 1993; Wright et al., 1994; Wright et al., 2000), o que pode alterar a densidade e diversidade das plantas, já que a remoção, dispersão e a predação das sementes são reduzidas, assim como a distância de dispersão e a sobrevivência de sementes e plântulas (Wright \& Duber, 2001).

As áreas defaunadas, que perderam parte ou a totalidade das espécies de herbívoros e dispersores de sementes, apresentam menores taxas ou a completa ausência de remoção de sementes (Asquith et al., 1999; Guariguata et al., 2000, Forget et al., 2001; Peres \& Van Rosmallen, 2002; Roldán \& Simonetti, 2001; Wright et al., 2000) e menores taxas de dispersão e predação de sementes (Bleher \& Bohning-Gaese, 2001; Roldán \& Simonetti, 2001; Wright et al., 2000).

Além disso, em áreas defaunadas, as sementes possuem menores distâncias de dispersão das sementes devido à extinção de dispersores de longa distância (Bleher \& Bohning-Gaese, 2001; Wright \& Duber, 2001), maiores taxas de predação por invertebrados (Wright et al., 2000; Wright \& Duber, 2001), pela concentração de sementes embaixo da planta-mãe que não são dispersas, (Cintra, 1997; Smythe, 1989; Wilson \& Janzen, 1972; Wright et al, 2000) e um maior recrutamento de plântulas longe das plantas-mãe (Bleher \& Bohning-Gaese, 2001; Cordeiro \& Howe, 2003; Wright \& Duber, 2001). 
Como os pequenos mamíferos não sofrem pressão de caça, como os de médio e grande porte (Wright, 2003), eles podem apresentar uma maior abundância em áreas mais defaunadas, onde a remoção das sementes por pequenos mamíferos tende a ser maior (Guariguata et al., 2002; Sanchez-Cordero \& Martinez-Gallardo, 1998).

Poucas áreas com grandes extensões restam na Mata Atlântica do Estado de São Paulo (5 áreas maiores que 30.000 ha), sendo que a maioria dos fragmentos apresentam menos de 5.000 hectares (Secretaria do Estado do Meio Ambiente, 2000). Atualmente um dos locais mais preservados de Mata Atlântica é a Serra do Mar, com uma área total de 315.390 hectares de floresta contínua, atingindo quase que a totalidade do litoral paulista e parte do paranaense e carioca. Esta grande área contínua torna-se, portanto, uma das últimas oportunidades de conservação de interações mutulísticas entre mamíferos de médio e grande porte e plantas.

Estudos recentes mostram, entretanto, que mesmo áreas de grandes extensões na Mata Atlântica são "florestas vazias" (Galetti, et al. in prep.), sendo que muitas áreas já não possuem mais os grandes mamíferos.

As sementes de A. aculeatissimum são dispersas exclusivamente por roedores estocadores e as cutias podem ser consideradas os dispersores de sementes mais efetivos. São responsáveis pela maior remoção das sementes, estocam uma alta porcentagem das sementes removidas e levam as sementes a maiores distâncias das plantas-mãe (ver cap.3). As cutias são caçadas em toda a sua distribuição geográfica (Chiarello, 1999; Cullen Júnior et al., 1999) e são eventualmente levadas a extinções locais (Smythe, 1978, 1989). Dessa forma, espera-se que a dispersão e o recrutamento de A.aculeatissimum sejam negativamente afetados em áreas onde as cutias estão ausentes ou em baixas densidades.

Este trabalho tem como objetivo avaliar o efeito da abundância de cutias na predação e dispersão de sementes de Astrocaryum aculeatissimum na Mata Atlântica paulista. As hipóteses testadas foram que a baixa abundância de cutias: (1) diminuiria a remoção, a dispersão e predação das sementes; (2) diminuiria a distância de remoção das sementes; (3) aumentaria a remoção das sementes por pequenos mamíferos, (4) 
aumentaria a predação por invertebrados devido ao acúmulo de sementes embaixo das plantas-mãe e (5) diminuiria o recrutamento de plântulas longe das plantas-mãe.

\subsection{Material e Métodos}

\subsection{1 Áreas de estudo}

O estudo foi desenvolvido em cinco áreas de Mata Atlântica do Estado de São Paulo (Parque Estadual da Ilha Anchieta, Parque Estadual da Ilha do Cardoso, Estação Ecológica Juréia Itatins, Parque Estadual da Serra do Mar- núcleo Picinguaba, Parque Estadual Xixová Japuí) (Figura 17). Estas áreas foram selecionadas pela sua localização geográfica, por apresentarem como tipo florestal dominante a Floresta Ombrófila Densa e por apresentarem uma variação na abundância de cutias.

\subsubsection{Ilha Anchieta (PEIA)}

O Parque Estadual da Ilha Anchieta ( $23^{\circ} 32^{\prime} \mathrm{S}$ e $\left.45^{\circ} 03^{\prime} \mathrm{W}\right)$ possui 828 hectares e localiza-se no litoral norte do Estado de São Paulo, na costa do município de Ubatuba. O clima é segundo a classificação de Koppen, do tipo Af, tropical úmido, com chuvas o ano todo, sem uma estação seca definida e com temperaturas superiores a $20^{\circ} \mathrm{C}$.

A Ilha Anchieta teve a sua cobertura vegetal original bastante alterada em função, principalmente, da ativação do presídio, onde parte da vegetação foi destruída para a retirada de madeira (Guillaumon et al., 1989). Em 1983, 8 cutias (Dasyprocta spp.) e 7 capivaras (Hydrochaeris hydrochaeris) foram introduzidas na ilha, o que contribuiu para a alteração vegetal devido à superpopulação dessas espécies que se encontram hoje na área (Paes, 1997, R. S. Bovendorp, dados não publicados).

As aves de médio e grande porte pertencentes às famílias Cracidae, Ramphastidae e Tinamidae, importantes frugívoros, não encontram-se na área de estudo (R.S. Bovendorp, dados não publicados; C. I. Donatti, obs. pessoal). A abundância de cutias é bastante alta, com 6,95 inds/10 km percorridos. 


\subsection{2 Xixová Japuí (PEXJ)}

Situado entre os municípios de Praia Grande e São Vicente, na Baixada Santista, o Parque Estadual Xixová Japuí possui 901 hectares, cuja maior parte da sua área envolve um maciço isolado, que recebe 4 denominações: Prainha, Japuí, Xixová e Itaipu. A Unidade foi criada em 1993 e é dividida entre os setores Xixová, Itaipu, Curtume e Parnapuã (Secretaria do Estado do Meio Ambiente, 1998b).

O clima da área é considerado, segundo a classificação de Koppen, uma transição entre o clima tropical úmido (Af) para o clima subtropical úmido (Cfa), com temperaturas médias de $22^{\circ} \mathrm{C}$ e pluviosidade média anual de $2.350 \mathrm{~mm}$ (Secretaria do Estado do Meio Ambiente, 1998b).

A área possui uma faixa marinha de 250 metros além da linha da costa que contorna todo o costão rochoso, do norte para o sudeste (Secretaria do Estado do Meio Ambiente, 2000). Apresentam-se na área ecossistemas de praia e restinga, com o predomínio da Floresta Ombrófila Densa (Secretaria do Estado do Meio Ambiente, 1998b). A área apresenta-se isolada de outros fragmentos florestais pela proximidade das cidades de Santos e São Vicente e é visualmente bastante pressionada pelo crescimento urbano e aumento populacional.

Não há um censo de fauna na área, mas a densidade de mamíferos e aves é, sem dúvida, a menor dentre as áreas de estudo. Nenhum mamífero ou ave frugívora de médio ou grande porte foi observada durante 10 dias consecutivos de trabalho de campo. Segundo funcionários do parque não há registro de avistamento de cutia desde 1999.

\subsubsection{Ilha do Cardoso (PEIC)}

O Parque Estadual da Ilha do Cardoso (25ำ 's e $\left.47^{\circ} 59^{\prime} \mathrm{W}\right)$ situa-se no litoral sul do Estado de São Paulo, na costa do município de Cananéia, fazendo fronteira com o Estado do Paraná. O parque foi criado em 1962 e possui uma área de 15.100 hectares (Secretaria do Estado do Meio Ambiente, 2001).

A topografia da ilha é predominantemente montanhosa, com a parte central dominada por elevações com mais de 814 metros (Secretaria do Estado do Meio Ambiente, 2001). O clima da região não apresenta estação seca definida e, segundo a 
classificação de Koppen, é do tipo Cfa, subtropical úmido. As chuvas estão bem distribuídas ao longo do ano com temperaturas médias mensais superiores a $22{ }^{\circ} \mathrm{C}$ nos meses mais quentes e inferiores a $18^{\circ} \mathrm{C}$ nos meses mais frios.

$\mathrm{Na}$ ilha encontram-se 6 povoamentos típicos caiçaras e índios da etnia Guarani Mbya, que estabeleceram-se na unidade em 1992 (Olmos et al., no prelo; Secretaria do Estado do Meio Ambiente, 2001).

A cobertura vegetal é composta por cinco tipos principais de formações vegetais: vegetação pioneira de duna, vegetação de restinga, floresta pluvial tropical da planície litorânea, floresta pluvial tropical da Serra do Mar e vegetação de mangue (Noffs \& Baptista-Noffs, 1982). Um levantamento florístico por parcelas, totalizando uma amostragem de 1 hectare, indicou a presença de 157 espécies de indivíduos arbóreos pertencentes a 47 famílias, cujas mais representativas foram Myrtaceae (29 espécies), Rubiaceae (10 espécies), Sapotaceae (7 espécies) e Arecaceae (5 espécies) (Fiuza de Melo, 1993).

Os levantamentos de fauna realizados indicam a existência de cerca de 70 espécies de mamíferos e 436 espécies de aves, número este que o torna um dos sítios de maior diversidade de espécies de aves dentro do domínio atlântico brasileiro (Secretaria do Estado do Meio Ambiente, 2001). A fauna se distribui diferentemente ao longo do gradiente altitudinal, do nível do mar até os picos de altitude, mas muitos grupos animais ainda permanecem desconhecidos (Secretaria do Estado do Meio Ambiente, 2001).

Estudos recentes sobre a fauna de mamíferos encontraram uma densidade de 28,78 indivíduos $/ \mathrm{km}^{2}$, com uma abundância de 0,7 cutias $/ 10 \mathrm{~km}$ percorridos (Dasyprocta leporina), 0,33 esquilos/10 km (Sciurus aestuans), 0,14 queixadas/10 km (Tayassu pecari) e 0,03 catetos/10 km (Pecari tajacu) (São Bernardo, 2004).

\subsubsection{Picinguaba (PESM/P)}

O Parque Estadual da Serra do Mar, núcleo Picinguaba (233'ㅇ'S e $45^{\circ} 03^{\prime} \mathrm{W}$ ) situa-se no litoral norte do Estado de São Paulo, no município de Ubatuba. Com uma área de aproximadamente 47.500 hectares, o núcleo Picinguaba foi criado em 1979 e é ecologicamente importante por estar bastante próximo ao Parque Nacional da Serra da 
Bocaina (RJ) e a Área de Proteção Ambiental - APA do Cairuçu (RJ). O núcleo Picinguaba é o único ponto do Parque Estadual da Serra do Mar que atinge a orla marítima (Piccolo, 1992), preservando ecossistemas litorâneos (costão rochoso, duna, mangue e restinga) associados à Floresta Ombrófila Mista, que é a vegetação predominante na área (Secretaria do Estado do Meio Ambiente, 1998).

A região de Picinguaba, onde está concentrada a infra-estrutura do núcleo, é cortada pela rodovia Rio-Santos (BR-101), tornando a área bastante susceptível a especulação imobiliária, ocupação turística e visitação descontrolada (Secretaria do Estado do Meio Ambiente, 1998).

O clima da região de Ubatuba é, segundo a classificação de Koppen do tipo Af, tropical úmido, com chuvas o ano todo, com pelo menos $60 \mathrm{~mm}$ de chuva no mês mais seco e com temperaturas médias mensais superiores a $18^{\circ} \mathrm{C}$.

Um levantamento florístico utilizando a metodologia de parcelas e uma amostragem de 0,6 hectares indicou a presença de 117 espécies ripárias arbóreas, pertencentes a 76 gêneros e 37 famílias, cujas mais representativas foram Myrtaceae (30 espécies), Rubiaceae (9 espécies), Fabaceae (9 espécies) e Lauraceae (8 espécies) (Sanchez, 1994).

Os levantamentos de fauna no núcleo incluem alguns estudos com aves (Willis \& Oniki, 1981; Castro, 1997), peixes (Uieda, 1995), anfíbios (Bastos, 1993; Bastos \& Haddad, 1995, 1996) e mais recentemente com mamíferos (R.M. Marques, dados não publicados).

Apesar de fazer parte da maior área protegida de Mata Atlântica do Estado de São Paulo (Parque Estadual da Serra do Mar com 315.390 hectares), o núcleo Picinguaba apresenta uma baixa densidade de mamíferos, com uma abundância de 0,014 cutias/10 km percorridos (Dasyprocta spp.) e de 0,005 queixadas/10 km (Tayassu pecari) (R. M. Marques, dados não publicados). 


\subsubsection{Juréia Itatins (EEJI)}

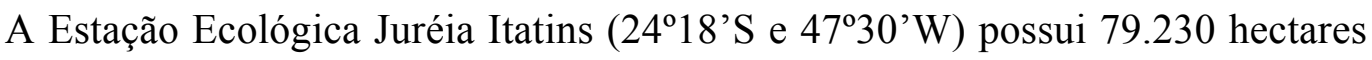
de área e tornou-se Unidade de Conservação em 1986, abrangendo parte dos municípios de Itariri, Miracatu, Peruíbe e Iguape, sendo neste localizada a sua maior extensão.

Segundo a classificação de Koppen, o clima da região é do tipo Cfa, subtropical úmido, com chuvas bem distribuídas ao longo do ano, temperaturas médias mensais superiores a $22^{\circ} \mathrm{C}$ nos meses mais quentes e inferiores a $18^{\circ} \mathrm{C}$ nos meses mais frios.

A ocupação remonta do século XVIII, iniciada por grupos negros, índios e descendentes de europeus (Secretaria do Estado do Meio Ambiente, 2000). Hoje, índios Guarani Mbya e aproximadamente 320 famílias de caiçaras povoam a unidade (Sanches, 2004).

O levantamento florístico pelo método de pontos quadrantes, indicou a presença de 178 espécies arbóreas, pertencentes a 51 famílias, cujas mais representativas foram Myrtaceae (37 espécies), Rubiaceae (9 espécies), Sapotaceae (6 espécies) e Lauraceae (5 espécies) (Mantovani, 1993).

Apresenta grande riqueza faunística, incluindo a onça pintada (Panthera onca), a onça parda (Puma concolor), a jaguatirica (Leopardus pardalis), o mono carvoeiro (Brachytelles arachnoides) e a anta (Tapirus terrestris). A área apresenta levantamento de fauna, com o registro de 314 espécies de aves (Develey, 2004) e 32 espécies de mamíferos de médio e grande porte (Pardini \& Develey, 2004).

Estudos recentes sobre a fauna indicam a presença de 39,84 mamíferos $/ \mathrm{km}^{2}$, com uma abundância de 0,27 de queixadas/10 km percorridos (Tayassu pecari), 0,18 catetos/10 km (Pecari tajacu) e 1,19 esquilos/10 km percorridos (Sciurus aestuans) (São Bernardo, 2004), números bastante baixos. 
Tabela 3 Fauna de mamíferos não voadores de médio e grande porte para as áreas de estudo, na Mata Atlântica do Estado de São Paulo

\begin{tabular}{|c|c|c|c|c|c|c|c|}
\hline Ordem & Família & Espécie & Nome popular & PEIA & PEIC & PESM/P & EEJI \\
\hline Xenartha & Myrmecophagidae & Tamandua tetradactyla & Tamanduá Mirim & $\mathrm{X}$ & $\mathrm{X}$ & $\mathrm{X}$ & $\mathrm{X}$ \\
\hline Xenartha & Bradypodidae & Bradypus variegatus & Bicho preguiça & & & $\mathrm{X}$ & $\mathrm{X}$ \\
\hline Xenartha & Dasypodidae & Cabassus sp. & Tatu de rabo mole & & & & $\mathrm{X}$ \\
\hline Xenartha & Dasypodidae & Dasypus hibridus & Tatu & & & $\mathrm{X}$ & \\
\hline Xenartha & Dasypodidae & Dasypus novemcinctus & Tatu galinha & $\mathrm{X}$ & $x$ & $\mathrm{X}$ & $\mathrm{X}$ \\
\hline Xenartha & Dasypodidae & Dasypus septemcinctus & Tatuí & $\mathrm{X}$ & & & \\
\hline Carnivora & Canidae & Cerdocyon thous & Cachorro do mato & & $\mathrm{X}$ & $\mathrm{X}$ & $\mathrm{X}$ \\
\hline Carnivora & Canidae & Speothos venaticus & Cachorro vinagre & & $\mathrm{X}$ & & \\
\hline Carnivora & Procyonidae & Nasua nasua & Quati & $\mathrm{X}$ & $\mathrm{X}$ & & $\mathrm{X}$ \\
\hline Carnivora & Procyonidae & Procyon cancrivorus & Mão pelada & & $\mathrm{X}$ & $\mathrm{X}$ & $\mathrm{X}$ \\
\hline Carnivora & Mustelidae & Eira barbara & Irara & & $x$ & & $\mathrm{X}$ \\
\hline Carnivora & Mustelidae & Galictis sp. & Furão & & & & $\mathrm{X}$ \\
\hline Carnivora & Mustelidae & Lontra longicaudis & Lontra & & $\mathrm{X}$ & $\mathrm{X}$ & $\mathrm{X}$ \\
\hline Carnivora & Felidae & Herpailurus yaguarondi & Gato mourisco & & $\mathrm{X}$ & & $\mathrm{X}$ \\
\hline Carnivora & Felidae & Leopardus pardalis & Jaguatirica & & $\mathrm{X}$ & $\mathrm{X}$ & $\mathrm{X}$ \\
\hline Carnivora & Felidae & Leopardus triginus & Gato do mato & & $\mathrm{X}$ & & \\
\hline Carnivora & Felidae & Leopardus wiedii & Gato maracajá & & $\mathrm{X}$ & & \\
\hline Carnivora & Felidae & Panthera onca & Onça pintada & & $\mathrm{X}$ & & $\mathrm{X}$ \\
\hline Carnivora & Felidae & Puma concolor & Onça parda & & $\mathrm{X}$ & & $\mathrm{X}$ \\
\hline Perissodactyla & Tapiridae & Tapirus terrestris & Anta & & & & $\mathrm{X}$ \\
\hline Artiodactyla & Tayassuidae & Pecari tajacu & Cateto & & $\mathrm{X}$ & & $\mathrm{X}$ \\
\hline Artiodactyla & Tayassuidae & Tayassu pecari & Queixada & & $\mathrm{X}$ & $\mathrm{X}$ & $\mathrm{X}$ \\
\hline Artiodactyla & Cervidae & Mazama sp & Veado & & $\mathrm{X}$ & $\mathrm{X}$ & $\mathrm{X}$ \\
\hline Rodentia & Sciuridae & Sciurus aestuans & Serelepe & & $\mathrm{X}$ & $\mathrm{X}$ & $\mathrm{X}$ \\
\hline Rodentia & Erethizontidae & Coendou prehensilis & Porco espinho & & $\mathrm{X}$ & $\mathrm{X}$ & $\mathrm{X}$ \\
\hline Rodentia & Erethizontidae & Sphiggurus villosus & Ouriço cacheiro & & $\mathrm{X}$ & & $\mathrm{X}$ \\
\hline Rodentia & Hydrochaeridae & Hydrochaeris hydrochaeris & Capivara & & $\mathrm{X}$ & $\mathrm{X}$ & $\mathrm{X}$ \\
\hline Rodentia & Agoutidae & Agouti paca & Paca & $\mathrm{X}$ & $\mathrm{X}$ & & $\mathrm{X}$ \\
\hline Rodentia & Dasyproctidae & Dasyprocta azarae & Cutia & $\mathrm{X}$ & & & \\
\hline Rodentia & Dasyproctidae & Dasyprocta leporina & Cutia & $\mathrm{X}$ & $\mathrm{X}$ & $\mathrm{X}$ & $\mathrm{X}$ \\
\hline Logomorpha & Leporidae & Sylvilagus brasiliensis & Tapiti & & $\mathrm{X}$ & $X$ & $\mathrm{X}$ \\
\hline Primates & Cebidae & Cebus nigritus & Macaco prego & $\mathrm{X}$ & & & $\mathrm{X}$ \\
\hline Primates & Atelidae & Alouatta guariba & Bugio & & $\mathrm{X}$ & $\mathrm{X}$ & $\mathrm{X}$ \\
\hline Primates & Atelidae & Brachyteles arachnoides & Mono carvoeiro & & & $\mathrm{X}$ & $\mathrm{X}$ \\
\hline
\end{tabular}




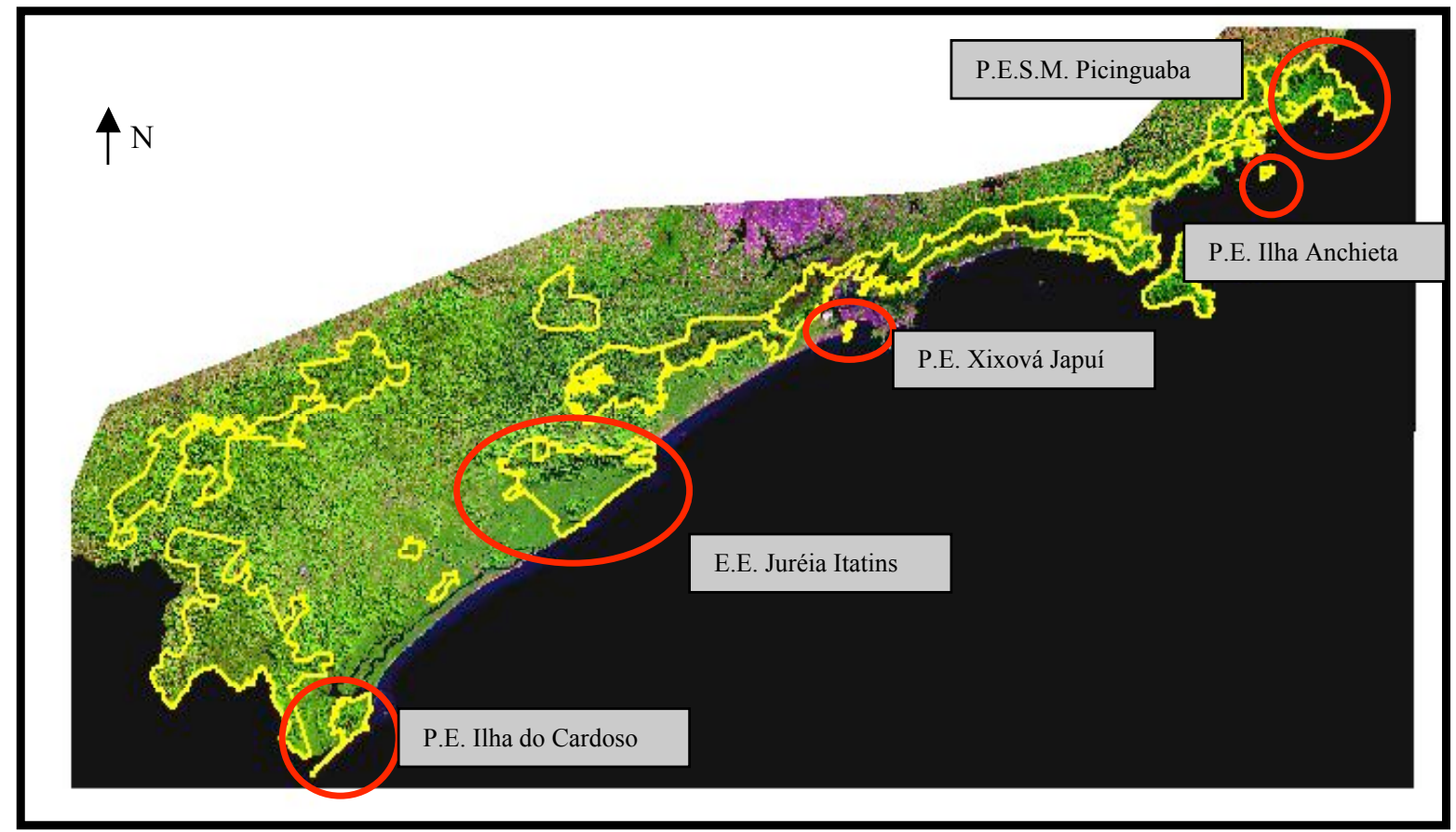

Figura 17. Áreas de estudo no litotal do Estado de São Paulo, Brasil

\subsubsection{Remoção de sementes}

Apesar de ratos de espinho e esquilos serem também responsáveis pela remoção de sementes de Astrocaryum aculeatissimum, a defaunação foi aqui relacionada apenas com a abundância de cutias, que são os dispersores mais efetivos desta palmeira (ver cap. 3). As abundâncias de ratos de espinho e esquilos não foram comparadas com as taxa de remoção de sementes, já que estas espécies são raramente caçados em florestas tropicais (Wright et al., 2000; Wright, 2003) e não são levadas a um decréscimo populacional em áreas caçadas e/ou fragmentadas (Cullen Júnior et al., 2001; Fonseca \& Robinson, 1990).

Os censos de mamíferos de médio e grande porte foram realizados em cada uma das áreas de estudo, nos anos anteriores, através do método de Line Transect (Burham et 
al., 1980) com exceção de Xixová Japuí. A partir das abundâncias de cutias (Dasyprocta spp.), em número de indivíduos/10 km percorridos, encontradas em cada área, bem como consultas bibliográficas definiu-se uma ordenação que variou de 0 (muito rara) a 3 (muito abundante) (Tabela 4).

Tabela 4 Locais de amostragem, áreas, abundância de cutias, km percorrida nos censos, ordenação da abundânia de cutias ( $\mathrm{o}=$ muito rara a $3=$ muito abundante) e referências consultadas

\begin{tabular}{cccccc}
\hline $\begin{array}{c}\text { Áreas } \\
\text { de estudo }\end{array}$ & $\begin{array}{c}\text { Área } \\
\text { (em hectares) }\end{array}$ & $\begin{array}{c}\text { Abundância de cutias } \\
\text { (inds/10 km) }\end{array}$ & $\begin{array}{c}\text { Km } \\
\text { Percorrida }\end{array}$ & $\begin{array}{c}\text { Rank } \\
\text { de abundância }\end{array}$ & Referências \\
\hline Ilha Anchieta & 828 & 6,95 & 96,3 & 3 & R.Bovendorp (dados não publicados) \\
Ilha do Cardoso & 15.100 & 0,69 & 221,0 & 2 & São Bernardo (2004) \\
Juréia Itatins & 79.230 & 0,1 & 110,0 & 1 & São Bernardo (2004)/Pardini (2004) \\
Picinguaba & 47.441 & 0,148 & 202,2 & 1 & R.M. Marques (dados não publicados) \\
Xixová Japuí & 901 & $*$ & & 0 & \\
\hline
\end{tabular}

* não há dados disponíveis sobre a área

Um estudo de campo piloto foi feito em 2002 para verificar quais espécies interagiam com as sementes e também para escolher o método dentro os mais efetivos no monitoramento das sementes removidas (veja Voltoloni, 2004). O tipo de marcação na semente bem como o comportamento na dispersão puderam ser inferidos para cada uma das espécies animais. Para evitar problemas de nomenclatura, o termo semente refere-se aqui ao pirênio do fruto, que inclui o endocarpo e a semente propriamente dita.

Antes do experimento ser montado, cada uma das sementes foi marcada com um número para permitir a identificação individual. Para medir a distância de dispersão, uma linha de pesponto Gutermann ${ }^{\circledR}$ (por ser mais resistente) foi amarrada a cada semente. A linha foi amarrada a um anel de arame que foi transpassado pela semente, evitando assim o corte da linha pelos frugívoros. A linha foi presa em um carretel de costura que foi colocado dentro da embalagem de filme fotográfico. Diversos estudos utilizaram-se de sementes marcadas para o acompanhamento do destino das mesmas (Forget, 1990;1991, 1993, 1996; Forget \& Milleron, 1991; Forget et al., 2000; Forget, 1996, Hallwachs, 1986; Peres \& Baider, 1997). 
Cinco sementes de Astrocaryum aculeatissimum amarrados aos carretéis foram distribuídos ao redor da palmeira e a aproximadamente $20 \mathrm{~cm}$ do estipe. As sementes foram colocados embaixo dos indivíduos adultos de Astrocaryum aculeatissimum, pois foi assumido que os animais forrageiam de forma mais intensa e freqüente nos locais onde têm mais chances de encontrar o recurso (Forget et al., 2000).

Os experimentos foram instalados entre dezembro de 2002 e fevereiro de 2003, imediatamente após o período de queda dos frutos, coincidindo com a época de disponibilidade das sementes aos animais. Os frutos de Astrocaryum aculeatissimum foram coletados diretamente dos indivíduos adultos, suas polpas foram removidas manualmente e as sementes foram secas ao sol. Dessa forma, somente as relações entre as sementes e os frugívoros foram aqui analisadas, excluindo-se portanto, os animais interessados somente na polpa do fruto.

Os indivíduos de Astrocaryum aculeatissimum foram selecionados por apresentarem os seguintes critérios: 1) estarem separados por pelo menos 50 metros uns dos outros; 2) situarem-se a 10 metros de qualquer outro indivíduo adulto da espécie; 3) localizarem-se em locais planos para evitar que os frutos rolassem ao chegarem ao solo e 4) localizarem-se nas mesmas trilhas onde foram realizados os censos de mamíferos e aves nos anos anteriores (exceto em Xixová Japuí onde o censo não foi realizado).

As sementes marcadas puderam ser seguidas, a distância de remoção foi medida e a espécie de frugívoro pôde ser inferida pelo tipo de marcação deixada nas sementes. Durante o projeto piloto, definiu-se que cinco dias seriam suficientes para verificar a remoção das sementes, devido a rápida remoção nas áreas com alta abundância de cutias. No geral em florestas tropicais, a falta de uma rápida remoção das sementes grandes dentro de uma semana sugerem que os roedores estocadores são menos abundantes (Asquith et al., 1999; Forget et al., 2001).

O comprimento da linha utilizada foi de 30 metros, tamanho suficiente quando levada em conta a dispersão de sementes executada por alguns roedores que em geral não ultrapassa esta medida (Forget, 1990; Peres et al., 1997; Forget et al., 2000; Pimentel \& Tabarelli, 2004). Apesar de cutias eventualmente levarem as sementes à distâncias que podem chegar a mais de 50 metros (Forget, 1991, 1999; Hallwachs, 1986) 
e a linha fixa poder atrapalhar o movimento dos frugívoros, a marcação com a linha permite um encontro mais rápido e eficiente das sementes removidas (ver Voltolini, 2004).

A dispersão foi considerada quando as sementes foram movidas a mais de 0,5 metro do estipe da palmeira e foram encontradas intactas ou enterradas (Guariguata et al., 2000) e a predação considerada quando as sementes foram total ou parcialmente destruídas (ver Forget, 1996; Guariguata et al., 2000). Aquelas sementes que foram encontradas sem a linha e aquelas que enroscaram no carretel também foram consideradas, mas usadas apenas para estimar a remoção e não o destino das sementes. A distância de remoção foi medida em linha reta, do local da instalação do experimento até o local onde a semente foi encontrada.

A separação entre predação e dispersão de sementes é necessária uma vez que a remoção das mesmas não é um bom indicador de predação e nem de disperão (Forget, 1990, 1996; Forget \& Milleron, 1991). Estes eventos, principalmente em relação aos roedores estocadores, dependem de fatores internos do animal, como sexo e idade e também de fatores relacionados ao ambiente como tipo de alimento disponível e estação do ano (Vander Wall, 1990).

Foram utilizados 32 indivíduos adultos de A. aculeatissimum em cada área, totalizando 160 sementes marcadas, com exceção de Picinguaba onde foram usados 28 indivíduos e 130 sementes e da Ilha Anchieta onde foram usados 26 indivíduos e 140 sementes, pela dificuldade de encontrar mais indivíduos adultos que apresentavam os critérios descritos acima.

O número de sementes removidas em cada estação experimental foi comparada entre as áreas de estudo através do teste de Kruskal Wallis, uma vez que os dados não apresentaram homogeneidade de variâncias e nem distribuição normal, mesmo após transformações.

O número de sementes removidas pelos frugívoros em cada uma das estações experimentais foi comparada entre as áreas de estudo por um teste de Kruskal-Wallis, assim como foi comparada a remoção pelos frugívoros dentro de cada área de estudo. A 
média do número de sementes removidas por estação em cada área foi correlacionada com a abundância de cutias (ver tabela 4).

A proporção de sementes predadas (número de sementes predadas/número de sementes removidas em cada uma das estações experimentais) e dispersas (número de sementes dispersas/número de sementes removidas em cada uma das estações experimentais) foram também comparadas em cada uma das cinco áreas pelo teste de Kruskal-Wallis (Zar, 1999). A proporção de sementes predadas foi comparada com a de sementes dispersas em cada uma das áreas de estudo através do teste de Mann-Whitney. A média da proporção de sementes predadas e dispersas em cada área foram relacionadas com a abundância de cutias (ver tabela 4) através da Correlação de Spearman (rs).

A distância máxima de dispersão em cada uma das estações experimentais, retirando-se aquelas estações sem remoção, bem como a distância de todas as sementes dispersas foram comparadas entre as áreas. Os dados de distância máxima de dispersão foram transformados em $\log (\mathrm{x}+1)$ e apresentaram distribuição normal e homogeneidade de variâncias (Shapiro-Wilk=0,9737, p=0,5563), sendo possível a comparação através de uma Análise de Variância. Os dados de distância de dispersão, mesmo quando transformados em $\log (x+1)$, não apresentaram distribuição normal nem homogeneidade de variâncias e foram então comparados entre as áreas de estudo através do teste de Kruskal-Wallis.

\subsubsection{Predação por vertebrados e invertebrados e recrutamento de plântulas}

Para quantificar a predação por vertebrados e invertebrados e o recrutamento de plântulas e jovens entre as áreas de estudo, foram utilizados os mesmos indivíduos adultos de Astrocaryum aculeatissimum dos experimentos de remoção de sementes.

Todos os endocarpos recentes encontrados num raio de 2 metros da planta mãe (Nascimento et al., 1997) foram amostrados em cada uma das áreas de estudo. Os indivíduos de Astrocaryum aculeatissimum localizavam-se em áreas planas e a pelo menos 10 metros de outro indivíduo adulto, para diminuir a possibilidade de coletar endocarpos de outros indivíduos próximos. 
Os endocarpos encontrados foram separados em predados por vertebrados, invertebrados ou intactos (Cintra, 1997; Wright et al, 2000; Wright \& Duber, 2001) os quais foram identificados por furos de emergência e marcas de entrada de invertebrados, marcas de dentes e sem marcações, respectivamente. Os endocarpos que podiam ser quebrados com a mão foram descartados da amostragem (Wright \& Duber, 2001), por ser difícil definir o tipo de predação em endocarpos quebrados e por estar-se restringindo a amostragem em eventos recentes.

As plântulas (indivíduos com até $50 \mathrm{~cm}$ de altura) e jovens (indivíduos com mais de $50 \mathrm{~cm}$ de altura mas que não apresentavam sinais de reprodução) da espécie presentes até $2 \mathrm{~m}$ e de 2 a $4 \mathrm{~m}$ de raio da planta mãe (Nascimento et al., 1997) foram amostrados. Essas distâncias utilizadas para medir o recrutamento da palmeira foram escolhidas porque assumiu-se que a espécie, por possuir frutos pesados $(\mathrm{x}=28,8 \mathrm{~g})$ e pelos indivíduos escolhidos estarem localizados em áreas planas, as plântulas e os jovens encontrados a mais de 2 metros de raio da planta mãe, seriam provavelmente provenientes de sementes dispersas.

A proporção de endocarpos predados por vertebrados (número de endocarpos predados por vertebrados/número total de endocarpos encontrados na estação experiemental), invertebrados e intactos em cada uma das estações experimentais, foram comparados entre as áreas através do teste de Kruskal-Wallis, já que os dados, mesmo transformados, não atingiram a normalidade e não apresentaram homogeneidade de variâncias.

A proporção de predação por vertebrados, invertebrados e endocarpos intactos foram comparadas em cada uma das áreas de estudo pelo teste de Kruskal-Wallis.

As médias das proporções de endocarpos predados por vertebrados, invertebrados e intactos em cada uma das áreas de estudo foram correlacionadas com a classificação de abundância de cutias (avistamentos/10 km percorridos), através da Correlação de Spearman (rs).

As proporções de plântulas (número de plântulas encontradas de 0 a 2 metros da planta-mãe/número de plantulas e jovens encontrados de 0 a 4 metros) e jovens de 0 a 2 metros e as proporções de plântulas e jovens de 2 a 4 metros em cada uma das estações 
experimentais foram comparadas separadamente entre as áreas de estudo, utilizando o teste de Kruskal-Wallis.

As proporções de plântulas de 0 a 2 metros da planta mãe foram comparadas com as proporções de plântulas de 2 a 4 metros da planta mãe em cada uma das áreas de estudo pelo teste de Mann-Whitney. As proporções de jovens foram comparados da mesma forma.

As médias das proporções de plântulas e jovens encontrados de 0 a 2 metros e de 2 a 4 metros da planta-mãe também foram correlacionadas com a abundância de cutias em cada uma das áreas (ver Tabela 4), pela Correlação de Spearman (rs).

\subsubsection{Densidade de plântulas, jovens e adultos}

Para obter os dados de densidade de plântulas, jovens e adultos de Astrocaryum aculeatissimum foram utilizadas 10 parcelas ao longo de 4 trilhas, com $50 \mathrm{~m}$ de comprimento e 2 metros para cada lado da trilha (Bleher \& Bohning-Gaese, 2001Cordeiro \& Howe, 2001), totalizando 0,8 hectares de amostragem em cada uma das áreas de estudo. Cada uma das trilhas foram marcadas com um número a cada 50 metros e o início da parcela correspondia ao número sorteado.

Em cada uma dessas parcelas foram contadas todas as plântulas, as jovens e os adultos de Astrocaryum aculeatissimum, obtendo-se posteriormente o número de indivíduos de cada estágio por hectare (Brewer \& Webb, 2001; Losos, 1995). Todos os indivíduos com até $50 \mathrm{~cm}$ de altura foram considerados plântulas (Losos, 1995; Vormisto, 2002), aqueles com sinais atuais ou passados de reprodução (inflorescências ou infrutescências novas ou velhas) foram considerados adultos e os intermediários, entre plântulas e adultos, os indivíduos jovens (Scariot, 1999).

A densidade de plântulas, jovens e adultos por hectare foram comparados entre as áreas de estudo pelo teste de Kruskal-Wallis. As médias das densidades de plântulas/hectare e de jovens/hectare foram relacionadas com as taxas de remoção, dispersão e predação de sementes em cada uma das trilhas, obtidas a partir do experimento de remoção de sementes, através da análise de Correlação de Spearman (rs). 
A probabilidade de $5 \%$ ou menos para rejeitar a hipótese nula foi considerada para todos os testes, que seguiram Zar (1999) e Sokal \& Rolf (1996) e foram executados no programa estatístico JMP (SAS, 2002).

\subsection{Resultados}

\subsubsection{Remoção de sementes}

A maior porcentagem de remoção de sementes ocorreu na Ilha Anchieta onde 110 sementes foram removidas $(84,61 \%)$, seguida da Ilha do Cardoso com 88 sementes removidas (55\%), da Juréia com 66 sementes (41,25\%), de Picinguaba com apenas 3 sementes removidas $(2,14 \%)$ e de Xixová Japuí, onde não houve remoção (Figura 18). As sementes enroscadas $(n=28)$ e as perdidas $(n=34)$ entraram nas análises de sementes removidas, mas não foram utilizadas nas demais análises.

$\mathrm{O}$ número de sementes removidas por estação experimental diferiu entre as áreas de estudo $(\square 2=84,4050 ; \mathrm{p}<0,0001 ; \mathrm{gl}=4, \mathrm{n}=150)$ (Tabela 5).

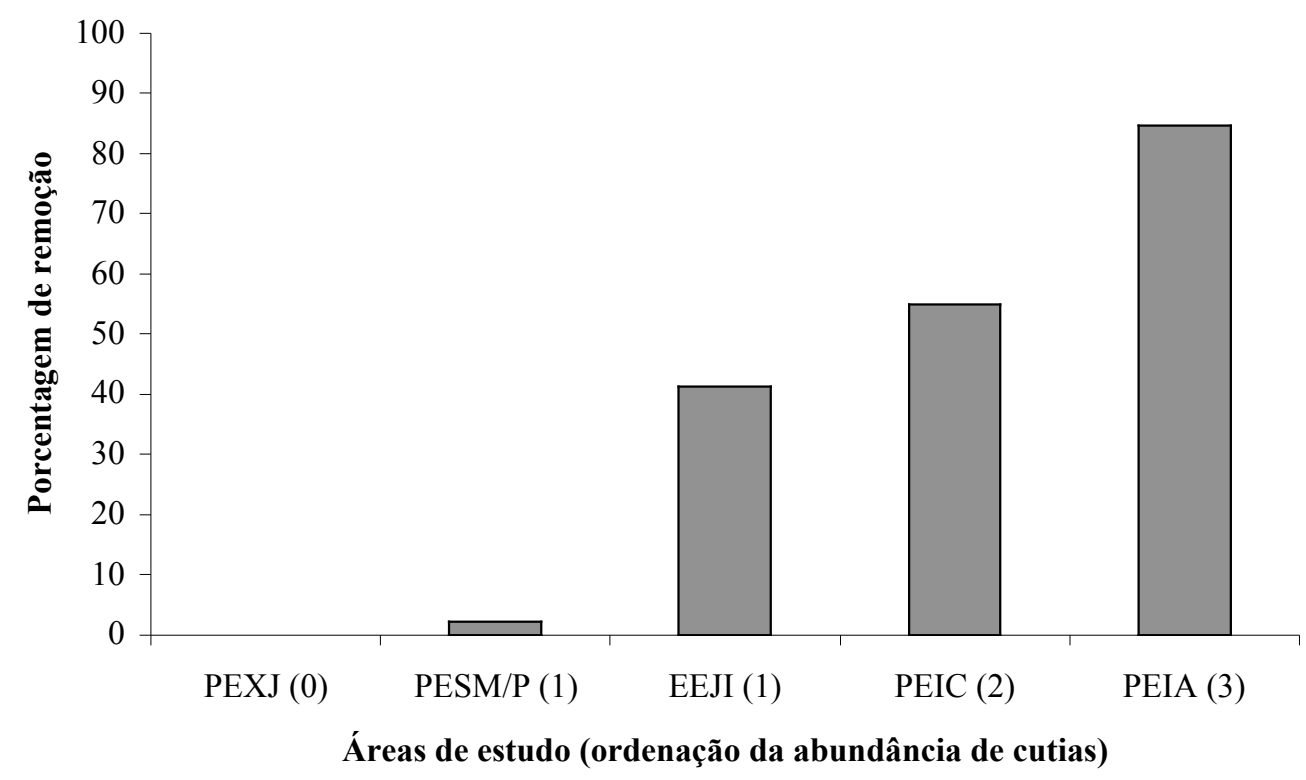

Figura 18 - Porcentagem de remoção das sementes de Astrocaryum aculeatissimum nas áreas de estudo, na Mata Atlântica do Estado de São Paulo, Brasil 
Na Ilha do Cardoso, na Juréia, em Picinguaba e em Xixová Japuí, a maior porcentagem das sementes (retirando-se as perdidas e enroscadas) foi encontrada intacta $(61,44 \%, 49,3 \%, 97,86 \%$ e $100 \%$, respectivamente) e na Ilha Anchieta a maior porcentagem foi encontrada enterrada (43,95\%) (Figura 19).

$\mathrm{Na}$ Ilha do Cardoso e na Ilha Anchieta, a cutia (Dasyprocta spp.) foi o maior responsável pela remoção das sementes. Na Juréia, o rato de espinho (Trynomis iheringi) foi o principal responsável e em Picinguaba, o esquilo (Sciurus aestuans), embora a porcentagem de remoção tenha sido extremamente baixa neste local $(2,14 \%)$ (Figura 20).

Houve diferença significativa na remoção das sementes pelos frugívoros na Ilha Anchieta $(\square 2=46,8802 ; p<0,0001 ;$ g.l. $=2)$ e na Ilha do Cardoso $(\square 2=19,5543 ; p<0,0001$; g.1.=2) mas não na Juréia $(\square 2=5,0615 ; \mathrm{p}=0,0796$; g.1.=2), nem em Picinguaba $(\square 2=4,0488 ; p=0,1321 ;$ g.l.=2). A remoção feita pela cutia apresentou diferença significativa entre as áreas de estudo $(\square 2=42,7417 ; \mathrm{p} \leq 0,001$ g.1.=3) assim como a remoção feita pelo rato de espinho $(\square 2=21,1716$; $<<0,0001$; g.1.=3) e pelo esquilo $(\square 2=14,0262 ; p=0,0029 ;$ g.1.=3) (Tabela 6).

A média do número de sementes removidas em cada área aumentou significativamente com o aumento da abundância de cutias (Correlação de Spearman $\mathrm{rs}=0,9747 ; \mathrm{p}=0,0048)$.

A proporção de sementes dispersas mostrou diferença significativa entre áreas $(\square 2=47,2598 ; \mathrm{p}<0,0001 ; \mathrm{g} .1 .=4)$ e a diferença entre as áreas foi também significativa para a proporção de sementes predadas $(\square 2=35,0246$; $p<0,0001$; g.1.=4) (Tabela 5). 


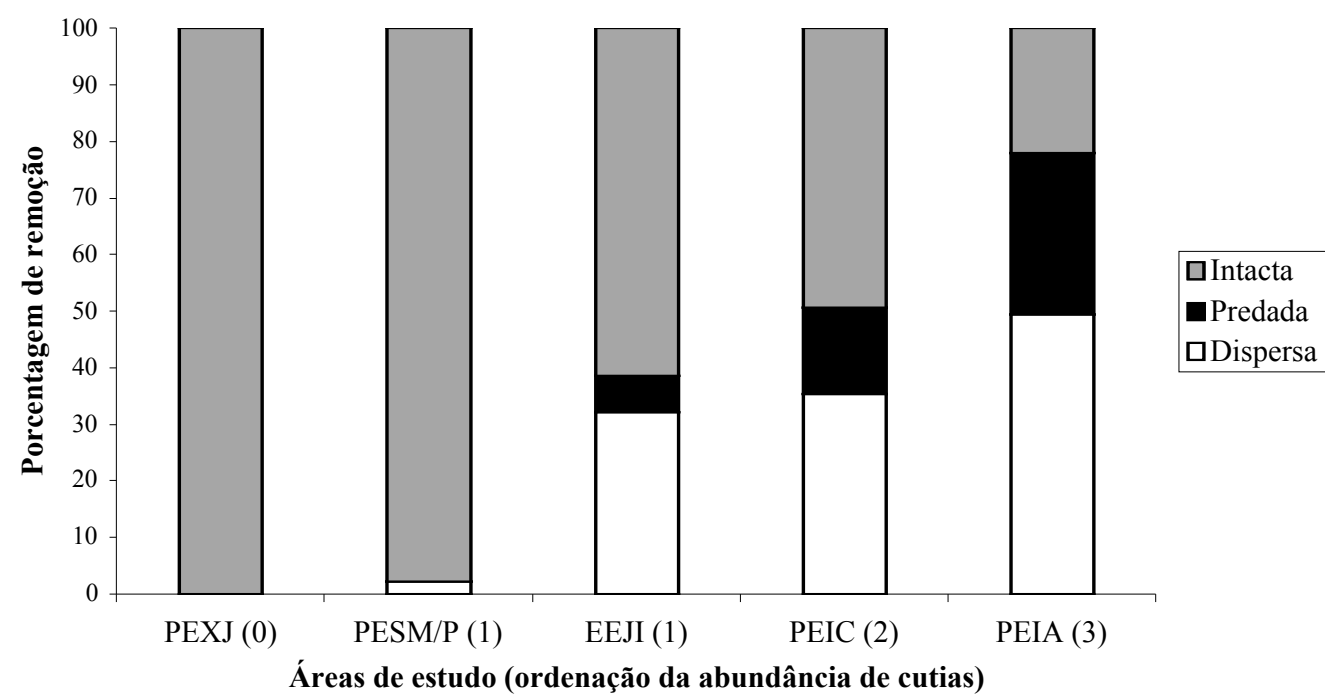

Figura 19 - Destino das sementes de Astrocaryum aculeatissimum nas áreas de estudo, na Mata Atlântica do Estado de São Paulo, Brasil.

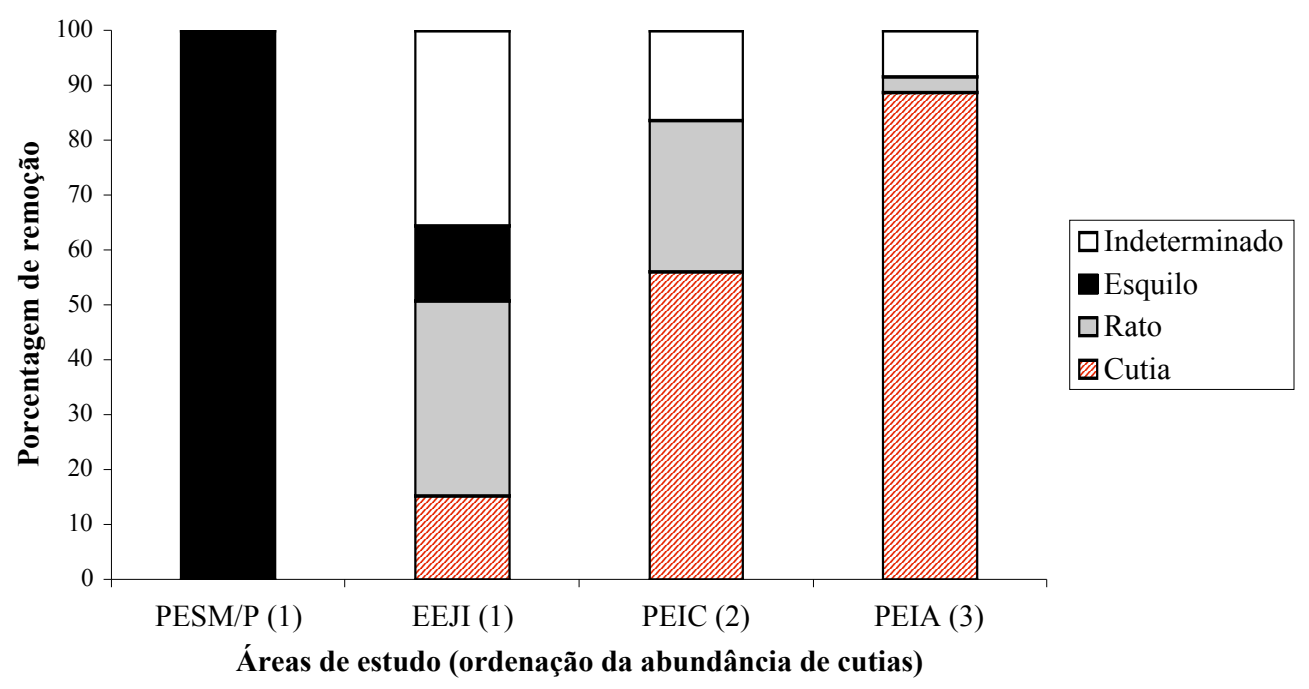

Figura 20 - Remoção das sementes pelas espécies de frugívoros nas áreas de estudo na Mata Atlântica do Estado de São Paulo, Brasil 
Houve diferença significativa entre a proporção de sementes dispersas e a proporção de sementes predadas na Ilha Anchieta, na Ilha do Cardoso e na Juréia $(\square 2=4,0662 ; p=0,0437 ; \square 2=5,7191 ; p=0,0168$ e $\square 2=17,246 ; p<0,0001 ; g . l=3$, respectivamente), com todas elas apresentando mais sementes dispersas do que predadas.

A média da proporção de dispersão de sementes não apresentou correlação com a abundância de cutias ( $r s=0,5643 ; p=0,3217$ ), mas a média da proporção de predação de sementes foi correlacionada positiva e significativamente com a abundância de cutias $(\mathrm{rs}=0,9211 ; \mathrm{p}=0,0263)$.

A distância máxima de dispersão das sementes em cada estação experimental não diferiu entre as áreas de estudo $(\mathrm{F}=1,6737 ; \mathrm{p}=0,1830 ; \mathrm{g} .1 .=3 ; \mathrm{n}=60)$ assim como não houve diferença na distância de todas as sementes dispersas entre as áreas de estudo ( $\square 2=0,7519 ; \mathrm{p}=0,8609 ; \mathrm{g} .1 .=3 ; \mathrm{n}=148$ ) (Tabela 7). As maiores distâncias de dispersão encontradas foram de 21 metros na Ilha Anchieta e de 19,23 metros na Ilha do Cardoso.

Tabela 5 Média e desvio padrão do número de sementes removidas, proporção de sementes predadas e dispersas de Astrocaryum aculeatissimum e tamanho da amostra $(\mathrm{N})$ nas áreas de estudo. Valores dos testes de Kruskal Wallis, de Mann-Whitney (comparando sementes predadas e dispersas) e das probabilidades (p)

\begin{tabular}{|c|c|c|c|c|c|c|c|}
\hline & $\begin{array}{c}\text { Xixová Japuí } \\
\text { (32) }\end{array}$ & $\begin{array}{l}\text { Picinguaba } \\
\text { (28) }\end{array}$ & Juréia (32) & $\begin{array}{c}\text { Ilha do } \\
\text { Cardoso (32) } \\
\end{array}$ & $\begin{array}{l}\text { Ilha Anchieta } \\
\text { (26) }\end{array}$ & Kruskal-Wallis & p \\
\hline Sementes removidas ${ }^{1}$ & * & $0,10 \pm 0,31$ & $2,06 \pm 2,01$ & $2,75 \pm 2,18$ & $4,23 \pm 1,42$ & 84,405 & $<0,0001$ \\
\hline Sementes dispersas $^{2}$ & * & $0,10 \pm 0,31$ & $0,58 \pm 0,45$ & $0,47 \pm 0,46$ & $0,49 \pm 0,41$ & 47,1598 & $<0,0001$ \\
\hline Sementes predadas ${ }^{3}$ & * & 0 & $0,097 \pm 0,22$ & $0,21 \pm 0,36$ & $0,31 \pm 0,36$ & 35,0246 & $<0,0001$ \\
\hline Mann-Whitney & & 3,1132 & 17,246 & 5,7191 & 4,0664 & & \\
\hline p & & 0,0777 & $<0,0001$ & 0,0168 & 0,0437 & & \\
\hline
\end{tabular}

1= Número de sementes removidas em cada estação experimental

2=Número de sementes dispersas/número de sementes removidas em cada estação experimental

3=Número de sementes predadas/número de sementes removidas em cada estação experimental

* não houve remoção 
Tabela 6 Média, desvio padrão e tamanho da amostra (N) de sementes de Astrocaryum aculeatissimum removidas por estação pelos frugívoros nas áreas de estudo. Valor dos testes de Kruskal-Wallis e da probabilidade (p)

\begin{tabular}{cccccccc}
\hline & $\begin{array}{c}\text { Xixová Japuí } \\
\text { (32) }\end{array}$ & $\begin{array}{c}\text { Picinguaba } \\
\mathbf{( 2 8 )}\end{array}$ & Juréia (32) & $\begin{array}{c}\text { Ilha do Cardosso } \\
\mathbf{( 3 2 )}\end{array}$ & $\begin{array}{c}\text { Ilha Anchieta } \\
\text { (26) }\end{array}$ & Kruskal-Wallis & P \\
\hline Cutia & $*$ & 0 & $0,31 \pm 0,64$ & $1,40 \pm 1,77$ & $2,5 \pm 1,86$ & 42,7417 & $<0,0001$ \\
Rato & $*$ & 0 & $0,62 \pm 0,79$ & $0,59 \pm 1,04$ & $0,07 \pm 0,27$ & 21,1716 & $<0,0001$ \\
Esquilo & $*$ & $0,07 \pm 0,26$ & $0,28 \pm 0,58$ & 0 & 0 & 14,0262 & 0,0029 \\
Kruskal-Wallis & & 4,0488 & 5,0615 & 19,5543 & 46,8802 & & \\
$\quad$ P & 0,1321 & 0,0796 & $\leq 0,0001$ & $<0,0001$ & &
\end{tabular}

Tabela 7 Média e desvio padrão da distância de dispersão das sementes e da distância máxima de dispersão das sementes de Astrocaryum aculeatissimum nas áreas de estudo. Tamanho da amostra de cada uma das variáveis $(\mathrm{N})$. Valores dos teste de Kruskal-Wallis e Análise de Variância e das respectivas probabilidades (p).

\begin{tabular}{lcccccccc}
\hline & Xixová-Japuí & Picinguaba & Ilha do Cardoso & Juréia & Ilha Anchieta & Teste & p \\
\hline \multicolumn{1}{c}{ Distância de dispersão } & $*$ & $3,7 \pm 1,30(3)$ & $3,83 \pm 3,87(51)$ & $3,20 \pm 2,20(49)$ & $4,64 \pm 4,61$ & $(45)$ & $\square 2=0,7519$ & 0,183 \\
Distância máxima de dispersão & $*$ & $3,7 \pm 1,30(3)$ & $6,71 \pm 5,03(18)$ & $4,29 \pm 2,78(21) 7,33 \pm 5,76(18)$ & $\mathrm{F}=1,6733$ & 0,8609 \\
\hline * não houve remoção & & & & & &
\end{tabular}

\subsubsection{Predação por vertebrados e invertebrados e recrutamento de plântulas}

Um total de 502 endocarpos foram encontrados nas 5 áreas de estudo sendo 265 encontrados intactos, 141 predados por vertebrados e 96 por invertebrados. Foram encontrados 269 endocarpos em Xixová Japuí, 98 na Ilha Anchieta, 71 na Ilha do Cardoso, 42 sementes na Juréia e 22 em Picinguaba (Figura 21). Nenhum dos endocarpos encontrados apresentou furos de emergência, a larva ou o besouro brocador dentro do endocarpo, comum para o gênero Astrocaryum (Terborgh et al., 1993) e também para a espécie (A. P. Fernandez, com. pessoal). A predação por invertebrados foi aqui identificada pela presença de pequenos furos de entrada de invertebrados (provavelmente formigas) e que era posteriormente comprovada com a abertura do endocarpo e confirmação da predação.

A proporção de endocarpos predados por vertebrados (número de endocarpos predados por vertebrados/número de endocapos encontrados) mostrou diferença significativa entre as áreas de estudo $(\square 2=19,9776$; $\mathrm{p}=0,0005$; g.l. $=4)$, assim como a 
proporção de endocarpos predados por invertebrados (número de endocarpos predados por invertebrados/número total de endocarpos encontrados) $(\square 2=32,2936 ; p<0,0001$; g.l.=4) e o número de endocarpos intactos (número de endocarpos intactos/número de endocapos encontrados) $(\square 2=19,9072 ; p=0,0005 ;$ g.1.=4) (Tabela 8).

Houve diferença significativa entre os tipos de predação (por vertebrados, invertebrados ou endocarpos intactos) na Ilha Anchieta $(\square 2=18,6915 ; \mathrm{p} \leq 0,000 ; \mathrm{g} .1 .=2)$ com uma maior taxa de predação por vertebrados; na Juréia $(\square 2=5,3507 ; p=0,00689$; g.l.=2), com uma maior taxa de endocarpos intactos e em Xixová Japuí $(\square 2=27,1892$; $\mathrm{p}<0,0001$ ), com uma maior taxa de predação por invertebrados (Tabela 8).

A média da proporção de endocarpos predados por vertebrados apresentou relação positiva e significativa com a abundância de cutias ( $r s=0,9747 ; p=0,048)$, mas a média da proporção de endocarpos predados por invertebrados e a média da proporção de endocarpos intactos não mostraram correlação significativa com a abundância de cutias ( $r s=-0,8208 ; p=0,0886$, para ambos).

Tabela 8 Média e desvio padrão da proporção de endocarpos de Astrocaryum aculeatissimum predados por vertebrados e invertebrados e de endocarpos intactos em cada uma das áreas de estudo. Tamanho da amostra $(\mathrm{N})$ em cada uma das áreas de estudo. Valores dos testes de Kruskal -Wallis e das probabilidades (p).

\begin{tabular}{|c|c|c|c|c|c|c|c|}
\hline & $\begin{array}{c}\text { Xixová } \\
\text { Japuí (32) }\end{array}$ & Picinguaba(28) & Juréia (32) & $\begin{array}{c}\text { Ilha do } \\
\text { Cardoso (32) } \\
\end{array}$ & $\begin{array}{c}\text { Ilha Anchieta } \\
\text { (26) }\end{array}$ & Kruskal-Wallis & $\mathbf{P}$ \\
\hline Predação por vertebrdos ${ }^{1}$ & $0,02 \pm 0,07$ & $0,12 \pm 0,30$ & $0,15 \pm 0,32$ & $0,23 \pm 0,33$ & $0,48 \pm 0,47$ & 19,9776 & 0,0005 \\
\hline Predação por invertebrados ${ }^{2}$ & $0,23 \pm 0,31$ & $0,03 \pm 0,11$ & $0,05 \pm 0,23$ & $0,05+0,18$ & $0,01 \pm 0,06$ & 32,2936 & $<0,0001$ \\
\hline Endocarpos intactos ${ }^{3}$ & $0,49 \pm 0,39$ & $0,19 \pm 0,38$ & $0,22 \pm 0,38$ & $0,21 \pm 0,33$ & $0,07 \pm 0,22$ & 19,9072 & 0,0005 \\
\hline Kruskal-Wallis & 27,1892 & 3,5834 & 5,3507 & 5,9901 & 18,6915 & & \\
\hline $\mathbf{P}$ & $<0,0001$ & 0,1667 & 0,00689 & 0,5 & $<0,0001$ & & \\
\hline
\end{tabular}

1=Número de endocarpos predadas por vertebrados/número de endocarpos encontrados em cada Astrocaryum aculeatissimum 2=Número de endocarpos predados por invertebrados/número de endocarpos encontrados em cada Astrocaryum aculeatissimum 3=Número de endocarpos intactos/número de endocarpos encontrados em cada indivíduo de Astrocaryum aculeatissimum

As proporções de plântulas encontradas de 0 a 2 metros e de 2 a 4 metros da planta-mãe e a proporção de indivíduos jovens de 0 a 2 metros da planta-mãe, não mostraram diferença significativa entre as áreas de estudo $(\square 2=7,3924 ; \mathrm{p}=0,1165 ;$ g.l. $=4$; $\square 2=5,1829 ;$ p=0,2690; g.l.=4; $\square 2=2,6486 ; p=0,2690 ;$ g.l.=4.). Entretanto, a proporção de 
jovens de 2 a 4 metros da planta-mãe mostrou diferença significativa entre as áreas de estudo $(\square 2=14,1573 ; \mathrm{p}=0,0068$; g.l.=4), com Xixová Japuí apresentando a maior proporção (Tabela 9).

Houve diferença significativa entre a proporção de plântulas encontradas nas duas distâncias em Picinguaba $(\square 2=5,3809 ; \mathrm{p}=0,0204)$, com mais plântulas encontradas de 0 a 2 metros da planta-mãe. Houve também diferença significativa na proporção de indivíduos jovens encontrados nas duas distâncias na Juréia $(\square 2=5, p=0,0253)$ e em Picinguaba $(\square 2=5,3809 ; \mathrm{p}=0,0204)$, com mais indivíduos jovens encontrados de 0 a 2 metros de raio da planta-mãe (Tabela 9).

A correlação entre a proporção de indivíduos encontrados ao redor da planta-mãe e a abundância de cutias, não foi significativa para as plântulas e jovens encontrados de 0 a 2 metros das plantas-mãe ( $r s=-0,3591 ; \mathrm{p}=0,5528$; $\mathrm{rs}=0,1316$; $\mathrm{p}=0,8330$, respectivamente) e de 2 a 4 metros das plantas-mãe ( $r s=-0,0789 ; p=0,8996 ; r s=0,1539$; $\mathrm{p}=0,8048$, respectivamente).

Tabela 9 Média, desvio padrão das proporções de plântulas e jovens em cada uma das classes de distâncias nas áreas de estudo e tamanho da amostra (N).Valores dos testes de Kruskal-Wallis e de MannWhitney (comparando as proporções de plântulas e jovens entre cada uma das classes de distância em cada uma das áreas de estudo) e das probabilidades (p)

\begin{tabular}{cccccccc}
\hline & $\begin{array}{c}\text { Xixová Japuí } \\
\mathbf{( 3 2 )}\end{array}$ & $\begin{array}{c}\text { Picinguaba } \\
\mathbf{( 2 8 )}\end{array}$ & Juréia (32) & $\begin{array}{c}\text { Ilha do } \\
\text { Cardoso (32) }\end{array}$ & $\begin{array}{c}\text { Ilha Anchieta } \\
(\mathbf{2 6})\end{array}$ & Kruskal-Wallis & p \\
\hline Taxa de plântulas (0 a 2m) & $0,04 \pm 0,19$ & $0,14 \pm 0,32$ & $0,04 \pm 0,18$ & $0,14 \pm 0,34$ & 0 & 7,3924 & 0,1165 \\
Taxa de plântulas (2 a 4 m) & $0,03 \pm 0,17$ & 0 & $0,09 \pm 0,39$ & $0,18 \pm 0,64$ & 0 & 5,1829 & 0,269 \\
Mann-Whitney & 0,3659 & 5,3809 & 0 & 0,7685 & & & \\
P & 0,5452 & 0,0204 & 1 & 0,3807 & & 2,6486 & 0,6182 \\
Taxa de jovens (0 a 2 m) & $0,20 \pm 0,39$ & $0,14 \pm 0,32$ & $0,20 \pm 0,39$ & $0,14 \pm 0,34$ & $0,30 \pm 0,47$ & $0,14,1573$ & 0,0068 \\
Taxa de jovens (2 a 4 m) & $0,20 \pm 0,37$ & 0 & $0,03 \pm 0,17$ & $0,16 \pm 0,34$ & $0,11 \pm 0,32$ & & \\
Mann-Whitney & 0,0298 & 5,3809 & 5 & 0,601 & 2,8271 & & \\
P & 0,8629 & 0,0204 & 0,0253 & 0,4382 & 0,0927 & & \\
\hline
\end{tabular}

1= Número de plântulas encontradas de 0 a 2 metros da planta mãe/número de plântulas e jovens encontrados de 0 a 4 metros da planta mãe

2= Número de plântulas encontradas de 2 a 4 metros da planta mãe/número de plântulas e jovens encontrados de 0 a 4 metros da planta mãe

3= Número de jovens encontrados de 0 a 2 metros da planta mãe/número de plântulas e jovens encontrados de 0 a 4 metros da planta mãe

4= Número de jovens encontrados de 2 a 4 metros da planta mãe/número de plântulas e jovens encontrados de 0 a 4 metros da planta mãe 


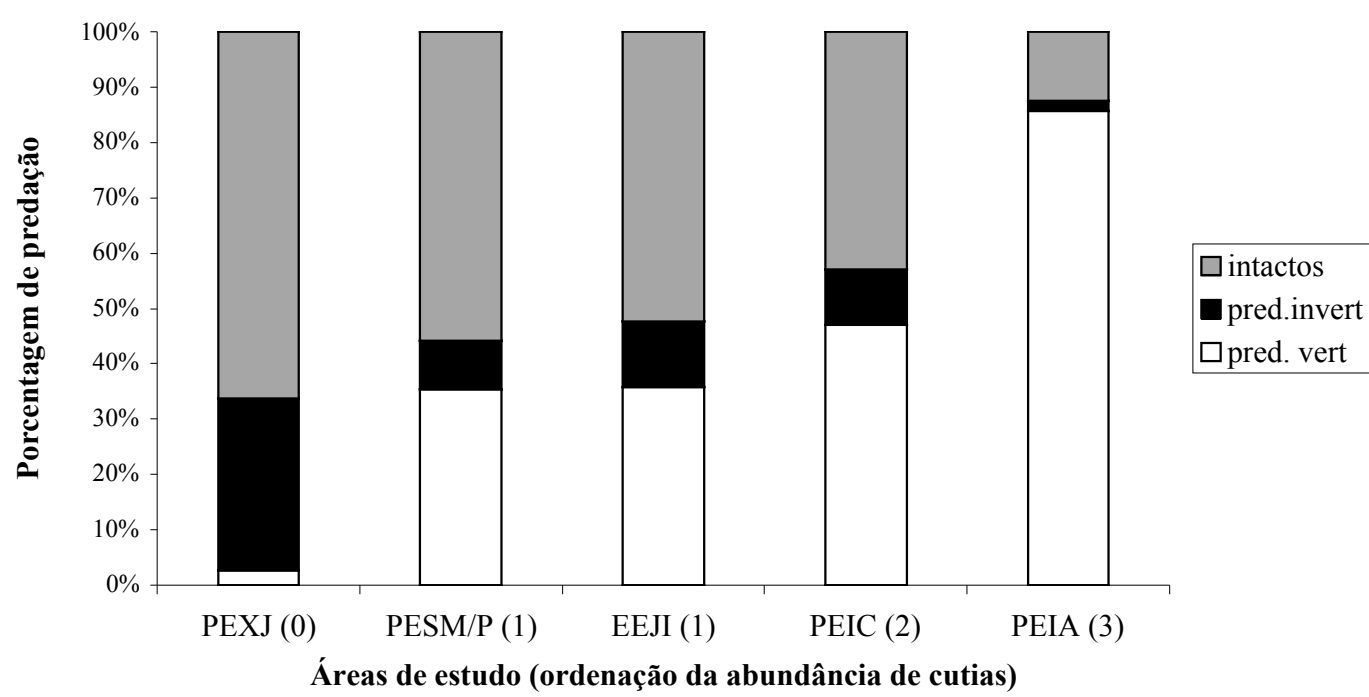

Figura 21 - Porcentagem de endocarpos de Astrocaryum aculeatissimum predados por vertebrados, invertebrados e intactos nas áreas de estudo de Mata Atlântica do Estado de São Paulo, Brasil

\subsubsection{Densidade de plântulas, jovens e adultos}

Houve diferença significativa na densidade de plântulas, jovens e adultos por parcela entre as áreas de estudo $(\square 2=43,2008$, g.l $=4$, p $<0,0001 ; \square 2=31,7088$, g.l. $=4$, $\mathrm{p} \leq 0,001 ; \square 2=22,825, \mathrm{~g} .1 .=4, \mathrm{p}=0,0001)($ Tabela 10$)$.

A maior densidade de plântulas, jovens e adultos de Astrocaryum aculeatissimum foi encontrado na Ilha do Cardoso. Xixová Japuí apresentou a menor densidade de plântulas, a Juréia apresentou a menor densidade de jovens e Picinguaba a menor densidade de adultos (Figura 22).

Tabela 10 Densidade de plântulas, jovens e adultos de Astrocaryum aculeatissimum por hectare nas áreas de estudo. Valores dos testes de Kruskal-Wallis e das probabilidades (p)

\begin{tabular}{cccccccc}
\hline & Xixová Japuí & Picinguaba & Juréia & Cardoso & Ilha Anchieta & Kruskal-Wallis & P \\
\hline Plântulas/hectare & 12,5 & 43,75 & 13,75 & 161,25 & 21,25 & 56,0807 & $<0,0001$ \\
Jovens/hectare & 101,25 & 77,5 & 27,5 & 228,75 & 46,25 & 42,2504 & $<0,0001$ \\
Adultos/hectare & 38,75 & 2,5 & 16,25 & 48,75 & 11,25 & 22,8250 & $<0,0001$ \\
\hline
\end{tabular}


Não houve relação significativa entre a densidade média de plântulas e jovens por hectare nas áreas e as taxas de remoção ( $\mathrm{rs}=0,3154, \mathrm{p}=0,1756$; $\mathrm{rs}=0,0690, \mathrm{p}=0,7724$, respectivamente), dispersão ( $\mathrm{rs}=0,2533, \mathrm{p}=0,2813 ; \mathrm{rs}=0,0099, \mathrm{p}=0,9669$, respectivamente) e predação de sementes de Astrocaryum aculeatissimum ( $\mathrm{rs}=0,1666$, $\mathrm{p}=0,4827 ; \mathrm{rs}=0,0038, \mathrm{p}=0,9872$, respectivamente).

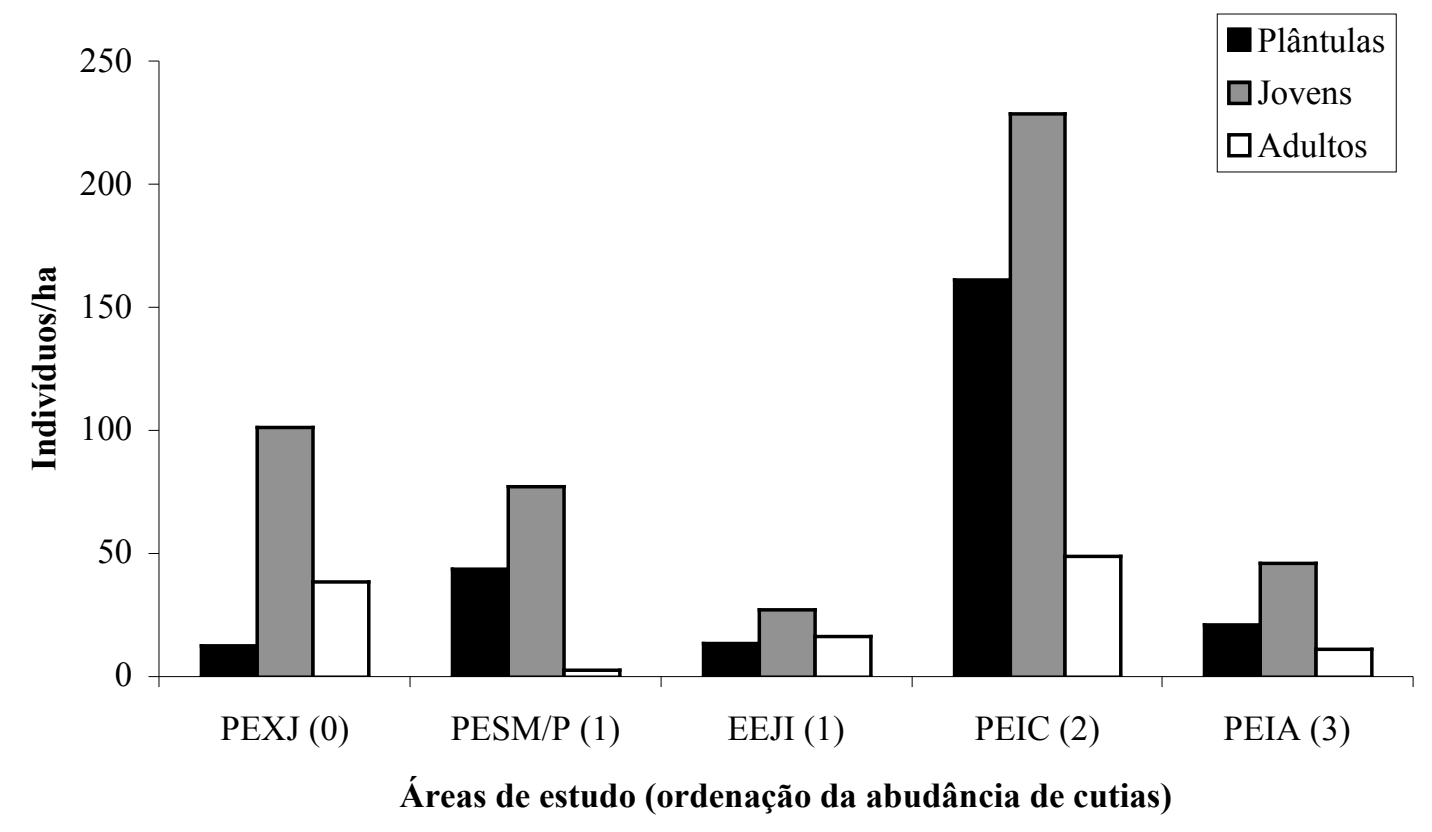

Figura 22 - Densidade de plântulas, jovens e adultos de Astrocaryum aculeatissimum por hectare nas áreas de estudo, na Mata Atlântica do Estado de São Paulo, Brasil

\subsection{Discussão}

\subsubsection{Remoção de sementes}

A remoção de sementes de Astrocaryum aculeatissimum esteve associada à abundância de cutias, onde as áreas mais defaunadas apresentaram menor remoção de sementes. A remoção das sementes embaixo das plantas-mãe, além de promover a dispersão, diminui a predação neste local de maior atividade dos predadores e patógenos, aumentando as chances das sementes germinarem (Connell, 1971; Janzen, 
1970; Schuup, 1988 a,b; Terborgh et al., 1993; Vander Wall, 2002). Além da área de estudo com maior abundânicia de cutias (Ilha Anchieta) apresentar a maior porcentagem de sementes removidas, apresentou também a maior porcentagem de sementes estocadas.

A maior abundância de agentes dispersores é responsável pelas maiores taxas de remoção de sementes (Bleher \& Bohning-Gaese, 2001; Guariguata et al., 2000), como também promove um maior recrutamento longe da planta-mãe (Cordeiro \& Howe, 2003). Roldán \& Simonetti (2001) encontraram uma maior sobrevivência de sementes de Astrocaryum murumuru (Arecaceae) embaixo das plantas-mãe em áreas intensamente caçadas quando comparadas com área ocasionalmente caçadas.

As áreas mais defaunadas que apresentaram remoção (Picinguaba e Juréia) tiveram uma maior porcentagem de sementes removidas por ratos de espinho e esquilos, devido a baixa abundância de cutias, mesmo resultado encontrado por Sanchez-Cordero \& Martínez Gallardo (1998). Na EEJI a maior porcentagem de remoção foi feita pelos ratos de espinho, já que a área, além de possui uma baixa abundância de cutias (Pardini \& Develey, 2004), apresenta uma alta densidade de ratos de espinho Trynomis iheringi (Bergallo \& Bossi, 2004). O mesmo ocorrreu em Picinguaba, onde a remoção foi feita exclusivamente por esquilos, devido às baixas densidades de cutias na área (R.M. Marques, dados não publicados).

$\mathrm{Na}$ ausência ou diminuição de competidores, a amplitude do nicho daquelas espécies que exploram o mesmo recurso tende a aumentar, favorecendo a espécie que permanece, o que chamamos de density compensation (Mac Arthur et al., 1972). Devido a ausência de competidores, a espécie pode ter sua densidade aumentada e isso pode ocorrer não pela troca de nicho, pois as espécies podem continuar se alimentando no mesmo local e da mesma maneira, mas podem simplesmente encontrar mais alimento (Mac Arthur, et al., 1972). Neste estudo, as áreas onde as cutias estão ausentes ou em baixas abundâncias, a remoção de sementes por esquilos e ratos de espinho foram maiores devido a menor competição com as cutias e à maior disponibilidade das sementes que não foram removidas por elas. 
Apesar das cutias estarem presentes em Picinguaba, sua baixa abundância reflete um decréscimo de quase 40 vezes na remoção das sementes quando comparada com a Ilha Anchieta, a área com maior abundância de cutias. A defaunação como decorrência da caça está intimamente associada ao tamanho da área e a proximidade de centros urbanos (Peres, 2000). As áreas que apresentaram, respectivamente, a menor porcentagem de remoção e a ausência de remoção de sementes, Picinguaba e Xixová Japuí, possuem também a maior proximidade com grandes centros urbanos.

Essas duas áreas continentais sofrem mais com a pressão do entorno, como o avanço das cidades e crescimento populacional e estão, dessa forma, mais vulneráveis ao impacto humano do que as áreas insulares. Xixová Japuí além de possuir uma área relativamente pequena (901 hectares), sofre com o impacto humano e proximidade dos centros urbanos e não apresentou remoção de sementes de A. aculeatissimum. Picinguaba encontra-se muito próxima a cidade de Ubatuba e é cortada pela BR-101, facilitando o acesso de pessoas (Secretaria do Estado do Meio Ambiente, 1998 a).

As duas ilhas (Ilha do Cardoso e Ilha Anchieta) foram as que apresentaram as maiores porcentagens de remoção de sementes. Isso pode ter ocorrido pelo fato dessas áreas serem mais protegidas do acesso humano do que as áreas continentais (devido a distância do continente e dificuldade de acesso) e especificamente no caso da Ilha Anchieta, a abundância de cutias é extremamente alta pela ausência de predadores de topo de cadeia, que não podem colonizar a área (Galetti et al., in prep.).

Os resultados confirmaram que a diminuição das cutias alteram principalmente as taxas de remoção de sementes (Guariguata et al., 2002; Bleher \& Bohning-Gaese, 2001) e estes roedores estocadores executam um papel fundamental na sobrevivência das sementes, uma vez que as retira do local de alta mortalidade embaixo da planta-mãe (Connell, 1971; Forget, 1992b; Hallwachs, 1986; Hulme, 1998; Jansen et al., 2002; Janzen, 1970, Sanchez-Cordeiro \& Martínez-Gallardo, 1998; Schupp, 1988a; Schupp, 1988b; Silva \& Tabarelli, 2001; Terborgh et al., 1993; Vander Wall, 2002).

As menores porcentagens de dispersão das sementes removidas foram encontradas nas áreas mais defaunadas (Picinguaba e Juréia) e a maior porcentagem foi encontrada na área com maior abundância de cutias (Ilha Anchieta), como o encontrado 
por Bleher \& Bohning-Gaese (2001) onde a dispersão das sementes foi maior em uma área menos defaunada. Wright et al. (2000) também encontraram que a densidade de sementes dispersas diminuiu com a intensidade de caça para as espécies Astrocaryum stendleyanum (Arecaceae) e Attalea butyraceae (Arecaceae) e Guariguata et al., (2000) encontraram que um maior número de sementes de Lecythis ampla (Lecythidaceae) e Carapa nicaraguensis (Meliaceae) foram dispersas nas áreas com maior abundância de dispersores de sementes.

A predação de sementes também foi diferente entre as áreas de estudo, com baixa predação nas áreas mais defaunadas (Picinguaba e Juréia) e maior predação na área com maior abundância de cutias (Ilha Anchieta). Embora a predação tende a ser maior nas áreas mais defaunadas e fragmentadas devido a maior abundância de pequenos roedores (Fleury, 2004; Guariguata et al., 2002; Sanchez-Cordeiro \& Martinéz-Gallardo, 1998), esse padrão não foi encontrado para este estudo. A dispersão de sementes foi maior do que a predação em todas as áreas dentro dos cinco dias de exposição das sementes e os ratos de espinho e os esquilos atuaram mais como dispersores do que predadores das sementes removidas (ver cap. 3).

Roldán \& Simonetti (2001) observaram que as áreas intensamente caçadas mostraram menores taxas de predação de sementes da espécie Astrocaryum murumuru e Wright et al (2000) observaram que as taxas de predação declinaram de 90\% em áreas com intensidade de caça baixa para 5 a 50\% em áreas com caça intensa.

A predação e a dispersão das sementes por roedores estocadores depende de vários fatores que referem-se tanto às características dos indivíduos, quanto do fruto e/ou semente em questão (Jansen et al., 2002; Smythe, 1978; Silvius \& Fragoso, 2002) e também do ambiente onde encontra-se o recurso (Vander Wall, 1990).

Embora as diferenças na distância de dispersão e na distância máxima de dispersão de sementes entre as áreas de estudo não tenham sido significativas, assim como as correlações entre essas variáveis e a abundância de cutias, essas distâncias foram maiores na área com maior abundância de cutias (Ilha Anchieta) e decresceram até as áreas mais defaunadas (Picinguaba e Juréia). 
Bleher \& Bohning-Gaese (2001) observaram que a distância foi maior em áreas com maior diversidade e densidade de frugívoros, e Wright \& Duber (2001) amostraram uma maior distância de dispersão em áreas protegidas da caça.

O número de sementes removidas foi maior nas áreas menos defaunadas, mostrando que os ratos de espinho e os esquilos, apesar de não diminuírem significativamente as distâncias de dispersão (ver cap. 3) não apresentam a mesma eficiência de remoção de sementes como o fazem as cutias.

\subsubsection{Predação por vertebrados e invertebrados e recrutamento de plântulas}

A baixa densidade de frugívoros em Xixová Japuí explica a grande diferença encontrada no número de endocarpos predados por vertebrados embaixo das plantasmãe neste local, quando comparado com a proporção encontrada na Ilha Anchieta, a área com maior abundância de cutias. O maior número de endocarpos intactos e predados por invertebrados encontrados em Xixová Japuí relaciona-se com a pouca remoção dos mesmos, já que a área é bastante defaunada e as cutias já estão provavelmente extintas localmente (ver áreas de estudo). O mesmo resultado foi encontrado por Wright et al. (2000) para Attalea butyraceae e Astrocaryum standleyanum, onde grandes quantidades de endocarpos intactos permaneceram embaixo da planta mãe em áreas com baixa abundância de mamíferos, os quais apresentam menos chances de sobrevivência devido à mortalidade por patógenos e predadores (Connell, 1971; Janzen, 1970).

O número de endocarpos predados por invertebrados foi menor na Ilha Anchieta e também na Ilha do Cardoso, como decorrência da menor disponibilidade dos mesmos embaixo da planta mãe, já que as altas abundâncias de cutias nessas áreas explicam as maiores porcentagens de remoção de sementes.

Ao contrário do esperado, não houve predação por besouros brocadores na espécie Astrocaryum aculeatissimum em nenhuma das áreas de estudo (ver cap. 3) fato comum para a espécie em fragmentos florestais do Rio de Janeiro (A.P.Fernandez, dados não publicados) e para outras espécies do gênero (Terborgh et al, 1993 para Astrocaryum macrocalyx; Cintra, 1997 para Astrocaryum murumuru e Brewer, 2001 para Astrocaryum mexicanum). 
Wright et al. (2000) encontraram maiores taxas de sementes predadas por besouros em áreas com caça intensa para a espécie Attalea butyraceae, mas não para a espécie Astrocaryum stendleyanum. Wright \& Duber (2001) encontraram que os níveis de infestação por besouros brocadores nas sementes de Attalea butyraceae, embora não significativos, tenderam a diferir com o nível de proteção, sendo maiores em áreas intensamente caçadas e menores em áreas mais protegidas da caça, com altos níveis de infestação na áreas pequenas (2 ha).

Um maior número de plântulas de 0 a 2 metros do que de 2 a 4 metros da plantamãe foi encontrado em Picinguaba e um maior número de indivíduos jovens de 0 a 2 metros do que de 2 a 4 metros da planta-mãe foi encontrado em Picinguaba e na Juréia. As maiores proporções de plântulas e jovens embaixo das plantas-mãe podem ter ocorrido como conseqüência das baixas taxas de remoção das sementes que foram encontrados nestas áreas.

Entretanto, Xixová Japuí, a área mais defaunada, apresentou uma maior proporção de jovens de 2 a 4 metros de distância da planta-mãe do que as demais áreas, diferente do esperado, já que estes indivíduos seriam provavelmente provenientes de sementes dispersas. Já a proporção de plântulas foi menor nesta área do que nas demais áreas nas duas classes de distância da planta-mãe.

Wright \& Duber (2001) encontraram que a densidade de plântulas de Attalea butyraceae longe da planta mãe não foi afetada pelo nível de caça, mas a densidade de plântulas foi maior próximo às plantas-mãe nas áreas com caça intensa, comprometendo a diversidade de plântulas nestes locais de dominância monoespecífica.

\subsubsection{Densidade de plântulas, jovens e adultos}

As densidades de plântulas e jovens de Astrocaryum aculeatissimum por parcela não estiveram relacionadas com as proporções de sementes removidas, dispersas e predadas. O mesmo foi observado para a espécie Astrocaryum standleyanum, onde a densidade de plântulas não esteve relacionada com as proporções de sementes dispersas e de sementes predadas por roedores (Wright et al., 2000). A densidade de plântulas de 
Attalea butyraceae foi, entretanto, negativamente relacionada com a proporção de sementes dispersas e predadas (Wright et al., 2000).

A remoção e a dispersão das sementes é o primeiro passo para o recrutamento de plântulas. Entretanto, a germinação de sementes e a sobrevivência das plântulas irão depender de vários outros fatores como a predação pós dispersão, a chegada das sementes em ambientes ideais para o estabelecimento da plântula, e a herbivoria (Brewer, 2001; Cintra, 1997; Cintra \& Horna, 1997). De acordo com o modelo de Janzen-Connel $(1970,1971)$, apenas poucas sementes irão sobreviver à alta mortalidade nas proximidades da planta-mãe e uma vez que estas sementes sobrevivam, as várias propriedades abióticas irão definir se elas terão um bom estabelecimento como plântulas (Terborgh et al., 2002).

$\mathrm{O}$ número de plântulas/hectare foi menor na área mais defaunada, provavelmente devido às poucas chances de dispersão das sementes, já que nenhuma semente exposta nos experimentos foi removida debaixo da planta-mãe. A Ilha Anchieta, apesar de possuir a maior abundância de cutias, não apresentou a maior densidade de plântulas, já que a predação de sementes foi alta. Um outro motivo para o baixo recrutamento de plântulas encontrado na Ilha Anchieta é a alta taxa de herbivoria de plântulas de $A$. aculeatissimum por capivaras (Paes, 1997), que apresentam-se em altas densidades na área (R.S. Bovendorp, dados não publicados).

Wright \& Duber (2001) observaram um aumento no número absoluto de plântulas de Attalea butyraceae com o aumento da distância da planta-mãe em áreas protegidas da caça, mas Wright et al. (2000), entretanto, encontraram um aumento na densidade de plântulas de Astrocaryum standleyanum e Attalea butyraceae de 300 a $500 \%$ em áreas intensamente caçadas. Estes resultados mostram que, além da dispersão das sementes, a predação e a herbivoria são extremamente importantes para o recrutamento e a densidade de plântulas, assim como as caractesrísticas abióticas do local de chegada das sementes.

Assim, alguns estudos, apesar de concluírem que a defaunação afetou negativamente a predação de sementes e o pisoteio das plântulas, mostraram que não 
houve efeito na diversidade de plântulas (Asquith et al., 1997; Roldán \& Simonetti, 2001; Wright et al., 2000).

\subsection{Conclusões}

O sucesso de dispersão de uma espécie vegetal zoocórica apresenta como fator primordial a densidade e a diversidade de frugívoros. Como Astrocaryum aculeatissimum não é dispersa por uma grande quantidade de frugívoros, mudanças sutis na composição faunística do local podem ter efeitos cruciais na população a longo prazo.

As cutias estão entre os animais preferidos pelos caçadores e como é o dispersor mais efetivo das sementes de $A$. aculeatissimum, a sua ausência ou baixa abundância causa uma diminuição na remoção das sementes, um aumento na predação por invertebrados e uma redução no recrutamento de plântulas.

Apesar do estudo ser restrito a apenas uma espécie vegetal e sua dependência principalmente de uma espécie de frugívoro, o mesmo efeito da defaunação encontrado para $A$. aculeatissimum certamente é encontrado para outras espécies vegetais que dependem de poucos dispersores de sementes. 


\section{CONCLUSÕES GERAIS}

As características do fruto de Astrocaryum aculeatissimum, com pouca polpa e semente grande e dura, restringem o número de animais que podem dispersar ou predar as suas sementes. Os ratos de espinho (Trynomis iheringi) e esquilos (Sciurus aestuans) foram os principais responsáveis pela remoção das sementes em áreas defaunadas, mas não foram tão efetivos na dispersão das sementes quanto as cutias (Dasyprocta spp.). Estas removeram um maior número de sementes, estocaram a maioria delas e as levaram a maiores distâncias das plantas-mãe, aumentando as chances das sementes germinarem e se estabelecerem como plântulas. A remoção das sementes, além de permitir que as sementes escapem da alta predação embaixo da planta-mãe, permite a colonização de novos ambientes, aumentando as chances de atingirem locais mais propícios à germinação.

As áreas que sofreram redução ou extinções locais das populações de cutias apresentam problemas de dispersão de $A$. aculeatissimum, como diminuição ou ausência de remoção, aumento da predação por invertebrados e baixo recrutamento de plântulas. Apesar do estudo ser restrito à A. aculeatissimum, o mesmo efeito pode estar ocorrendo com outras espécies, já que, pelo menos 10 das 31 espécies de palmeiras que ocorrem na Mata Atlântica, por possuírem frutos grandes, são dispersos exclusivamente por roedores estocadores. Dessa forma, a defaunação que a maioria das áreas vem sofrendo

pode contribuir, a longo prazo, para a redução de 1/3 das espécies de palmeiras da Mata Atlântica.

A conservação da biodiversidade não se restringe apenas em criar novas Unidades de Conservação, mas, sim, proteger de fato as espécies animais, vegetais e, principalmente, as interações que acabam escapando dos nossos olhos. 


\section{REFERÊNCIAS BIBLIOGRÁFICAS}

ALVAREZ-SÁNCHEZ. J.; GUEVARA, S. Litter interception on Astrocaryum mexicanum (Palmae) in a tropical rain forest. Biotropica, v. 31, n.1, p. 89-92, 1999.

ALVES, M.R.P.; DEMATTÊ, M.E.S. Palmeiras - Características botânicas e evolução. Campinas: Fundação Gargill, 1987. 129p.

ARAÚJO, L.G. Diversidade de uso de recursos vegetais em duas comunidades caiçaras da estação ecológica Juréia Itatins, Litoral sul de São Paulo. Rio Claro. 2000. 87p. Trabalho (Conclusão de Curso) - Instituto de Biociências, Universidade Estadual Paulista.

ASQUITH, N.M. Misdirections in conservation biology. Conservation Biology, v. 15, n.2, p. 345-352, 2001.

ASQUITH, N.M.; TERBORGH, J.; ARNOLD, A.E..; RIVEROS, M. The fruits the agouti ate: Hymenaea courbaril seed fate when its disperser is absent. Journal of Tropical Ecology, v. 15, p.229-236, 1999.

ASQUITH, N.M.; WRIGHT, S.J.; CLAUSS, M.J. Does mammal community composition control recruitment in neotropical forests? Evidence from Panama. Ecology, v. 78, n.3, p. 941-946. 1997.

BASTOS, R.P. Biologia reprodutiva de Hyla elegans (ANURA, Hylidae) na região de Ubatuba, Estado de São Paulo. Rio Claro. 1993, 93p. Dissertação (Mestrado) - Instituto de Biociências, Universidade Estadual Paulista.

BASTOS, R.P.; HADDAD, C.F.B. Vocalizações e interações acústicas de Hyla elegans (Anura, Hylidae) durante a atividade reprodutiva. Naturalia 20:165-176. 1995.

BASTOS, R.P.; HADDAD, C.F.B. Breeding activity of the neotropical treefrog Hyla elegans (Anura, Hylidae). Journal of Herpetology 30(3): 355-360. 1996.

BECK, H.; TERBORGH, J. Groves versus isolates: how spatial aggregation of Astrocaryum murumuru palm affects seed removal. Journal of Tropical Ecology, v. 28, p.275-288, 2002.

BENITEZ-MALVIDO, J. Impact of forest fragmentation on seedling abundance in a tropical rain forest. Conservation Biology, v.12, n.2, p. 380-389, 1998. 
BERGALLO, H.G; BOSSI, D.E.P. Os roedores e os marsupiais da Juréia: ecologia e parasitismo na comunidade de pequenos mamíferos terrestres. In: O.A.V. MARQUES \& W. DULEBA (Ed.).Estação Ecológica Juréia-Itatins. Ambiente físico, flora e fauna. Ribeirão Preto: Ed. Holos. 2004. cap.24, p. 296-303.

BLEHER, B.; BOHNING - GAESE, K. Consequences of frugivores diversity for seed dispersal, seedling stablishment and spatial pattern of seedlings and trees. Oecologia, v. 129, p.385-394, 2001.

BODMER, R.E. Strategies of seed dispersal and seed predation in amazonian ungulates. Biotropica, v. 23, p.255-261, 1991.

BODMER, R.E., EISENBERG; J.F., REDFORD, K.H. Hunting and the likelihood of extinction of Amazonian mammals. Conservation Biology, v.11, p. 460-466, 1997.

BREWER, S.W. Predation and dispersal of large and small seeds of a tropical palm. Oikos, v.92, p.245-255, 2001.

BROWN JR., K.S.; BROWN, G.G. 1992. Habitat alteration and species loss in Brazilian forests. In: T.C. WHITMORE, T.C., SAYER, J.A. (Ed.).Tropical deforestation and species extinction. London: Chapman and Hall Books, 1992. p. 119-142.

BURHAM, K.P.; ANDERSON, D.R.; LAAKE, J.L. Estimation of density from line transect sampling of biological population. Wildlife Monographs., v. 72, p.1-202, 1980.

CARILlO, E.; WONG, G.; CUARÓN, A.D. Monitoring mammal populations in Costo Rican protected areas under different hunting restrictions. Conservation Biology, v.14, n.6, p.1580-1591, 2000.

CASTRO, S.L.R. Ecologia populacional do Tiê Sangue, Ramphocelus bresilius (Aves: Emberizidae: Thraupidae) no PESM/P, Ubatuba, SP. Rio Claro, 1997. 105 p. Dissertação (Mestrado) - Instituto de Biociências, Universidade Estadual Paulista.

CHAPMAN, C.A., CHAPMAN, L.J. Survival without dispersers: seedling recruitment under parents. Conservation Biology, v.9, n.3, p.675-678, 1995.

CHIARELLO, A.G. Effects of fragmentation of the Atlantic forest on mammal communities in south-eastern Brazil. Biological Conservation, v. 89, p. 71-82, 1999.

CHIARELLO, A.G. Conservation value of a native forest fragment in a region of extensive agriculture. Revista Brasileira Biologia, v. 60, n. 2, p. 237-247, 2000.

CHIARELLO, A.G. Effects of fragmentation of the Atlantic forest on mammal communities in south-eastern Brazil. Biological Conservation, v. 89, p. 71-82, 1999.

CINTRA, R. Test of Janzen-Connnell model with two common tree species. Journal of Tropical Ecology, v. 13, p. 641-658, 1997. 
CINTRA, R.; HORNA, V. 1997. Seed and seedling survival of the palm Astrocaryum murumuru and the legume tree Dipteryx micantha in gaps in Amazonian forest. Journal of Tropical Ecology, v. 13, p. 257-277, 1997.

CLARK, D.A.; CLARK, D.B.; SANDOVAL, M.R.; CASTRO, M.V. 1995. Edaphic and human effects on landscape-scale distributions of tropical rain forest palms. Ecology, v. 76, p. 2581-2594.

CONNELL, J.H. On the role of natural enemies in preventing competitive exclusion in some marine animals and in rain forest trees. In: BOER, P.J. DEN; GRANDWELL, G.R. (Ed.). Dynamics of populations. Wageningen: Centre of Agricultural Publications and Documentation, 1971. p. 298-310

CONSÓRCIO MATA ATLÂNTICA - UNIVERSIDADE ESTADUAL DE CAMPINAS. Reserva da Biosfera da Mata Atlântica. Plano de Ação. 1992. v.1.

CORDEIRO, N. J.; HOWE, H.F. Low recruitment of trees dispersed by animals in African forest fragments. Conservation Biology, v.15, n.6, p.1733-1741, 2001.

CORDEIRO, N.J.; HOWE, H.F. Forest fragmentation severs mutualism between seed dispersers and an endemic african tree. Proceedings of the National Academy of Sciences of the United States of America, v.100, n.24, p. 14052-14056, 2003.

COSTA, L.P.; LEITE, Y.L.R.; FONSECA, G.A.B.; FONSECA, M.T. Biogeography of south american forest mammals: endemism and diversity in the Atlantic Forest. Biotropica, v. 32, n.4b, p.872-881, 2000.

CROOKS, K.R.; SOULÉ, M.E. Mesopredator release and avifaunal extinctions in a fragmented system. Nature, v. 400, p.563-566, 1999.

CULLEN JÚNIOR L.; BODMER, R.E.; VALLADARES-PÁDUA, C. Caça e biodiversidade nos fragmentos florestais da Mata Atlântica, São Paulo, Brasil In: FANG, T.G.; MONTENEGRO, O.L.; BODMER R.E. (Ed.). Manejo y Conservación de Fauna Silvestre en América Latina. La Paz, 1999. cap 4. p.125-140.

CULLEN JÚNIOR, L.; BODMER, R.E.; VALLADARES-PÁDUA, C. Effects of hunting in habitat fragments of the Atlantic forests, Brazil. Biological Conservation, v. 95, p.49-56, 2000 .

CULLEN JÚNIOR, L.; BODMER, R.E.; VALLADARES-PÁDUA, C. Ecological consequences of hunting in Atlantic Forest patches, São Paulo, Brazil. Oryx, v. 35, n.2, p.137-144, 2001.

CUTLER, A. Nested faunas and extinction in fragmented areas. Conservation Biology, v.5, n.4, p.496-505, 1991.

DE STEVEN, D.; PUTZ, F.E. Impact of mammals on early recruitment of a tropical canopy tree, Dipteryx panamensis, in Panama. Oikos, v. 43, p.207-216, 1984. 
DEAN, W. 1997. A ferro e fogo. A história e a devastação da Mata Atlântica brasileira.. São Paulo: Companhia das Letras. 1997. 484 p.

DEVELEY, P.F. As aves da estação ecológica Juréia Itatins. In: MARQUES, O.A.V. \& DULEBA,W. (Ed.).Estação ecológica Juréia-Itatins. Ambiente físico, flora e fauna. Ribeirão Preto: Ed. Holos. 2004. cap.23, p. 278-295.

DIRZO, R.; MIRANDA, A. Altered pattern of herbivory in the forest understory: a case study of the possible consequences of contempory defaunation. In: PRICE, P.W.; FERNANDES, G.W.; BENSON, W.W. (Ed.). Plant-animal interactions: Evolucionary ecology in tropical and temperate regions. New York: Wiley, 1991. cap. 13. p. 273-287.

DOS ANJOS, L. Bird communities in five atlantic forest fragments in southern Brazil. Ornitologia Neotropical, v.12, p. 11-27, 2001.

EMMONS, L.H. Neotropical rainforest mammlas. A field guide. Chicago: The University of Chicago Press, 1990. 281 p.

FA, J.E.; PERES, C.A. Game vertebrate extration in african and neotropical forests: an intercontinental comparison. Conservation Biology, v. 16, n.1, p.232-237, 2002.

FA, J.E.; YUSTE, J.E.G.; CASTELO, R. Bushmeat markets on Bioko Island as a measure of hunting pressure. Conservation Biology, v.14, n.6, p.1602-1613, 2000.

FEER,F.; HENRY, O.; FORGET, P-M.; GAYOT, M. Frugivory and seed dispersal by terrestrial mammals. In: BONGERS, F., CHARLES-DOMINIQUE, M.; FORGET, P-M.; THERY, M. (Ed.). Nouragues. Dynamics and plant-animals interactions in a neotropical rainforest. London: Kluwer Academic Publishers, 2001. cap. 21. p. 227-232.

FIUZA DE MELO, M.M.R. Composição florística e estrutura de trecho de Mata Atlântica de encosta, na Ilha do Cardoso (Cananéia, SP, Brasil). São Paulo, 1993. 104p. Dissertação (Mestrado) - Instituto de Biociências, Universidade de São Paulo.

FLEURY, M. Efeito da fragmentação florestal na predação de sementes da palmeira jerivá (Syagrus romanzoffiana) em florestas semidecíduas do Estado de São Paulo. Piracicaba, 2003. 101p. Dissertação (Mestrado) - Escola Superior de Agricultura "Luiz de Quiroz", Universidade de São Paulo.

FONSECA, G.A.B.; ROBINSON, J.G. Forest size and structure competitive and predatory effect on small mammals communities. Biological Conservation, v.53, p.265-294, 1990.

FORGET, P-M. Seed dispersal of Vouacaporia americana by caviomorph rodents in French Guiana. Journal of Tropical Ecology, v.6, p.459-468, 1990.

FORGET, P-M. Scatterhoarding by Astrocaryum paramaca by Proechymis in French Guiana: comparison with Myoprocta exilis. Journal of Tropical Ecology, v.32, p. 155-167, 1991.

FORGET, P-M. Seed removal and seed fate in Gustavia superba (Lecythidaceae). Biotropica, v. 24, n.3, p.408-414, 1992a. 
FORGET, P-M. Regeneration Ecology of Eperua grandiflora (Caesalpiniaceae), a large-seeded tree in French Guiana. Biotropica, v.24, n.2, p.146-156, 1992 b.

FORGET, P-M. Pos-dispersal predation and scatterhoarding of Dipteryx panamensis (Papilionaceae) seeds by rodents in Panama. Oecologia, v. 94, p.255-261, 1993.

FORGET, P-.M. Recruitment pattern of Vouacaporia americana (Caesalpiniaceae), a rodent dispersed tree species in French Guiana. Biotropica, v.26, p.408-419, 1994.

FORGET, P.M. Removal of seeds of Carapa procera (Meliaceae) by rodents and their fate in rainforest in French Guiana. Journal of Tropical Ecology, v.12, p.751-761, 1996.

FORGET, P.M.; MILLERON, T. Evidence for secondary seed dispersal by rodents in Panama. Oecologia, v.87, p.596-599, 1991.

FORGET, P-M.; MUNOZ, E.; LEIGHT, E.G. Predation by rodents and bruchid beetles on seeds of Schelea palms on Barro Colorado Island, Panama. Biotropica, v.26, p.420-426, 1994.

FORGET, P-M.; MERCIER, F.; COLLINET, F. Spatial pattern of 2 rodent-dispersed rain forest trees Carapa procera (Meliaceae) and Vouacaporia americana (Caesalpinaceae) at Paracou, French Guiana. Journal of Tropical Ecology, v.15, p.301-313, 1999.

FORGET, P-M.; MERONA, J.M.R.; JULLIOT, C. The effects of forest type, harvesting and stand refinement in a tropical rain forest. Journal of Tropical Ecology, v.17, p.593-609, 2001.

FORGET, P.M.; MILLERON, T.; FEER, F.; HENRY, O.; DOBOST, G. Effects of dispersal pattern and mammalian herbivores on seedling recruitment for Virola michelii (Myristicaceae) in French Guiana. Biotropica, v.32, n.3, p.452-462, 2000.

FORGET, P-M., HAMMOND, D.S., MILLERON, T., THOMAS, R. Seasonality of fruiting and food hoarding by rodents in neotropical forests: consequences for seed dispersal and seedling recruitment. In: D.J. LEVEY; W.R. SILVA E M. GALETTI (eds.). Seed dispersal and frugivory: Ecology, evolution and conservation. Wallingford: CABI Publishing. 2002. Cap. 16. p. 241-256.

FORGET, P-M., FEER, F., CHAUVET, S., JUlliot, C., SiMMEN, B., BAYART, F., PAGES-FEUILLADE. Pos-dispersal seed removal in four frugivore-dispersed tree species. In: BONGERS, F.; CHARLES-DOMINIQUE, M.; FORGET, P-M.; THERY, M. (Ed.). Nouragues. Dynamics and plant-animals interactions in a neotropical rainforest. Kluwer Academic Publishers, 2001. cap. 21. p. 227-232.

FRAGOSO, J.M.; SILVIUS, K.M.; CORREA, J.A. Long distance seed dispersal by tapirs increases seed survival and aggregates tropical trees. Ecology,v.84, n.8, p.1998-2006, 2003.

GALETTI, M. Fruits and frugivores in a brazilian Atlantic forest. Cambridge, 1996. 220 p. Thesis (Ph.D.), Cambridge University. 
GALETTI, M. Indians within Conservation Units: Lessons from the Atlantic Forest. Conservation Biology, v.15, n.3, p.798-799, 2001.

GALETTI, M.; ALEIXO, A. Effects of palm heart harvesting on avian frugivores in the Atlantic forest of Brazil. Journal of Applied Ecology, v. 35, p.286-293, 1998.

GALETTI, M.; PASCHOAL, M.; PEDRONI, F. Predation by palm nuts (Syagrus romanzoffiana) by squirrel (Sciurus ingrami) in the Southeast Brazil. Journal of Tropical Ecology, v. 8, p. 121-123, 1992..

GALETTI, M.; ZIPARRO, V.B.; MORELLATO, P.C. Fruiting phenology and frugivory on the palm Euterpe edulis in a lowland atlantic forest of Brazil. Ecotropica, v. 5, p.115-122, 1999.

GALETTI, M.; LAPS, R.; PIZO, M.A. Frugivory by toucans (Ramphastidae) at two altituds in the Atlantic forest of Brazil. Biotropica, v. 32, n. 4b, p. 842-850, 2000.

GALETTI, M.; MARTUSCELLI,P.; OLMOS, F.; ALEIXO, A. Ecology and conservation of the jacutinga Pipile jacutinga in the Atlantic forest of Brazil. Biological Conservation, v. 82, p. 31-39, 1997.

GUARIGUATA, M.R.; ADAME, J.J.R.; FINEGAN, B. Seed removal and fate in two selectively logged lowland forests with contrasting protection levels. Conservation Biology, v.14, n.4, p.1046-1054, 2000.

GUARIGUATA, M.R.; CLAIRE, H.A.; JONES, G. Tree seed fate in a logged and fragmented forest landscape, Northeastern Costa Rica. Biotropica, v.34, n.3, p.405-415, 2002.

GUILLAUMON, J.R.; MARCONDES, M.A.P.; NEGREIROS, O.C.; MOTA, I.S.; EMMERICH, W.; BARBOSA, A.F.; BRANDO, I.H.D.C.; CAMARA, J.J.C.; OSTINI, S.; PEREIRA, R.T.L.; SCORVO FILHO, J.D.; SHIMOMICHI, P.Y.; SILVA, D.A.; MELO NETO, J.E. Plano de Manejo do Parque Estadual da Ilha Anchieta. Sao Paulo, 1989. 103 p. (I.F.- Série Registros).

HALLWACKS,W. Agoutis (Dasyprocta punctata), the inheritors of guapinol (Hymenaea courbaril: Leguminosae). In: ESTRADA, A.; FLEMING, J.H. (Ed.). Frugivores and seed dispersal. Boston: Dr. W. Junk Publishers. cap. 22. p. 285-304.

HAMMOND, D.S.; BROWN, V.K.; ZAGT, R. Spatial and temporal patterns of seed attack and germination ina large-seeded neotropical tree species. Oecologia, v.119, p.208-218, 1999.

HAMPE, A. Frugivory in Europian Laurel: how extinct seed dispersers have been substituted. Bird Study, v.50, p.280-284, 2003.

HARPER, J.L. Population biology of plants. London: Academic Press. 1977. 892p.

HENDERSON, A.; GALEANO, G.; BERNAL, R. Field guide to the palms of the Americas. Princeton: Princeton University Press. 410 p. 1995. 
HENRY, O. Frugivory and the importance of seeds in the diet of the orange-gumped agouti (Dasyprocta leporina) in French Guiana. Journal of Tropical Ecology, v.15, p.291-300, 1999.

HERRERA, C.M. Vertebrate frugivores and their interaction with invertebrate fruit predators: supporting evidence from a Costa Rican dry forest. Oikos, v.54, p.185-188, 1989.

HERRERA, C.M. Seed dispersal by vertebrates. In: HERRERA, C.M. \& PELLMYR, O. (Ed.). Plant-animal interactions: an evolutionary approach. Oxford: Blackwell, 2002. cap. 8. p.210-220.

HOSHIZAKI, K.; WAJIROU, S.; SATOHIKO. Impacts of secondary seed dispersal and herbivory on seedling survival in Aesculus turbinata. Journal of Vegetation Science, v.8, p.735-742, 1997.

HOSHIZAKI, K.; HULME, P.E. Mast seedling and predator-mediated indirect interactions in a forest community: evidence from post dispersal fate of rodent-generated caches. In: LEVEY, D.J.; SILVA, W.R.; GALETTI, M. (Ed.). Seed dispersal and frugivory: Ecology, Evolution and Conservation. Wallingford: CABI Publishing. 2002. cap. 15. p. 227-240.

HOWE. H.F. Implications of seed dispersal by animals for tropical reserve management. Biological Conservation, v.30, p.261-281, 1984.

HOWE, H.F.; SMALLWOOD, J. Ecology of seed dispersal. Ann. Rev. Ecol. Syst, v.13, p.201-228.1982.

HULME, P.E. Post dispersal seed predation and the establishment of vertebrate dispersed plantas in mediterranean scrublands. Oecologia, v. 111, p.91-98, 1997.

HULME, P.E. Seed-eaters: seed dispersal, destruction and demography. In: LEVEY, D.J.; SILVA, W.R.; GALETTI, M. (Ed.). Seed dispersal and frugivory: Ecology, evolution and conservation. Wallingford: CABI Publishing. 2002. cap. 17. p. 257-274.

JANSEN, P.A.; BARTHOLOMEUS, M.; BONGERS, F.; ELZINGO, J.A.; OUDEN, J.D.; VAN WIEREN, S.E. The role of seed size in dispersal by scatter-hoarding rodent. In: D.J. LEVEY; W.R. SILVA E M. GALETTI (eds.). Seed dispersal and frugivory: Ecology, evolution and conservation. Wallingford: CABI Publishing. 2002. Cap.14. p. 209-226.

JANZEN, D.H. Herbivores and the number of species in tropical forest. American Naturalist, v.104, p.501-528, 1970.

JONES, D.L. Palms troughout the world. Washington D.C: Smithsonian Institutiton Press.1995.

JORDANO, P.; SCHUPP, E.W. Seed disperser effectiveness: the quantity component and patterns of seed rain for Prunus mahaleb. Ecological monographs, v. 70, n.4, p.591-615. 2000. 
KAHN, F. Amazonian Palms: food resource for management of forest ecosystems. In: Tropical forests, people and food. 1993.

LOGUIDICE, K.; OSTFELD, R.S. Interactions between mammals and trees: predation on mammal-dispersed seeds and the effect of ambient food. Oecologia, v.130, p.420-425, 2002.

LOISELLE, B.A.; BLAKE, J.G. Potential consequences of extinction of frugivorous birds for shrubs of a tropical wet forest. In: LEVEY, D.J.; SILVA, W.R.; GALETTI, M. (Ed.). Seed dispersal and frugivory: Ecology, Evolution and Conservation. Wallingford: CABI Publishing. 2002. cap. 26. p. 397-406.

LORENZI. H.; SOUZA.H.M.; MEDEIROS-COSTA, J.T.; CERQUEIRA, L.S.C.; VON BEHR, N. Palmeiras no Brasil - Nativas e Exóticas. Nova Odessa: Ed. Plantarum. 1996. 330p.

LOSOS, E. Habitat specificity of two palms species: experimental transplantation in amazon successional forest. Ecology, v.76, n.8, p.2595-2606, 1995.

MANTOVANI, W. Estrutura e dinâmica da Floresta Atlântica na Juréia - Iguape, SP. São Paulo, 1993. 126p. Tese (Livre Docência) - Instituto de Biociências, Universidade de São Paulo.

MAC ARTHUR, R.H.; DIAMOND, J.M.; KARR, J.R. Density compensation in island faunas. Ecology, v. 53, n. 2, p.330-342.

MC CONKEY, K.R., DRAKE, D.R., MEEHAM, H.J., PARSONS, N. Husking stations provide evidence of seed predation by introduced rodents in Tongan rain forest. Biological Conservation, 2002.

MINISTÉRIO DO MEIO AMBIENTE. Diretrizes para a política de conservação e desenvolvimento sustentável da Mata Atlântica. Caderno n º 13. Brasília, DF, Brasil. 1999.

MIRANDA, I.P.A., RABELO, A., BUENO, C.R., BARBOSA, E.M., RIBEIRO, M.N.S. Frutos de palmeiras da Amazônia. Manaus: MCT INPA, 2001.78 p.

MYERS, N. Florestas tropicais e suas espécies - sumindo, sumindo,...? In: WILSON, E.O. (Ed.). Biodiversidade. Rio de Janeiro: Ed. Nova Fronteira, 1997. cap. 3. p 36-45.

MYERS N.; MITTERMEIER, R.A.; FONSECA, G.A.B.; KENT, J. Biodiversity hotspots for conservation priorities. Nature, v. 403, p.853-858, 2000.

NASCIMENTO, A.R.T.; CORTELETTI, J.M.; ALMEIDA, S.S. Distribuição espacial de sementes e juvenis de Astrocaryum aculeatum G.F. W. Meyer (arecaceae) em Floresta de Terra Firme. In: LISBOA, P.L.B. (Ed.). Caxiuanã. Belém: Museu Paraense Emílio Goeldi. 1997. cap. 16. p. 287-296.

NOFFS, M.S.; BAPTISTA-NOFFS, L.J. 1982. Mapa da vegetação do Parque Estadual da Ilha do Cardoso - as principais formações. In: CONGRESSO NACIONAL DE ESSÊNCIAS NATURAIS, Campos do Jordão, 1982. p. 613-619. Anais. 
PAES, F.M. Aspectos ecológicos da população de capivaras (Hydrochaeris hydrochaeris RODENTIA) do Parque estadual da Ilha Anchieta - Ubatuba (SP). Rio Claro, 1997. 45 p. (Relatório final do projeto de dissertação de Mestrado em "Conservação e Manejo dos Recursos" - CEA - Rio Claro).

PARDINI, R.; DEVELEY, P.F. Mamíferos de médio e grande porte na Estação Juréia - Itatins. In: MARQUES, O.A.V.; DULEBA, W. (Ed.). Estação ecológica Juréia-Itatins. Ambiente físico, flora e fauna. Ribeirão Preto: Ed. Holos. 2004. cap.24, p.296-303.

PASCHOAL, M.; GALETTI, M. Seasonal food use by the neotropical squirrel Sciurus ingrami in southeastern Brazil. Biotropica, v.27, n.2, p.268-273, 1995.

PERES, C.A. Composition, density and fruiting phenology of arborescent palms in an Amazonian terra firme forest. Biotropica, v.26, p.285-294, 1994.

PERES, C.A. Identifying keystone plant resources in tropical forests: the case of gums from Parkia pods. Journal of Tropical Ecology, v.16, p.287-317, 2000.

PERES, C.A. Synergistics effects of subsistence hunting and habitat fragmentation on Amazon forest vertebrates. Conservation Biology, v.15, n.6, p.1490-1505, 2001.

PERES, C.A.; BAIDER, C. Seed dispersal, spatial distribution and population structure of Brazil nut trees (Bertholletia excelsa) in southeastern Amazonia. Journal of Tropical Ecology, v.13, p.595-616, 1997.

PERES, C.A.; VAN ROOSMALEN, M. Primate frugivory in two species-rich neotropical forests: implications for the demography of large-seeded plants in overhunted areas. In: D.J. LEVEY; W.R. SILVA E M. GALETTI (eds.). Seed dispersal and frugivory: Ecology, evolution and conservation. Wallingford: CABI Publishing. 2002. Cap. 27. p. 407-422.

PERES, C.; SCHIESDARI, L.C.; DIAS-LEME, C.L. Vertebrate predation of Brazil-nuts (Bertholletia excelsa, Lecythidaceae), an agouti-dispersed Amazonian seed crop: a test of the escape hypothesis. Journal of Tropical Ecology, v.13, p.69-79, 1997.

PICCOLO, P.R. Ensaio Metodológico sobre a ocupação humana e as transformações no mosaico ambiental na Fazenda de Picinguaba - SP, nos períodos de 1962 e 1990. Rio Claro, 1992. 110p. Dissertação (Mestrado) - Instituto de Biociências , Universidade Estadual Paulista.

PIMENTEL, D.S.; TABARELLI, M. Seed dispersal of the palm Attalea oleifera in a remnant of the brazilian Atlantic Forest. Biotropica, v.36, n.1, p.74-84, 2004.

REDFORD, K.H. The empty forest. BioScience, v.42, p.412-422, 1992.

REDFORD, K.H.; ROBINSON, J.G. The game of choice: Patterns of Indian and Colonist Hunting in the neotropics. American Anthropologist, v.89, p.650-667, 1987.

ROLDÁN, A.I.; SIMONETTI, J.A. Plant-animal interections in Tropical Bolivian Forests with different hunting pressures. Conservation Biology, v.15, n.3, p.617-623, 2001. 
SANCHES, R.A. 2004. Caiçaras e a Estação Ecológica Juréia - Itatins. Histórico de ocupação no contexto político, econômico, social e ambiental do Vale do Ribeira. In: O.A.V. MARQUES, O.A.V.; DULEBA, W. (Ed.). Estação Ecológica Juréia-Itatins. Ambiente físico, flora e fauna. Ribeirão Preto: Ed. Holos. 2004. cap.28, p. 349-359.

SANCHEZ, M. Florística e fitossociologia da vegetação arbórea nas margens do Rio da Fazenda (Parque Estadual da Serra do Mar- Núcleo Picinguaba - Ubatuba - SP). Rio Claro, 1994. 75p. Dissertação de Mestrado - Instituto de Biociências, Universidade Estadual Paulista.

SANCHEZ-CORDERO, V.; MARTINEZ-GALLARDO, R. Postdispersal fruit and seed removal by forest-dwelling rodents in a lowland rainforest in Mexico. Journal of Tropical Ecology, v.14, p.139-151, 1998.

SÃO BERNARDO, C.S. Aves e mamíferos cinegéticos do Parque Estadual Ilha do Cardoso: ocorrência, censo populacional e relação com variáveis ambientais e antrópicas. Piracicaba, 2004. Dissertação (Mestrado) - Escola Superior de Agricultura "Luiz de Queiroz", Universidade de São Paulo.

SECRETARIA DO ESTADO DE MEIO AMBIENTE. 2000. Atlas das Unidades de Conservação ambiental do Estado de São Paulo. São Paulo.

SECRETARIA DO ESTADO DO MEIO AMBIENTE. Plano de manejo do Parque Estadual da Ilha do Cardoso, 2001

SECRETARIA DO ESTADO DO MEIO AMBIENTE. Planos de Manejo das Unidades de Conservação - Parque Estadual da Serra do Mar - Núcleo Picinguaba Fase1. Plano de Gestão Ambiental. 1998 a..

SECRETARIA DO ESTADO DO MEIO AMBIENTE. Planos de Manejo das Unidades de Conservação - Parque Estadual Xixová-Japuí. Fase1. Plano de Gestão Ambiental. 1998b

SCARIOT, A. Forest fragmentation effects on palm diversity in Central Amazon. Journal of Ecology, v.87, p.66-76, 1999.

SCHUPP, E.W. Seed and early seedling predation in the forest understoryand in treefall gaps. Oikos, v.51, p.71-78, 1988 .

SCHUPP, E.W. Factors affecting post-dispersal seed survival in a tropical forest. Oecologia, v.76, p.525-530, 1988 b.

SILVA, M.G.; TABARELLI, M. Tree species, impoverishment and the future flora of the Atlantic Forest of northeast Brazil. Nature, v.404, p.72-74, 2000.

SILVA, M.G.; TABARELLI, M. Seed dispersal, plant recruitment and spatial distribution of Bactris acanthocarpa Martius (Arecaceae) in a remnant of Atlantic forest in Northeast Brazil. Acta Oecologica-International Journal of Ecology, v.22, n.5-6, p.259-268, 2001. 
SILVIUS, K.M.; FRAGOSO, J.M.V. Pulp handling by vertebrate seed dispersers increases palm seed predation by bruchid beetles in the northern Amazon. Journal of Tropical Ecology, v.90, p.1024-1032, 2002.

SILVIUS, K.M. Spatio-temporal patterns of palm endocarp use by three amazonian forest mammals granivory or “ grubivory”? Journal of Tropical Ecology, v.18, p.707-723, 2002.

SMYTHE, N. The natural history of Central American Agouti (Dasyprocta punctata). Smithsonian Contributions to Zoology. 257p. 1978.

SMYTHE, N. Competition and resource partitioning in the guild of neotropical terrestrial frugivores mammals. Ann. Rev. Ecol. Syst., v.17, p.169-188, 1986.

SMYTHE, N. Seed survival in the palm Astrocaryum standleyanum: Evidence for dependence upon its seed dispersers. Biotropica, v.21, n.1, p.50-56, 1989.

SOKAL, R.R.; ROHLF, J. Introduction to Biostatistics. $2^{\text {a }}$. ed. New York: W.H. Freeman. 1996. $363 \mathrm{p}$.

S.O.S. MATA ATLÂNTICA; INPE - INSTITUTO NACIONAL DE PESQUISAS ESPACIAIS. 1998. Atlas da evolução dos remanescentes florestais e ecossistemas associados no domínio da Mata Atlântica no período 1990-1995. São Paulo, 1998, 55 p.

SOUZA, A.F.; MARTINS, F.R.; SILVA MATOS, D.M. Detecting ontogenetic stages of the palm Attalea humilis in fragments of the Brazilian Atlantic Forest. Can. J. Bot., v.78, p. $1227-1237.2000$

TABANEZ, A.A.J.; VIANA, V.M. Patch structure within Brazilian Atlantic Forest and implications for conservation. Biotropica, v.32, n.4b, p.925-933, 2000.

TABARELLI, M.; SILVA, J.M.C.; GASCON, C. Forest fragmentation, synergism and the impoverishment of neotropical forests. Biodiversity and Conservation, v.13, p.1419-1425, 2004.

TERBORGH, J. Community aspects of frugivory in tropical forests In.: ESTRADA, A.; T.H. FLEMING, T.H. (Ed.). Frugivores and Seed Dispersal. Boston: Dr. W. Junk Publishers, 1986. p. 371-384.

TERBORGH, J.; WRIGHT, S.J. Effects of mammalian herbivores on plant recruitment in two neotropical forests. Ecology, v.75, n.6, p.1829-1833, 1994

TERBORGH, J.; LOSOS, E.; RILEY, M.P.; BOLAÑOS RILEY, M. Predation by vertebrates and invertebrates on the seeds of five canopy tree species of an Amazonian forest. Vegetatio, v.107/108, p.375-386, 1993.

TERBORGH, J., PITMAN, N., SILMAN, M., SCHICHTER, H., NÚNEZ, P.V. Maintenance of tree diversity in Tropical Forests. In: D.J. LEVEY; W.R. SILVA E M. GALETTI (eds.). Seed dispersal and frugivory: Ecology, Evolution and Conservation. Wallingford: CABI Publishing. 2002. cap. 1. p 1-18. 
TERBORGH, J.; LOPEZ, L.; NUNES, P.V.; RAO, M.; SHAHADUBBIN, G.; ORIHUELA, G.; RIVEROS, M.; ASCANIO, R.; ADLER, G.H.; LAMBERT, J.D.; BALBAS, L. Ecological Meltdown in predator-free forest fragments. Science, v.294, p.1923-1926, 2001.

TRAVESET, A. Effects of vertebrate frugivores on bruchid beetles that prey on Acacia farnesiana seeds. Oikos, v.63, p.200-206, 1992.

TURNER, I.M.; CHUA, K.S.; ONG, J.S.Y.; SOONG, B.C.; TAN, H.T.W. A century of plant species loss from an isolated fragment of lowland tropical rain forest. Conservation Biology, v.10, p.1229-1244, 1996.

UIEDA, V.S. Cominidade de peixes de um riacho litorâneo: composição, habitat e hâbitos. Campinas, 1995. 229p. Tese de Doutorado - Instituto de Biociências, UNICAMP.

VANDER PIJL, L. Principles of Dispersal in higher plants. $3^{\mathrm{a}}$. ed. New York: Berlin Hidelberg. 1982. 214 p.

VANDER WALL, S.B. Food hording by animals. Chicago: The Chicago University Press. 1990, 445p.

VANDER WALL, S.B. The role of animals in dispersing a "wind-dispersed" pine. Ecology, v.73, p.614-621, 1992.

VANDER WALL, S.B. Secondary dispersal by Jeffrey pine seeds by rodent scat-hoarders: the role of pilfering, reaching and variable environment. In: D.J. LEVEY; W.R. SILVA E M. GALETTI (eds.). Seed dispersal and frugivory: Ecology, evolution and conservation. Wallingford: CABI Publishing. 2002. cap. 13. p. 193-208.

VOLTOLINI, J.C. Predação e dipersão de sementes de palmeiras por mamíferos na floresta atlântica do Parque Estadual da Serra do Mar, SP. Rio Claro, 2004. 75p. Tese (Doutorado) Instituto de Biociências, Universidade Estadual Paulista.

VOEKS, R.A. Reproductive ecology of the piassava palm (Attalea oleifera) of the Bahia, Brazil. Journal of Tropical Ecology, v. 18, p. 121-136, 2002.

VORMISTO, J. Palms as rainforest resources: how evenly are they distributed in Peruvian Amazonia? Biodiversity and Conservation, v.11, p.1025-1045, 2002.

WEBB, C.O.; PEART, D.R. High seed dispersal rates in faunally intact tropical rain forest: theoretical and conservation implications. Ecology Letters, v.4, p.491-499, 2001.

WENNY, D.G. Seed dispersal, seed predation and seedling recruitment of neotropical montane tree. Ecological Monographs, v.70, n.2, p.331-351, 2000.

WILLIS, E.O. The composition of avian communities in remanescent woodlots in southern Brazil. Papéis Avulsos de Zoologia, v.33, p.1-25, 1979. 
WILLIS, E.O., ONIKI, Y. Levantamento preliminar de aves em treze áreas do estado de São Paulo. Revista Brasileira de Biologia, v.48, n.2, p.161-167, 1981.

WILSON, D.E.; JANZEN, D.H. Predation of Scheelea palm seeds by bruchid beetles: seed density and distance form parent palm. Ecology, v.53, n.5, p. 954-959, 1972.

WRIGHT S.J. The dispersion of eggs by bruchid beetle among Scheelea palm seeds, and the effect of distance to the parent palm. Ecology, v.65, p.1016-1021, 1983.

WRIGHT, S.J. The myriad consequences of hunting for vertebrates and plants in tropical forests. Perspectives in plant ecology, Evolution and Systematics, v.6., p.73-86, 2003.

WRIGHT, S.J.; DUBER, H.C. Poachers and forest fragmentation alter seed dispersal, seed survival and seedling recruitment in the palm Attalea butyraceae, with implications for tropical tree diversity. Biotropica, v.33, n.4, p.583-595, 2001.

WRIGHT, S.J., GOMPER, M.E., DE LEON, B. Are large predators keystone species in neotropical forests? The evidence from Barro Colorado Island. Oikos, v.71, p.279-294, 1994.

WRIGHT, S.J.; ZEBALLOS, H.; DOMÍNGUEZ, I.; GALLARDO, M.M.; MORENO, M.C.; IBÁÑEZ, R. Poachers alter mammal abundance, seed dispersal and seed predation in neotropical forest. Conservation Biology, v.14, n.4, p.227-239, 2000.

ZAR, J.H. Biostatistical Analysis. 4a . ed. New Jersey: Prentice-Hall. 1999. 662 p.

ZONA, S; HENDERSON, A. A review of animal-mediated seed dispersal of palms. Selbyana, v.11, p.6-21.1989. 